University of Tennessee Health Science Center

UTHSC Digital Commons

$12-2011$

\title{
Spatial Distribution of Obesity among West Virginia 5th Grade Children: Analysis of the Socioeconomic, Physical, and Personal Environment
}

Sherry Roper

University of Tennessee Health Science Center

Follow this and additional works at: https://dc.uthsc.edu/dissertations

Part of the Epidemiology Commons, Maternal and Child Health Commons, and the Nutritional and Metabolic Diseases Commons

\section{Recommended Citation}

Roper, Sherry, "Spatial Distribution of Obesity among West Virginia 5th Grade Children: Analysis of the Socioeconomic, Physical, and Personal Environment" (2011). Theses and Dissertations (ETD). Paper 227. http://dx.doi.org/10.21007/etd.cghs.2011.0266.

This Dissertation is brought to you for free and open access by the College of Graduate Health Sciences at UTHSC Digital Commons. It has been accepted for inclusion in Theses and Dissertations (ETD) by an authorized administrator of UTHSC Digital Commons. For more information, please contact jwelch30@uthsc.edu. 


\title{
Spatial Distribution of Obesity among West Virginia 5th Grade Children: Analysis of the Socioeconomic, Physical, and Personal Environment
}

\begin{abstract}
Childhood obesity defined as a body mass index (BMI) at or above the 95th percentile for children of the same age and sex, is considered an epidemic in the United States. Biology and lifestyle behaviors have been identified as important factors in the development of childhood obesity; however, researchers are beginning to place more emphasis upon the impact that continual environmental exposures have upon obesity development. Environmental risk factors associated with obesity are distributed continuously over space, yet evidence suggests that burden of risk may not be evenly dispersed across a community. West Virginia (WV), a rural Appalachian community has the tenth highest childhood obesity rate in the nation, yet little is known about the spatial distribution of the environmental risks and obesity within the state. The purposes of this study were threefold: 1) to determine which socioeconomics, physical, and personal environmental attributes contribute to a BMI equal to or greater than the 85th percentile for age, and gender; 2) to determine which socioeconomics, physical, and personal environmental attributes contribute to obesity (BMI equal to or greater than the 95th percentile for age, and gender); and 3) to assess the geographic distribution of attributes (socioeconomic, physical, and personal) in relation to BMI equal to or greater than the 85th percentile (overweight) and BMI equal to or greater than the 95th percentile (obese) among WV 5th graders.

Secondary data analyses of cross-sectional statewide data were performed to examine the proposal that obesity is the consequence of environmental exposures and that the distribution of obesity disproportionally affects some WV communities greater than others. The study sample was comprised of 12,194 fifth grade children ranging in age from 10-12 years old with a verifiable zip code for the state of WV. Study indicators used to quantify socioeconomic, physical, and personal environmental attributes were derived from various data sources. Data were gathered for the academic school years of 2007/2008 and 2008/2009. Individual data for each child subject consisting of BMI percentile and family history (diabetes and heart disease) were coded at the zip code level. Aggregate data for socioeconomic, physical, and personal environmental attributes were computed per zip code. County level data (violent crime) and school level fitness (percent of children in the fitness zone per 5th grade class) were linked back to each child by means of county to school to zip code or school to zip code. Binary logistic regression methods were employed to determine which attributes (socioeconomic, physical, and personal environment) contributed to overweight and obesity. Geographic Information System (GIS) technology was utilized to explore obesity spatial distribution and the relationship of obesity and overweight to environmental attributes at the zip code level.
\end{abstract}

Findings indicate that elements of the socioeconomic, physical, and personal environment are heterogeneous and independent, yet interact dynamically as predictors of obesity. Spatially groupings of overweight and obesity and identified risk factors were observed. Findings from this study support the need for additional research to examine the significance of spatial clusters and associated risk factors.

\section{Document Type}

Dissertation

\section{Degree Name}

Doctor of Philosophy (PhD)

\section{Program}

Nursing 


\section{Research Advisor}

Patricia A. Cowan, Ph.D.

\section{Keywords}

Appalachian, childhood obesity, GIS, obesogenic, spatial analysis, West Virginia

\section{Subject Categories}

Diseases | Epidemiology | Maternal and Child Health | Medicine and Health Sciences | Nutritional and Metabolic Diseases | Public Health 


\title{
SPATIAL DISTRIBUTION OF OBESITY AMONG WEST VIRGINIA $5^{\text {TH }}$ GRADE CHILDREN: ANALYSIS OF THE SOCIOECONOMIC, PHYSICAL, AND PERSONAL ENVIRONMENT
}

\author{
A Dissertation \\ Presented for \\ The Graduate Studies Council \\ The University of Tennessee \\ Health Science Center
}

In Partial Fulfillment

Of the Requirements for the Degree

Doctor of Philosophy

From The University of Tennessee

By

Sherry Roper

December 2011 
Copyright (C) 2011 by Sherry Roper. All rights reserved. 


\section{DEDICATION}

This dissertation is dedicated to my husband, Gary G. Roper, for his unconditional love, words of encouragement, and never wavering support throughout this challenging endeavor. Your endless reassurance has enabled me to endure and your love continues to inspire me to do great things. In addition, to my children Chelsea, Katelyn, and Shane, you bring great joy to my life and are a continued source of inspiration.

Proverbs 3: 5-6 "Trust in the LORD with all your heart and lean not on your own understanding; in all your ways acknowledge Him, and He will make your paths straight."

"To God be the glory." 


\section{ACKNOWLEDGEMENTS}

I would like to express my sincere gratitude to, Dr. Patricia A. Cowan for serving as my committee chair. Her advice, guidance, and encouragement throughout my $\mathrm{PhD}$ endeavor have been fundamental to the completion of this project. Her expertise and support from the initial stages of the dissertation process to the concluding project has enabled me to grow professionally. I also thank my committee members Dr. Eloise Elliott, Dr. Joyce Carolyn Graff, Dr. Patricia M. Speck, and Dr. Jim Y. Wan for their valuable contribution and support. I would also like to express my earnest gratefulness to Dr. Esra Ozdenerol for her assistance with GIS mapping techniques and the application of medical geography concepts and Tina Geer, GIS Specialist.

I would like to acknowledge my family for their diligence and patience throughout this process. I especially thank my parents, Charlie and Vena Powell and mother-in-law Joy Roper for their unconditional love and encouragement. Dr. Karen Fankhauser for her guidance and endless advice of which has helped to make this dream a reality. My sister Tawana Martin, my brothers Dustin Martin and Eldridge Cool, and my close friends for their endless reassurance of which helped me remain steadfast. With a final declaration to those who have passed in body but remain in my heart forever my father, Ronald Lee Martin and father-in-law William D. Roper.

I wish to express appreciation to my fellow classmates for their encouragement with a special thanks to Randy Post. I am especially grateful to Randy and his wife Tara for their warm hospitality during my many trips to Memphis.

Additionally, I would like to express my appreciation to the CARDIAC project especially Dr. Neil, Dr. Christa Ice, and Emily Murphy for providing the pediatric obesity data necessary to conduct this study. Finally, I would like to acknowledge my gratefulness to the University of Tennessee Health Science Center for tuition support without which this degree would not have been possible. 


\begin{abstract}
Childhood obesity defined as a body mass index (BMI) at or above the $95^{\text {th }}$ percentile for children of the same age and sex, is considered an epidemic in the United States. Biology and lifestyle behaviors have been identified as important factors in the development of childhood obesity; however, researchers are beginning to place more emphasis upon the impact that continual environmental exposures have upon obesity development. Environmental risk factors associated with obesity are distributed continuously over space, yet evidence suggests that burden of risk may not be evenly dispersed across a community. West Virginia (WV), a rural Appalachian community has the tenth highest childhood obesity rate in the nation, yet little is known about the spatial distribution of the environmental risks and obesity within the state. The purposes of this study were threefold: 1) to determine which socioeconomics, physical, and personal environmental attributes contribute to a BMI equal to or greater than the $85^{\text {th }}$ percentile for age, and gender; 2) to determine which socioeconomics, physical, and personal environmental attributes contribute to obesity (BMI equal to or greater than the $95^{\text {th }}$ percentile for age, and gender); and 3) to assess the geographic distribution of attributes (socioeconomic, physical, and personal) in relation to BMI equal to or greater than the $85^{\text {th }}$ percentile (overweight) and BMI equal to or greater than the $95^{\text {th }}$ percentile (obese) among WV $5^{\text {th }}$ graders.
\end{abstract}

Secondary data analyses of cross-sectional statewide data were performed to examine the proposal that obesity is the consequence of environmental exposures and that the distribution of obesity disproportionally affects some WV communities greater than others. The study sample was comprised of 12,194 fifth grade children ranging in age from 10-12 years old with a verifiable zip code for the state of WV. Study indicators used to quantify socioeconomic, physical, and personal environmental attributes were derived from various data sources. Data were gathered for the academic school years of 2007/2008 and 2008/2009. Individual data for each child subject consisting of BMI percentile and family history (diabetes and heart disease) were coded at the zip code level. Aggregate data for socioeconomic, physical, and personal environmental attributes were computed per zip code. County level data (violent crime) and school level fitness (percent of children in the fitness zone per $5^{\text {th }}$ grade class) were linked back to each child by means of county to school to zip code or school to zip code. Binary logistic regression methods were employed to determine which attributes (socioeconomic, physical, and personal environment) contributed to overweight and obesity. Geographic Information System (GIS) technology was utilized to explore obesity spatial distribution and the relationship of obesity and overweight to environmental attributes at the zip code level.

Findings indicate that elements of the socioeconomic, physical, and personal environment are heterogeneous and independent, yet interact dynamically as predictors of obesity. Spatially groupings of overweight and obesity and identified risk factors were observed. Findings from this study support the need for additional research to examine the significance of spatial clusters and associated risk factors. 


\section{TABLE OF CONTENTS}



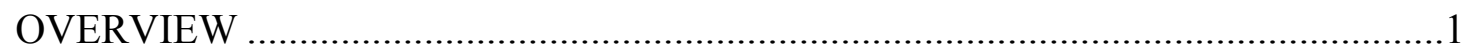

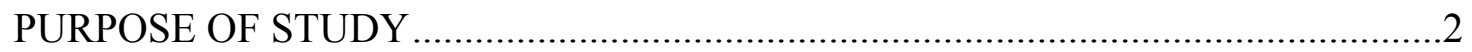

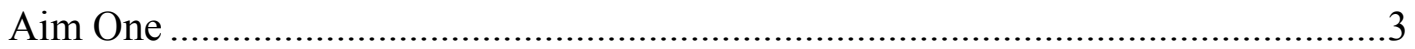

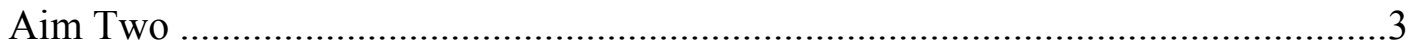

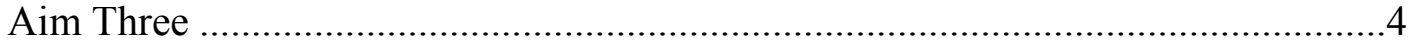

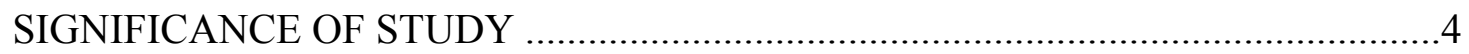

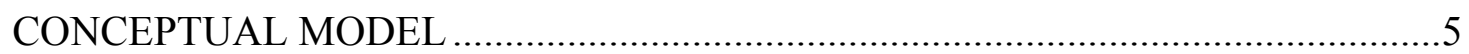

MAJOR CONCEPTS AND DEFINITIONS ……………........................................

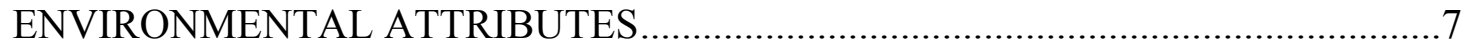

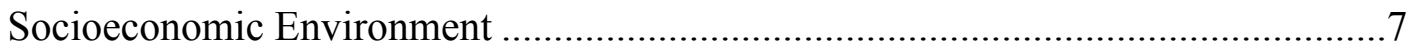

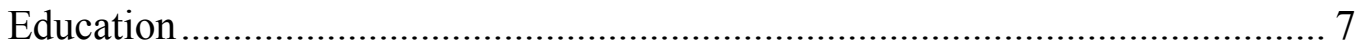

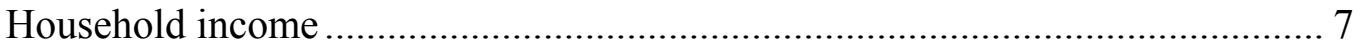

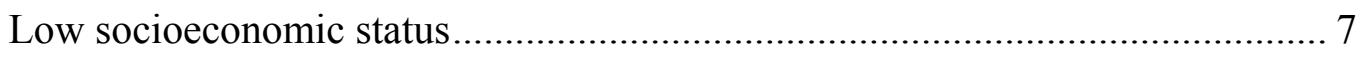

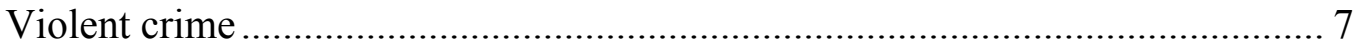

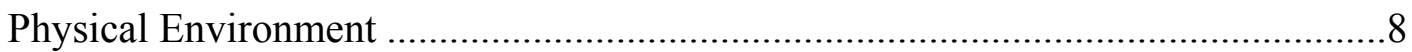



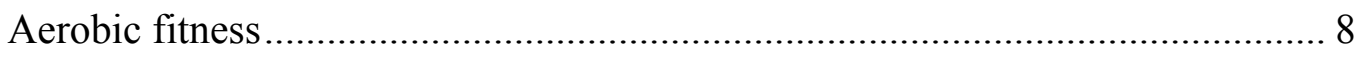

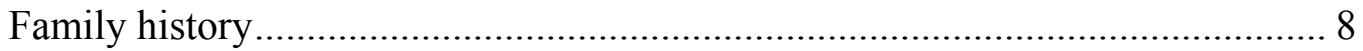



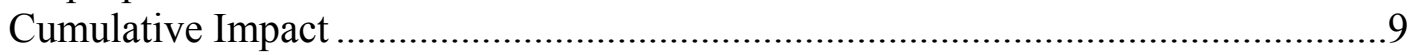

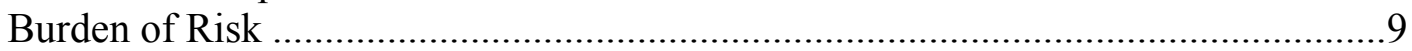







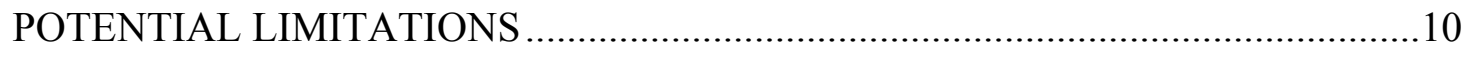

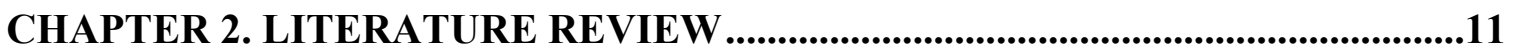



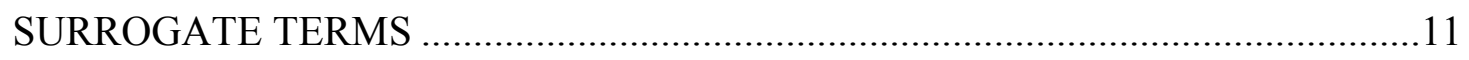

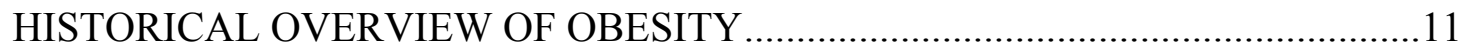

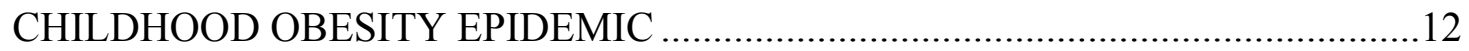





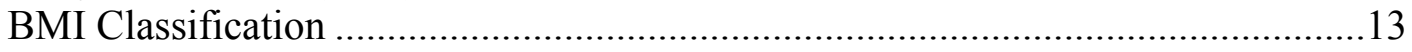

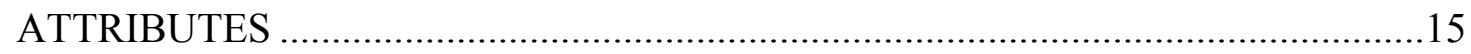

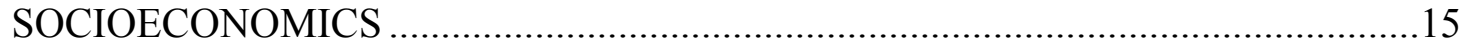

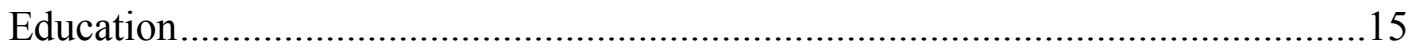





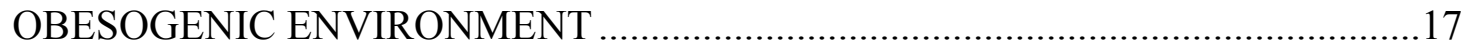

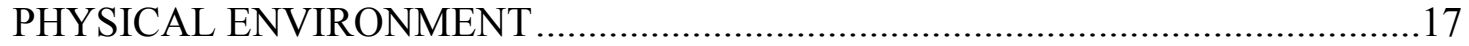

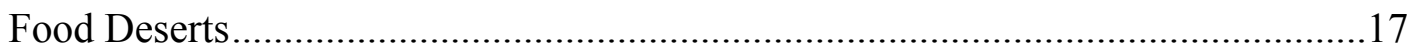


Fruit and Vegetable Markets .......................................................................... 18

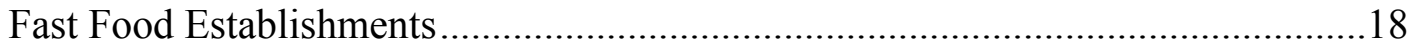

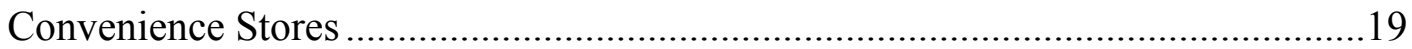



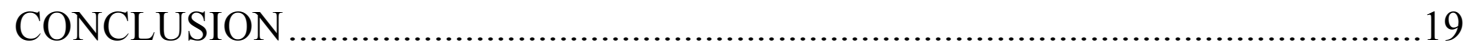



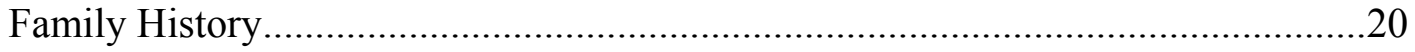

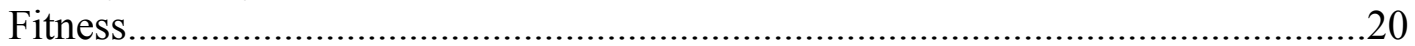



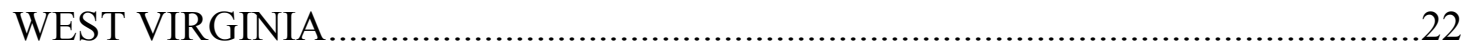



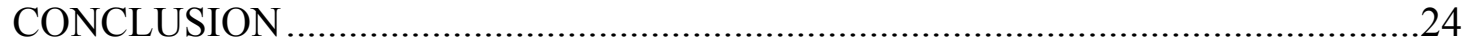

\section{CHAPTER 3. PREDICTORS OF OVERWEIGHT AND OBESITY AMONG} WV $5^{\text {TH }}$ GRADE CHILDREN ..............................................................................25





OPERATIONALIZATION OF SECONDARY DATA VARIABLES ......................27

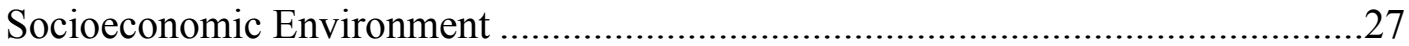

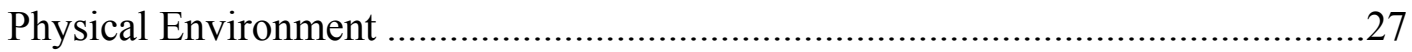

Personal Environment ................................................................................... 27



CARDIAC project: BMI and family history ............................................. 28

WV Board of Education: Fitnessgram and low socioeconomic status.............. 28

U.S. Census Bureau: Education and median household income ....................... 28

U.S. Census Bureau: WV business patterns .................................................... 28

WV State Police: Crime ............................................................................... 28





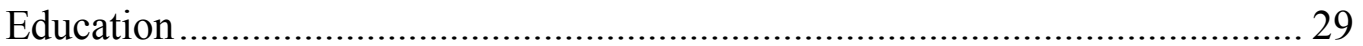

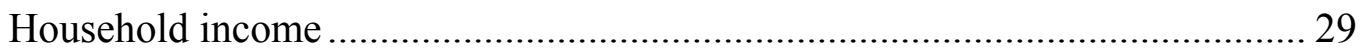

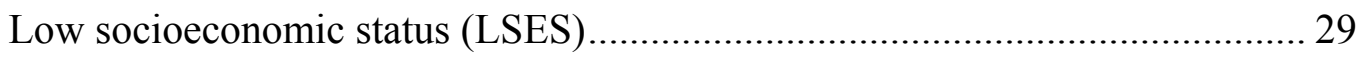

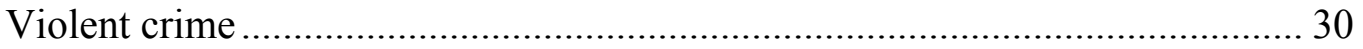

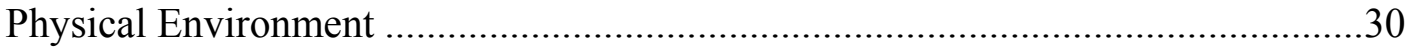

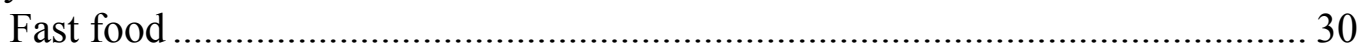

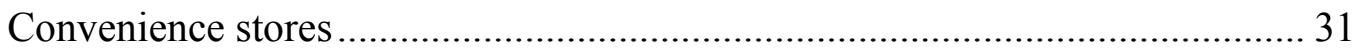

Supermarkets and other grocery ......................................................... 31

Fruit and vegetable markets............................................................... 31

Fitness and recreational sports centers ….................................................. 31

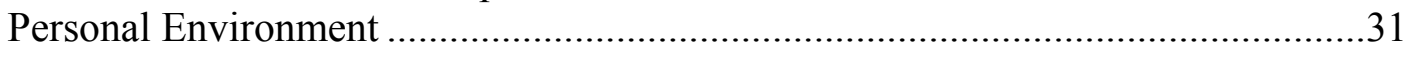

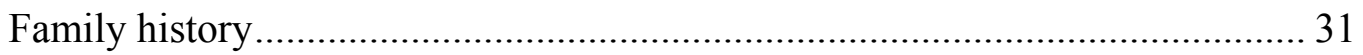

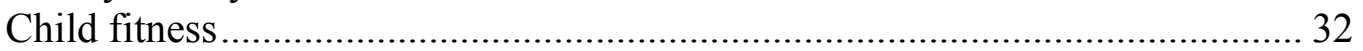

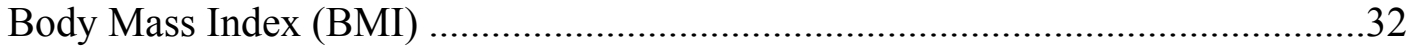

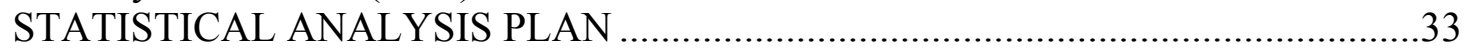

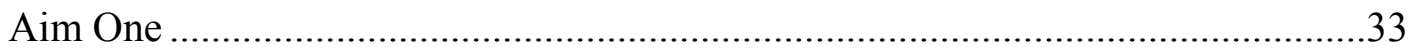

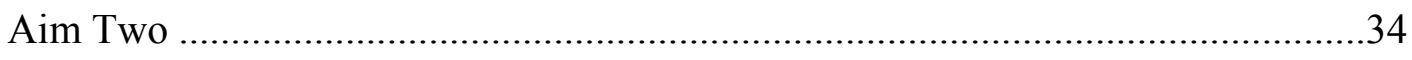

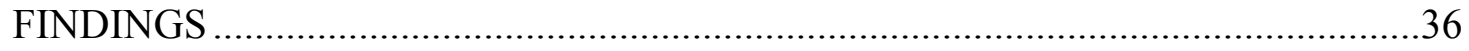






SOCIOECONOMIC ENVIRONMENTAL PREDICTORS ..........................................37

Univariate Analysis of Socioeconomic Environmental Predictors ............................37

Forward (LR) Stepwise Analysis of Socioeconomic Environmental Predictors ......38

PHYSICAL ENVIRONMENTAL PREDICTORS ………......................................38

Univariate Analysis of Physical Environmental Predictors .......................................38

Forward (LR) Stepwise Analysis of Physical Environmental Predictors .................40

PERSONAL ENVIRONMENTAL PREDICTORS .................................................40

Univariate Analysis of Personal Environmental Predictors .......................................40

Forward (LR) Stepwise Analysis of Personal Environmental Predictors .................41



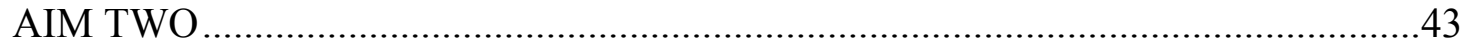

SOCIOECONOMIC ENVIRONMENTAL PREDICTORS …………......................43

Univariate Analysis of Socioeconomic Environmental Predictors ............................43

Forward (LR) Stepwise Analysis of Socioeconomic Environmental Predictors .....44

PHYSICAL ENVIRONMENTAL PREDICTORS ………....................................44

Univariate Analysis of Physical Environmental Predictors …………………..........44

Forward (LR) Stepwise Analysis of Physical Environmental Predictors ..................44

PERSONAL ENVIRONMENTAL PREDICTORS ................................................46

Univariate Analysis of Personal Environmental Predictors .......................................46

Forward (LR) Stepwise Analysis of Personal Environmental Predictors .................46



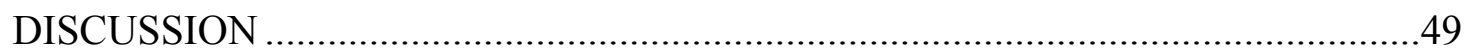

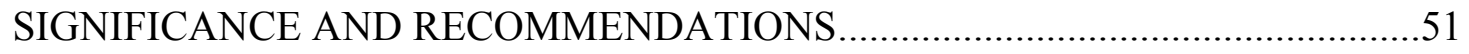



CHAPTER 4. SPATIAL ANALYSIS .............................................................................53

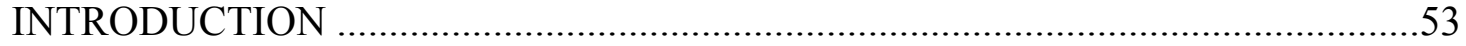

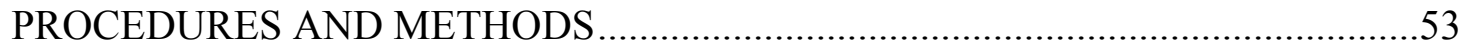



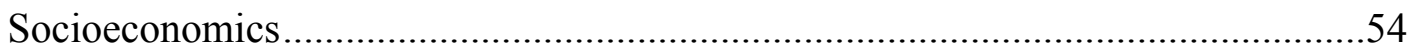

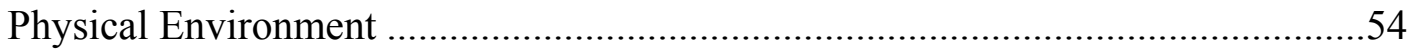

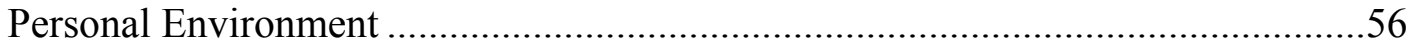

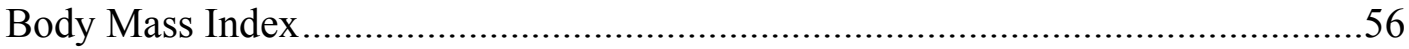

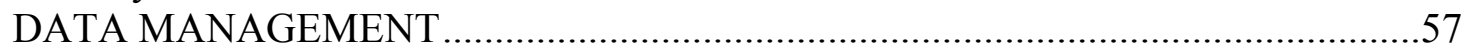



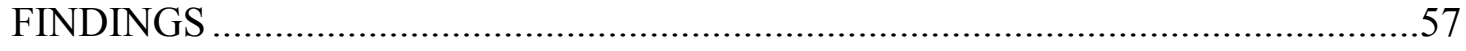





Distribution of overweight and obese $5^{\text {th }}$ grade children ................................. 59



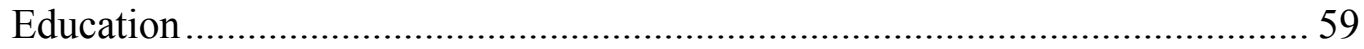



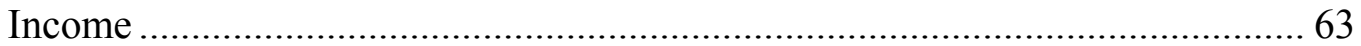

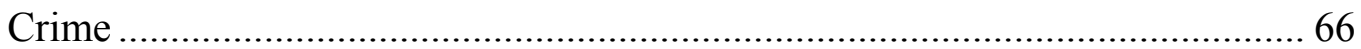



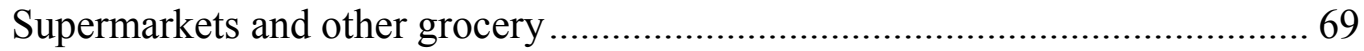






Fast food restaurants .............................................................................. 70

Fruit and vegetable markets........................................................................ 70

Fitness and recreational facilities ............................................................ 70



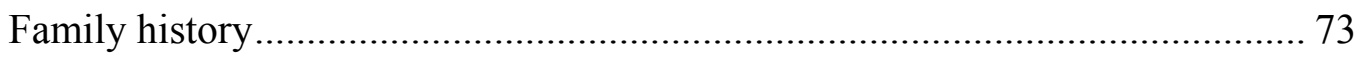



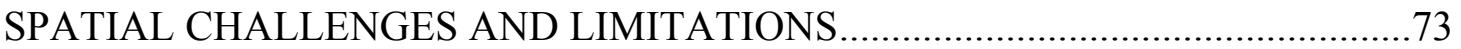

DISCUSSION ............................................................................................... 78

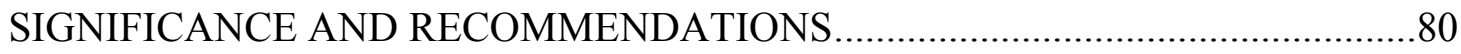



LIST OF REFERENCES ........................................................................................83

APPENDIX A. SPATIAL DISTRIBUTION OF STUDY VARIABLES..................100

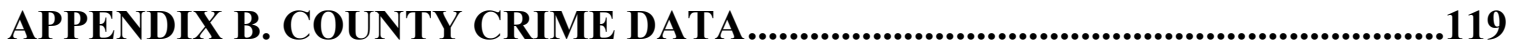

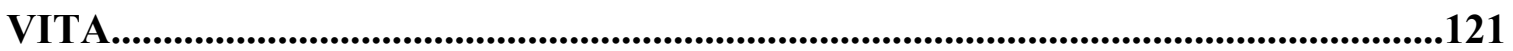




\section{LIST OF TABLES}

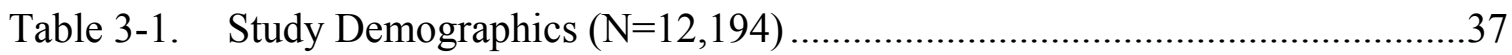

Table 3-2. Univariate Analysis: Socioeconomic Environmental Predictors of BMI Equal to or Greater than the $85^{\text {th }}$ Percentile in WV $5^{\text {th }}$ Grade Children ........38

Table 3-3. Forward (LR) Stepwise Analysis: Adjusted Model of Socioeconomic Environmental Predictors of BMI Equal to or Greater than the $85^{\text {th }}$ Percentile in WV $5^{\text {th }}$ Grade Children

Table 3-4. Univariate Analysis: Physical Environmental Predictors of BMI Equal to or Greater than the $85^{\text {th }}$ Percentile in WV $5^{\text {th }}$ Grade Children

Table 3-5. Forward (LR) Stepwise Analysis: Adjusted Model of Physical Environmental Predictors of BMI Equal to or Greater than the $85^{\text {th }}$ Percentile in WV ${ }^{\text {th }}$ Grade Children

Table 3-6. Univariate Analysis: Personal Environmental Predictors of BMI Equal to or Greater than the $85^{\text {th }}$ Percentile in WV $5^{\text {th }}$ Grade Children

Table 3-7. Forward (LR) Stepwise Analysis: Adjusted Model of Personal Environmental Predictors of BMI Equal to or Greater than the $85^{\text {th }}$ Percentile in WV $5^{\text {th }}$ Grade Children

Table 3-8. Final Model: Forward (LR) Stepwise Analysis of Environmental Predictors of BMI Equal to or Greater than the $85^{\text {th }}$ Percentile in WV $5^{\text {th }}$ Grade Children.

Table 3-9. Univariate Analysis: Socioeconomic Environmental Predictors of BMI Equal to or Greater than the $95^{\text {th }}$ Percentile in WV $5^{\text {th }}$ Grade Children ........45

Table 3-10. Forward (LR) Stepwise Analysis: Adjusted Model of Socioeconomic Environmental Predictors of BMI Equal to or Greater than the $95^{\text {th }}$ Percentile in WV ${ }^{\text {th }}$ Grade Children

Table 3-11. Univariate Analysis: Physical Environmental Predictors of BMI Equal to or Greater than the $95^{\text {th }}$ Percentile in WV $5^{\text {th }}$ Grade Children.

Table 3-12. Forward (LR) Stepwise Analysis: Adjusted Model of Physical Predictors of BMI Equal to or Greater than the $95^{\text {th }}$ Percentile in WV $5^{\text {th }}$ Grade Children

Table 3-13. Univariate Analysis: Personal Environment Predictors of BMI Greater than the $95^{\text {th }}$ Percentile in $5^{\text {th }}$ Grade Children. 
Table 3-14. Forward Stepwise Analysis: Adjusted Model of Personal Environmental Predictors of BMI Equal to or Greater than the $95^{\text {th }}$ Percentile in WV $5^{\text {th }}$ Grade Children.

Table 3-15. Final Model: Forward (LR) Stepwise Analysis of Predictors of BMI Equal to or Greater than the $95^{\text {th }}$ Percentile in WV $5^{\text {th }}$ Grade Children ........48

Table 4-1. Community Demographic Characteristics......................................................54

Table 4-2. Socioeconomic Environmental Variables, Data Level, and Source ...............55

Table 4-3. Physical Environmental Variables, Data Level, and Source ..........................55

Table 4-4. Personal Environmental Variables, Data Level, and Source .........................56

Table 4-5. Percentage of Overweight and Obese $5^{\text {th }}$ Graders Living in Communities Where Less than $75 \%$ of the Population Aged 25 Years or Older Had a High School Diploma or Greater

Table 4-6. Percentage of Overweight and Obese $5^{\text {th }}$ Graders Attending Schools in Which $50 \%$ or More of the $5^{\text {th }}$ Grade Population Was Defined as Low Socioeconomic Status

Table 4-7. Percentage of Overweight and Obese $5^{\text {th }}$ Graders Living in Zip Code Regions with Incomes below the State Median Household Income

Table 4-8. Percentage of Overweight and Obese $5^{\text {th }}$ Graders Living in Counties with a Crime Rate Greater than 6 per 100 Persons

Table 4-9. Percentage of Overweight and Obese $5^{\text {th }}$ Graders Living in Zip Code Regions with No Grocery Stores

Table 4-10. Percentage of Overweight and Obese $5^{\text {th }}$ Graders Living in Zip Code Regions with No Convenience Stores

Table 4-11. Percentage of Overweight and Obese $5^{\text {th }}$ Graders Living in Zip Code Regions with One or More Fast Food Facilities

Table 4-12. Percentage of Overweight and Obese $5^{\text {th }}$ Graders Reporting a Family History of Heart Disease.

Table 4-13. Percentage of Overweight and Obese $5^{\text {th }}$ Graders Reporting a Family History of Diabetes .

Table 4-14. Percentage of Overweight and Obese $5^{\text {th }}$ Graders Attending Schools Where $70 \%$ or More of $5^{\text {th }}$ Graders Were in the Healthy Zone for Aerobic Fitness 


\section{LIST OF FIGURES}

Figure 1-1. Conceptual Framework of Environmental Attributes Perceived to Stimulate an Obesogenic Environment.................................................6

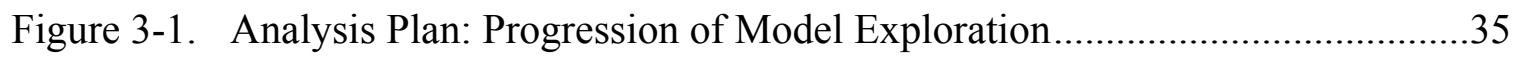

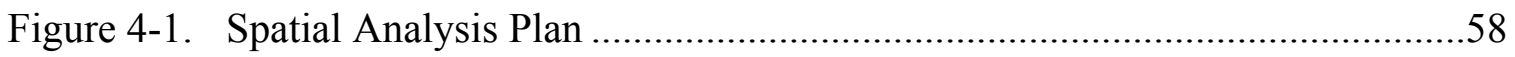

Figure 4-2. Spatial Distribution of Study Sample at the Zip Code Level......................60

Figure 4-3. Distribution of Overweight at the Zip Code Level ...................................61

Figure 4-4. Distribution of Obese $5^{\text {th }}$ Graders at the Zip Code Level ...........................62

Figure 4-5. Distribution of the Percentage of $5^{\text {th }}$ Grade Children Classified as Low Socioeconomic Status According to Free or Reduced Lunch Eligibility .....65

Figure 4-6. Distribution of Violent Crime at the County Level and Obese $5^{\text {th }}$ Grade Children .......................................................................................6

Figure 4-7. Distribution of Fast Food Facilities at the Zip Code Level and Obesity ......72

Figure 4-8. Distribution of Child's Family History of Heart Disease at the Child's Zip Code Level .................................................................................... 75

Figure 4-9. Distribution of Child's Family History of Diabetes at the Child's Zip Code Level. 


\section{LIST OF ABBREVIATIONS}

ACS

BMI

BRFSS

CARDIAC

CDC

CVD

DHHR

DXA

ESRI

FBI

FIPSSTCO

GIS

H-L

IOTF

IRB

LSES

NAICS

NCHS

NHANES

NHES

NIBRS

NIH

SES

SSI

US

WHO

WV

WVEIS

ZCTA
American Community Survey

Body Mass Index

Behavioral Risk Factor Surveillance System

Coronary Artery Risk Detection in Appalachian Communities

Centers for Disease Control

Cardiovascular Disease

Department of Health and Human Resources

Dural Energy X-Ray Absorptiometry

Environmental Systems Research Institute

Federal Bureau of Investigations

Fipscode for the State and County

Geographic Information System

Hosmer-Lemeshow

International Obesity Task Force

Institutional Review Board

Low Socioeconomic Status

North American Industry Classification System

National Center for Health Statistics

National Health and Nutrition Examination Survey

National Health and Examination Survey

National Incident Based Reporting System

National Institutes of Health

Socioeconomic Status

Supplemental Security Income

United States

World Health Organization

West Virginia

West Virginia Education Information System

ZIP Code Tabulation Area 


\section{CHAPTER 1. INTRODUCTION}

\section{OVERVIEW}

Childhood obesity, defined as a body mass index (BMI) at or above the $95^{\text {th }}$ percentile for children of the same age and sex, is considered an epidemic in the United States (Centers for Disease Control and Prevention [CDC], 2011a). In the last 30 years the prevalence of childhood obesity (children aged 6 to 11 ) has increased from $6.5 \%$ in 1980 to $19.6 \%$ in 2008 (Ogden, Carroll, Curtin, Lamb, \& Flegal, 2010; Ogden \& Flegal, 2010; Wilkinson \& Marmot, 2003). This increase in prevalence has been so severe that some perceive that the obesity epidemic threatens to reverse the steady increase in life expectancy observed over the last decade (Olshansky et al., 2005; Whitlock, Williams, Gold, Smith, \& Shipman, 2005). Biology and lifestyle behaviors have been identified as important factors in the development of childhood obesity; however, researchers are beginning to place more emphasis upon the impact that continual environmental exposures such as low socioeconomics, low levels of education, and lack of access to healthy food sources have upon obesity development. Environmental risk factors associated with obesity are distributed continuously over space, yet evidence suggests that the burden of risk may not be evenly dispersed across a community. Additionally, the obesity epidemic appears to disproportionately affect some communities greater than others. Analysis of spatial distribution may help provide answers to fundamental childhood obesity questions related to environmental risks. Such methods may provide a means to identify geographical obesity patterns and offer the ability to filter information to identity obesity related events.

Spatial analysis techniques have been utilized to examine how environmental attributes may influence weight (Cutts, Darby, Boone, \& Brewis, 2009; Davies-Cole, Kidane, Lum, \& Richardson, 2003; Michimi \& Wimberly, 2010), as well as in the identification of obesity related events of hypertension, diabetes, and cardiovascular disease (Davies-Cole et al., 2003). Epidemiological studies have employed spatial techniques to examine disease clusters associated with outbreaks and to assist in the quantification of risk factors associated with environment determinants of disease (Siaway, Davies-Cole, \& Kidane, 2007). Yet, few spatial studies have been performed at the micro level regarding childhood obesity.

While it is well documented that the physical environment is associated with obesity development (Galvez, Pearl, \& Yen, 2010; Papas et al., 2007), there is a paucity of information on the effect of cumulative environmental factors on overweight and obese children. The literature supports the linkage between individual environmental risks factors including the built, home, and socioeconomic environment; however, it is unclear whether such environmental risks produce an environment prone to obesity development. The phenomenon of an obesogenic environment is not well understood. Yet, researchers contend that behaviors are a reflection of one's environment and that the more obesogenic the environment the stronger the influence towards developing obesity (Kirk, Penney, \& McHugh, 2010; Papas et al., 2007). 
Community socioeconomic status (SES) such as poverty, is a fundamental factor perceived to influence child weight (Drewnowski \& Specter, 2004). Socioeconomically individuals who are less educated and/or make less money have higher obesity rates (Trust for America's Health, 2011). Economically the poorest states: West Virginia (WV), Mississippi, and Tennessee have the heaviest children (Trust for America's Health, 2011).

Ethnic minorities, low socioeconomic status families, and children in southern states have higher rates of obesity than the rest of the population (Cochran, 2008). Geographically, a higher percentage of rural children are obese compared to urban children (Trust for America's Health, 2009).

Over the last 15 years, the adult obesity rate in WV has increased more than $80 \%$ (Trust for America's Health, 2011); whereas, the current combined obesity and overweight rate among adults in WV is $68.1 \%$. West Virginia ranks tenth in the nation for childhood obesity and third for adult obesity. The obesity rate for children and adolescents (ages 10 to 17 years) is 18.9\% (Trust for America's Health, 2011).

For the purpose of this study, associations between attributes of the socioeconomic, physical, and personal environment, overweight, and obesity were examined statistically using binary logistic regression techniques. Geographic Information System (GIS) technology was utilized to explore obesity spatial distribution and burden of risk at the zip code level.

\section{PURPOSE OF STUDY}

West Virginia, a rural Appalachian community, has the third highest adult and tenth highest childhood obesity rates $(32.2 \%$ and $18.9 \%$, respectively) in the nation (Trust for America's Health, 2011); therefore, WV serves as an ideal environment to examine childhood obesity. The study design supports the hypothesis that overweight and obesity are the consequence of environmental exposures and that the distribution of overweight and obesity disproportionately affects some WV communities more than others. Therefore, the purposes of this study were threefold: 1) to determine which socioeconomics, physical, and personal environment attributes contribute to a BMI equal to or greater than the $85^{\text {th }}$ percentile for age, and gender; 2) to determine which socioeconomics, physical, and personal environment attributes contribute to obesity (BMI equal to or greater than the $95^{\text {th }}$ percentile for age, and gender); and 3 ) to assess the geographic distribution of attributes (socioeconomic, physical, and personal) in relation to BMI equal to or greater than the $85^{\text {th }}$ percentile (overweight) among WV $5^{\text {th }}$ graders and BMI equal to or greater than the $95^{\text {th }}$ percentile (obese) among WV $5^{\text {th }}$ graders. 


\section{Aim One}

To determine which socioeconomic, physical, and personal environment attributes contribute to overweight (BMI equal to or greater than the $85^{\text {th }}$ percentile for age and gender) in WV $5^{\text {th }}$ graders. Hypotheses:

1.a. Socioeconomic attributes (lower level of education, lower household income, and higher level of violent crime in the county) will be associated with a BMI equal to or greater than the $85^{\text {th }}$ percentile (overweight).

1.b. BMI equal to or greater than the $85^{\text {th }}$ percentile (overweight) will be inversely associated with physical attributes of the number of grocery stores, fruit and vegetable markets, and the number of recreational facilities.

1.c. BMI equal to or greater than the $85^{\text {th }}$ percentile (overweight) will be positively associated with physical attributes of the number of fast food restaurants and convenience stores.

1.d. BMI equal to or greater than the $85^{\text {th }}$ percentile (overweight) will be positively associated with personal attributes of a family history of cardiovascular disease and diabetes.

1.e. BMI equal to or greater than the $85^{\text {th }}$ percentile (overweight) will be inversely associated with the personal attribute of child aerobic fitness at the school level.

\section{Aim Two}

To determine which socioeconomic, physical, and personal environment attributes contribute to obesity (BMI equal to or greater than the $95^{\text {th }}$ percentile for age and gender) in WV $5^{\text {th }}$ graders. Hypotheses:

2.a. Socioeconomic attributes (lower level of education, lower household income, and higher level of violent crime in the county) will be associated with a BMI equal to or greater than the $95^{\text {th }}$ percentile (obese).

2.b. BMI equal to or greater than the $95^{\text {th }}$ percentile (obese) will be inversely associated with physical attributes of the number of grocery stores, fruit and vegetable markets and the number of recreational facilities.

2.c. BMI equal to or greater than the $95^{\text {th }}$ percentile (obese) will be positively associated with physical attributes of the number of fast food restaurants and convenience stores.

2.d. BMI equal to or greater than the $95^{\text {th }}$ percentile (obese) will be positively associated with personal attributes of a family history of cardiovascular disease and diabetes.

2.e. BMI equal to or greater than the $95^{\text {th }}$ percentile (obese) will be inversely associated with the personal attribute of child aerobic fitness at the school level. 


\section{Aim Three}

To assess the geographic distribution of attributes (socioeconomic, physical, and personal) in relation to BMI equal to or greater than the $85^{\text {th }}$ percentile and obesity BMI equal to or greater than the $95^{\text {th }}$ percentile among WV $5^{\text {th }}$ graders. Hypotheses:

3.a. BMI equal to or greater than the $85^{\text {th }}$ percentile will be disproportionately distributed across the state of WV.

3.b. BMI equal to or greater than the $95^{\text {th }}$ percentile will be disproportionately distributed across the state of WV.

3.c. Socioeconomic attributes (lower level of education, lower household income, and higher level of violent crime) will be disproportionately distributed across the state of WV.

3.d. Physical attributes (the number of grocery stores, fruit, and vegetable markets, the number of recreational facilities, and fast food restaurants and convenience stores) will be disproportionately distributed across the state of WV.

3.e. Personal attributes (family history of cardiovascular disease and diabetes, and child aerobic fitness) will be disproportionately distributed across the state of WV.

3.f. Overweight will be spatially patterned in association with the distribution of socioeconomic, physical, and personal environmental attributes.

3.g. Obesity will be spatially patterned in association with the distribution of socioeconomic, physical, and personal environmental attributes.

\section{SIGNIFICANCE OF STUDY}

Over the last 5 years, WV has consistently ranked among the top tenth most obese stateS in the nation for both adults and children Additionally, WV residents experience among the highest rates of chronic conditions associated with obesity including diabetes and hypertension (Trust for America's Health, 2009, 2011). Obese children are more likely to become obese adults (Biro \& Wien, 2010; Centers for Disease Control and Prevention [CDC], 2011a; Serdula et al., 1993) and are at increased risk of morbidity, mortality (Flegal, Carroll, Ogden, \& Curtin, 2010; Flegal, Graubard, Williamson, \& Gail, 2005; Fontaine, Redden, Wang, Westfall, \& Allison, 2003; Franks, Hanson, \& Knowler, 2010), disability, premature death due to cardiovascular disease (Freedman, Dietz, Srinivasan, \& Berenson, 1999; Freedman et al., 2005; Mokdad et al., 2001; Must et al., 1999; Must \& Strauss, 1999), and increased insulin resistance and type 2 diabetes in adulthood (Whitlock et al., 2005). Nationally, medical expenditures associated with obesity constituted approximately $\$ 147$ billion in 2008 (Finkelstein, Trogdon, Cohen, \& Dietz, 2009). Expenditures associated with overweight and obesity in WV were estimated to be $\$ 668$ million in 2008 . If current trends continue, expenditures are estimated to be between $\$ 1,556-3,212$ million by 2018 (Thorpe, 2009). 
Researchers contend that an obesogenic environment is a major explanation for the increased incidence of overweight and obesity (Boehmer, Lovegreen, Haire-Joshu, \& Brownson, 2006; Giskes, Van Lenthe, Avendano-Pabon, \& Brug, 2011; Michimi \& Wimberly, 2010); however, what constitutes an environment that promotes obesity is not well understood. Additionally, the obesity epidemic appears to disproportionately affect some communities greater than others (Cochran, 2008) yet, few studies have examined childhood overweight and obesity among Appalachian children from an obesogenic environmental perspective.

Spatial analysis methods may help provide answers to fundamental questions related to childhood obesity and environmental risk, furthering understanding of the obesogenic environment phenomenon. Such findings could aid in predicting overweight and obesity in children. Developing a spatial understanding may help provide more information about the obesity epidemic within the state of WV in order to help shape local obesity-prevention interventions.

\section{CONCEPTUAL MODEL}

Childhood obesity is perceived to be the result of an increased risk derived from the cumulative impact of socioeconomic (education, income, socioeconomic status, and crime); physical (fast food establishments, convenience stores, supermarkets, recreational facilities, and fruit and vegetable markets); and personal (family history of heart disease, diabetes, and child aerobic fitness) environmental attributes that stimulate an obesogenic environment. Environmental attributes are perceived to be disproportionality distributed across the state of WV, but spatially clustered resulting in an increased burden of risk for overweight and/or obesity development.

The conceptual framework supports the proposed hypothesis that overweight and obesity are the consequence of the cumulative impact of environmental factors that are disproportionately distributed across the state. The cumulative impact of such factors is perceived to create an environment supportive of obesity development with an end consequence of overweight and/or obesity among WV children. In turn, overweight and obesity disproportionately affects some WV communities greater than others, resulting in a cycle of unequal distribution and risk. See Figure 1-1.

\section{MAJOR CONCEPTS AND DEFINITIONS}

Theoretical and operational definitions for the major concepts presented within the conceptual model included socioeconomic (income, education, LSES, and violent crime); physical (supermarket, convenience stores, fitness and recreational facilities, fruit and vegetable markets, and fast food establishments); and personal (family history of heart disease, family history of diabetes, and child aerobic fitness). 


\section{Environmental Attributes}

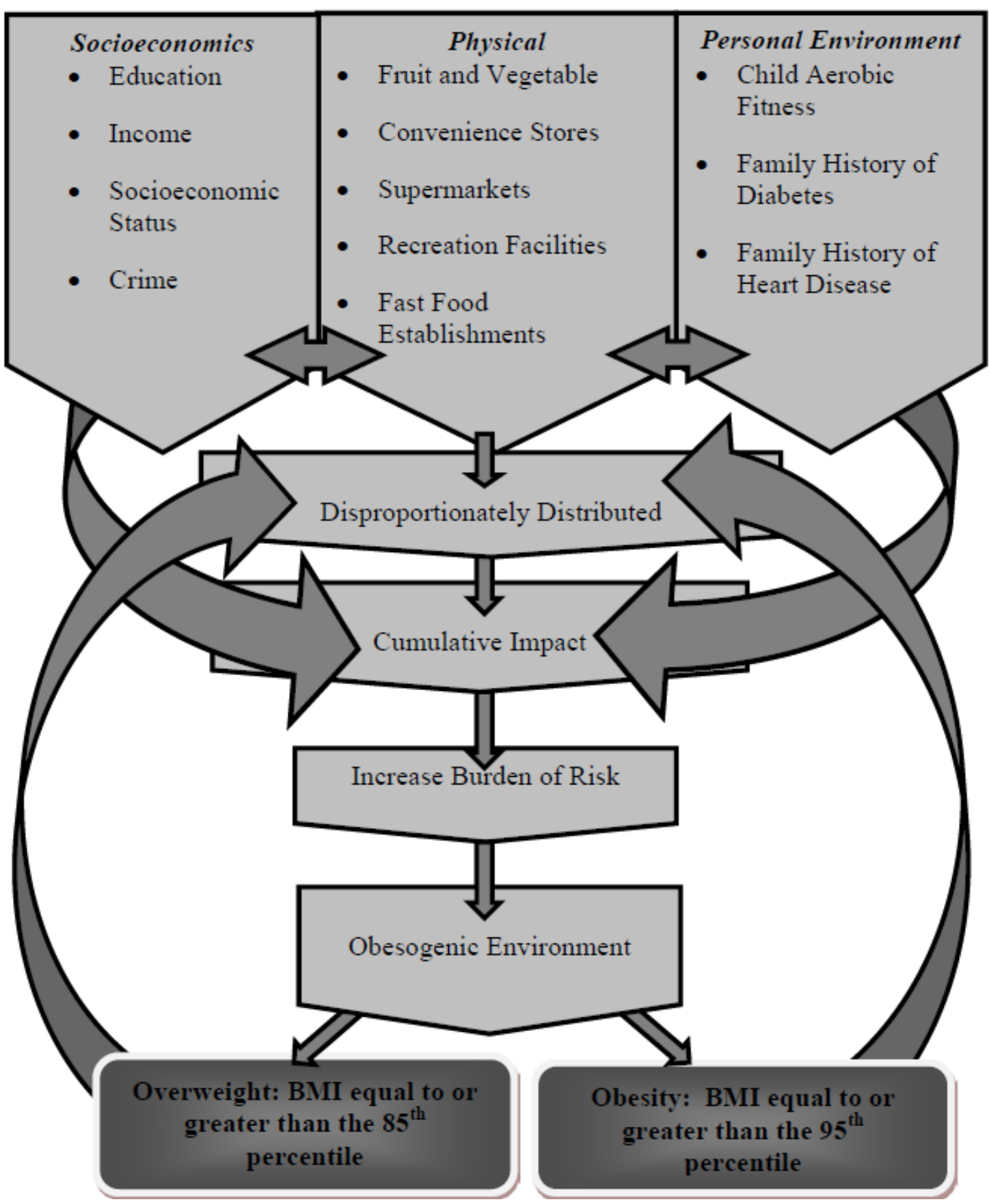

Figure 1-1. Conceptual Framework of Environmental Attributes Perceived to Stimulate an Obesogenic Environment. 


\section{ENVIRONMENTAL ATTRIBUTES}

Environment attributes were defined as the socioeconomic, physical, and personal attributes, which cumulatively shape one's environment and health risks. Attributes included: education, income, socioeconomic status, violent crime, fast food establishments, convenience stores, supermarket and other grocery establishments, fruit/ vegetable markets, fitness/recreational sports centers, family history of heart disease and/or diabetes, and child fitness.

\section{Socioeconomic Environment}

The socioeconomic environment was defined according to attributes of education (total population $25+$ years with at least a high school diploma), median household income, low socioeconomic status, and number of violent crimes in the community. Data were defined at the zip code, school, and county level.

Education. The number of high school graduates age $25+$ years included people whose highest degree was a high school diploma or its equivalent, people who attended college or professional school, and persons who received a college, university, or professional degree. Persons completing the $12^{\text {th }}$ grade but not receiving a diploma were not considered high school graduates and were excluded from the tabulation (U.S. Census Bureau [Data file], 2010).

Household income. Household income was the sum of money income including wage or salary income; net self-employment income; interest, dividends, or net rental or royalty income or income from estates and trusts; Social Security or Railroad Retirement income; Supplemental Security Income (SSI); public assistance or welfare payments; retirement, survivor, or disability pensions; and all other income, received by all household members 15 years of age and older (U.S. Census Bureau [Data file], 2011). All household members included unrelated household members such as household members not related to the householder, people living alone, and other nonfamily household members (U.S. Census Bureau [Data file], 2011).

Low socioeconomic status. Low Socioeconomic Status (LSES) was defined according to aggregate data based on free and reduced lunch eligibility per child's $5^{\text {th }}$ grade class of attendance. According to 2007 and 2008 criteria, families with an income at or below 130 percent of the poverty level were eligible for free meals and children from families between 130 percent and 185 percent of the poverty level were eligible for reduced-price meals (West Virginia Department of Education [Data file], 2011).

Violent crime. Crime was defined as the aggregate total of crime data at the county level: rape, sexual assault, robbery, assault, burglary, motor vehicle theft, and theft for 52 of the $55 \mathrm{WV}$ counties. Putman and Wood counties were excluded from the analysis due to lack of complete data. 


\section{Physical Environment}

Physical environmental attributes were examined and coded at zip code level. The physical environment was defined according to the physical attributes of food services (fast food, convenience store, supermarket and other grocery, fruit and vegetable markets and fitness/recreational sports centers). The North American Industry Classification System (NAICS) was utilized to define and classify food services (U.S. Census Bureau [Data file], 2007):

- $\quad$ Fast food establishments (NAICS code 722211)

- Convenience store establishments (NAICS code 445120)

- Supermarket and other grocery establishments (NAICS code 445110)

- Fruit and vegetable markets (NAICS code 445230)

- Fitness and recreational sports centers (NAICS code 713940)

\section{Personal Environment}

For the purpose of this study, the personal environment of interest was that of the child's at the zip code and school level. Personal environment was defined according to family history of diabetes, heart disease, and child aerobic fitness. Attributes of interest are described below.

Aerobic fitness. Child fitness was categorized as 1) "in the healthy fitness zone" (student met or exceeded fitness target) or 2) "needs improvement" (student failed to meet fitness target) (Cureton \& Plowman, 2008). Fitness categorizations are criterionreferenced health standards defined according to the minimal level of performance on each test item that is consistent with acceptable good health and adequate function. Good health being defined as minimal disease risk and adequate functions as the ability to carry out activities of daily living (Welk \& Meredith, 2008). Five fitness types, i.e., aerobic capacity, abdominal strength, upper body strength, flexibility, and trunk strength are measured in the assessment of child fitness (Welk \& Meredith, 2008). Fitness types are categorized as aerobic capacity or musculoskeletal fitness (abdominal strength, upper body strength, flexibility, and trunk strength performance). Children are then classified as "in the healthy fitness zone" or "needs improvement" for each of the two categories: aerobic capacity and musculoskeletal fitness. For the purpose of this study, only aerobic fitness was examined per percentage of $5^{\text {th }}$ graders in the "healthy fitness zone" at the school level.

Family history. For the purpose of this study, parental self-reported data were obtained from the CARDIAC project's disease surveillance and intervention program. Family history was based on parental self-report of current or past occurrence of heart disease and/or diabetes. 


\section{Disproportionate Distribution}

Disproportionate distribution was defined as an unequal spatial dispersion of occurrences across a community, county or state. For the purpose of this study, data were examined at the zip code, school, and/or county level.

\section{Cumulative Impact}

Cumulative impact was defined as the totality of influence (positive or negative) socioeconomic, physical, and personal environmental factors imposes on overweight and obesity development. Cumulative impact was perceived to increase a child's probability of overweight and/or obesity.

\section{Burden of Risk}

Burden of risk was defined as the encumbrance produced by the cumulative impact of environmental factors of socioeconomic, physical, and personal attributes that place the individual at greater odds for the development of BMI at or greater than the $85^{\text {th }}$ percentile (overweight) or BMI at or greater than the $95^{\text {th }}$ percentile (obese).

Therefore, for the purpose of this study, the burden of risk was defined according to the socioeconomic, physical, and personal attributes significantly associated (statistically and spatially) with increased odds of overweight or obesity.

\section{Obesogenic Environment}

According to the literature, an obesogenic environment is the totality of influences that the environments have on promoting obesity (Kirk et al., 2010; Papas et al., 2007). Therefore, for the purpose of this study the obesogenic environment was defined according to the sum of socioeconomic, physical, and personal attributes significantly associated (statistically and spatially) with increased odds of overweight or obesity.

\section{Overweight-Obesity in Children}

Overweight was defined as a BMI $\geq 85^{\text {th }}$ percentile for age and gender, while obesity was defined as a BMI $\geq 95^{\text {th }}$ percentile for age and gender (Barlow \& Expert Committee, 2007). BMI was computed by weight in kilograms divided by height in meters squared and plotted on a growth chart. Percentile cut points developed by the NHANES was utilized for the classification of overweight $\left(\geq 85^{\text {th }}\right.$ percentile $)$ and obese $\left(\geq 95^{\text {th }}\right.$ percentile) (Centers for Disease Control and Prevention [CDC], 2000). Data from the NHANES (conducted in three cycles 1970s, 1980s, and 1990s) has been utilized in previous studies and by various organizations to derive a statistical definition of overweight and obesity. Although BMI does not directly measure body fatness, 
measurements taken using the BMI method have been found to correlate with the dual energy x-ray absorptiometry (DXA) and underwater weighting (Flegal, 1993). Both methods; the DXA and underwater weighing, provide direct measures of body fatness, but are time consuming and expensive. Therefore, BMI offers a valid, rapid and inexpensive method to measuring obesity in children (Centers for Disease Control and Prevention, 2000).

\begin{abstract}
ASSUMPTIONS
The following assumptions were made for this study:

- Data in the original studies were collected in an accurate manner and in congruency with the original research question/aims.

- An excess risk of obesity in children is associated with environmental attributes.

- Children progressed to the next grade level and were included only once in the sample.

- Children accurately reported zip code of residence.
\end{abstract}

\title{
POTENTIAL LIMITATIONS
}

A secondary data analysis was utilized and was suitable to address proposed research questions. Although the secondary data analysis design has both strengths and limitations the plan did allow the investigation of previously unanalyzed combinations of variables and provided access to a large sample (Burns \& Groves, 2001; Rew, KoniakGriffin, Lewis, Miles, \& O'Sullivan, 2000). Study limitations are presented below:

- Data were obtained for other purposes; therefore, this researcher had limited control over the data collection process (Burns \& Groves, 2001; Mainous \& Hueston, 1997; Nicoll \& Beyea, 1999).

- BMI was considered to be a crude measurement of obesity limiting the ability to evaluate fat mass.

- A lack of a unified definition of an obesogenic environment.

- Trans-boundary spillover due to activities in one community influencing activities in other communities (Amarasinghe, D'Souza, Brown, \& Borisova, 2006) .

- ZIP Codes were administrative entities of the U.S. Postal Service. As such, boundaries were implied and may not necessarily follow clearly identifiable physical features.

- A lack of crime data for three WV counties. 


\section{CHAPTER 2. LITERATURE REVIEW}

\section{INTRODUCTION}

Chapter 2 presents the major findings within the literature relevant to the concepts proposed in the conceptual framework of the study. The first section of the review presents a brief discussion regarding the surrogate terms utilized within the literature to describe the concepts obesity and childhood. A historical overview of the concept obesity follows and transitions into a discussion regarding the childhood obesity epidemic. The second section provides an overview of anthropometric techniques utilized to measure the concept obesity, controversies associated with utilization in children and obesity classifications. The third section examines the social and economic attributes of education, income, and violent crime; the physical attributes (convenience stores, supermarkets and other grocery, fast food facilities, recreational and fitness centers), and personal environment (family history of diabetes and/or heart disease and childhood aerobic fitness). The final section examines the geographical distribution of childhood obesity universally and within the state of WV and the utilization of spatial analyses techniques to describe environmental risk factors on obesity development in children.

\section{SURROGATE TERMS}

According to Rodgers (1989), surrogate terms can be used interchangeably to express the same concept. Fatness, stout, obeseness, adiposis, and plumpness were used interchangeably throughout the literature to describe obesity. Obesity, overweight and "at risk of overweight" were the most commonly utilized terms. The terms "obese" and "overweight" are often used interchangeably, but rather ambiguously (Mullen \& Shield, 2004). In addition, the term childhood was also examined revealing a variety of surrogate terms utilized in the literature: youth, preadolescents, child, and children. To ensure a thorough examination of the literature the concept of childhood obesity was examined using known surrogates.

\section{HISTORICAL OVERVIEW OF OBESITY}

Obesity dates back to the stone age and has been described since the time of Galen and the Roman Empire (Bray, 1990; Papavramidou, Papavramidis, \& Christopoulou-Aletra, 2004). Galen was among the first to utilize scientific methods to describe obesity: pachis (fat), efsarkos (chubby), and polysarkos (obese) (Papavramidou et al., 2004). Even though Galen's views regarding the physiology and pathology of obesity have been proven wrong his observations regarding the association of obesity to diet, exercise, and the environment are still observed today (Papavramidou et al., 2004). It was not until the era of Hippocrates that obesity was first recognized as a medical 
disorder. Hippocrates identified obesity as a risk to health and noted the value of dietary restriction, and increasing exercise (Bray, 1990; Haslam, 2007).

Scholarly discussions regarding the concept first began to appear in the late 16th century; however, it was not until the end of $18^{\text {th }}$ century and throughout the $19^{\text {th }}$ that published identification of familial factors of obesity began to emerge (Bray, 1990). The discoveries of fat cells in the 19th century lead to the identification of specific types of obesity and standards for measuring body weight. Beginning in the 20th century obesity began to be analyzed more intensely by physicians as a medical disorder (Hamin, 1999; Moffat, 2010; Stearns, 1999) and in the last 25 years obesity has drawn attention on a global scale.

\section{CHILDHOOD OBESITY EPIDEMIC}

In the past 30 years the rate of childhood obesity has more than tripled (Ogden et al., 2010; Ogden, Flegal, Carroll, \& Johnson, 2002). From 1980 to 2008 the rate increased from $6.5 \%$ to $19.6 \%$ among children aged 6 to 11 years and from $5.0 \%$ to 18.1 in children ages 12-18 years of age (Centers for Disease Control and Prevention [CDC], 2011a; Flegal et al., 2010; Ogden et al., 2010). According to findings from the National Survey of Children's Health (NSCH), a survey of parents in each state, obesity rates for children ages 10-17 ranged from a low of 9.6 percent in the state of Oregon to a high of 21.9 percent in Tennessee (Centers for Disease Control and Prevention [CDC], 2011b). Eight states had childhood obesity rates over 20 percent: Arkansas, Georgia, Illinois, Kentucky, Louisiana, Mississippi, Tennessee, and Texas (Centers for Disease Control and Prevention [CDC], 2011b) .

\section{ANTHROPOMETRY}

Anthropometry is the non-invasive method of assessing size, shape, and body composition. Body weight and stature are utilized to estimate body size, whereas, ratios of body weight to height are used to represent body proportion. Historically, overweight and obesity anthropometry measurement techniques have included circumference or girth measurements, waist-to-hip ratio, skin fold thickness, bioelectrical impedance, and body mass index (BMI) to name a few (Claessens, Beunen, \& Malina, 2008; Lasker, 1994).

\section{Body Mass Index (BMI)}

BMI correlates well with body fat in adults (Bertakis \& Azari, 2005; Freedman et al., 2005) and children (Dietz \& Robinson, 1998; Freedman, Khan, Serdula, Ogden, \& Dietz, 2006; Maynard et al., 2001; Velasquez-Mieyer, Neira, Nieto, \& Cowan, 2007) and is considered a safe, simple, inexpensive method to express relative weight to height to characterize childhood obesity (Freedman et al., 2005; Himes \& Dietz, 1994; Krebs et al., 
2007; National Research Council, 2005). The technique has been widely utilized to characterize childhood weight in epidemiological studies (Borecki et al., 1998).

Although BMI does not directly measure body fatness, measurements taken using the BMI method have been found to correlate with the dual energy x-ray absorptiometry (DXA) and underwater weighing (Rothman, 2008). Both methods; the DXA and underwater weighing, provide direct measures of body fatness but are time consuming and expensive (Rothman, 2008). BMI offers a valid, rapid and inexpensive method to measuring obesity in children (Zuguo et al., 2002).

\section{BMI Classification}

Earlier studies (1959 to 1983) of obesity relied on Metropolitan Life Insurance tables of weight-for-height as the reference for overweight (Flegal, Carroll, Kuczmarski, \& Johnson, 1998). More recently, the scientific community has relied on data collected from a series of National Health Examination cross-sectional surveys (NHES): the National Center for Health Statistics (NCHS) conducted by the Centers for Disease Control and Prevention (CDC) and the National Health and Nutrition Examination Survey (NHANES).

Data from the NHES (spanning the years 1960 to 1970) and NHANES (1970s, 1980s, and early 1990s) has been utilized by various organizations to derive a statistical definition of overweight and obesity. For example, the World Health Organization (WHO) utilized NHANES II data to recommend a 3 "grade" classification system of overweight using body mass index (BMI) cutoff points of 25, 30, and 40 (Kuczmarski \& Flegal, 2000; World Health Organization [WHO], 2000). In 1998, the National Institutes of Health $(\mathrm{NIH})$ expert panel on obesity released a report of definitions for overweight and obesity that were similar to those introduced by the WHO. The panel categorized normal weight as a BMI of $18.5-24.9$; overweight as a BMI of $25-29.9$; and obesity as a BMI in adults greater than 30. BMI cutoff points of 25 and 30 are used collectively to define overweight and obesity in adults (Björntorp, 1998; Kuczmarski, Carroll, Flegal, \& Troiano, 1997; Kuczmarski et al., 2000); however, no standard BMI definition of overweight and obesity for children existed (Cole, 2002; Cole, Bellizzi, Flegal, \& Dietz, 2000).

For children, the use of BMI is problematic due to maturation changes in the distribution and amount of body fat in children (Dietz \& Robinson, 1998); thus, BMI percentiles are used to estimate overweight and obesity in children up to the age of 18 years (Barlow \& Dietz, 1998; Barlow \& Expert Committee, 2007). BMI percentiles are derived from the plotting of child age and BMI on age and gender specific growth charts. Age is plotted on the horizontal axis and BMI on the vertical, a single point where the two meet is drawn and the curved lines indicate selected percentiles that designate rank of the child's measurement (Dietz \& Robinson, 1998; Roberts \& Dallal, 2001).

Based on percentiles, the CDC and NHANES previously classified children as "at risk of overweight" if the BMI-for-age and- gender ranges from the $85^{\text {th }}$ to less than the 
$95^{\text {th }}$ percentile and "overweight" if the BMI-for-age-and gender specific greater than or equal to the $95^{\text {th }}$ (Barlow \& Dietz, 1998; Barlow \& Expert Committee, 2007; Kuczmarski et al., 1997; Kuczmarski \& Flegal, 2000; Kuczmarski et al., 2000). Much of the literature however fails to make reference to children as "at risk of overweight" but rather classifies all children above the $85^{\text {th }}$ percentile as overweight or obese (Moffat, 2010).

In an effort to internationally standardize the classification of weight in children the International Obesity Task Force (IOTF) created an age sex specific table of percentile cutoffs for overweight and obese to match those of the 25 and 30 BMI cutoffs used for adults (Cole et al., 2000; Dietz \& Robinson, 1998). However, the $85^{\text {th }}$ and $95^{\text {th }}$ percentiles proposed by the CDC and NHANES are more commonly referenced within the literature (Moffat, 2010).

In 2010, the American Medical Association introduced changes in BMI terminology; whereas, a BMI for age and gender equal to or greater than the $85^{\text {th }}$ percentile now constitutes overweight and the $95^{\text {th }}$ percentile obese (Ogden \& Flegal, 2010). The terminology change was most notably due to the need to convey the seriousness of the $95^{\text {th }}$ cutoff value (previously referred to as overweight) and to denote the increased risk for negative health outcomes in the future (U.S. Department of Health and Human Services [DHHS], 2010) including cardiovascular disease (Freedman, Mei, Srinivasan, Berenson, \& Dietz, 2007) and insulin resistance and type 2 diabetes (FagotCampagna, 2000; Fagot-Campagna et al., 2000; Whitlock et al., 2005).

A great deal of empirical evidence exists supporting the specificity of BMI percentile cut-offs for the diagnosis of childhood obesity (Barlow \& Dietz, 1998; Barlow \& Expert Committee, 2007; Cole, 2002; Cole et al., 2000; Flegal, 1993; Reilly, Dorosty, \& Emmett, 2000; Reilly et al., 2003; Reilly, Wilson, Summerbell, \& Wilson, 2002). Thus, BMI percentile cut-offs are unlikely to diagnose a non-obese child as obese; however, due to only moderate sensitivity these percentile cut-points may lead to under diagnoses (Reilly et al., 2000; Reilly et al., 2002).

A substantially consistent body of evidence exists that children with BMI percentiles in the $85^{\text {th }}$ or $95^{\text {th }}$ range are at greater risk of morbidity than their peers (Bertakis \& Azari, 2005; Hickman et al., 1998; Reilly et al., 2003). Such findings confirm the relevance and validity of cut off points and associated definitions in the diagnosis of obesity and obesity related outcomes (Barlow \& Dietz, 1998; Cole, 2002; Cole et al., 2000; Reilly, 2002; Reilly et al., 2000; Reilly et al., 2002).

In conclusion, BMI assessment offers a valid, inexpensive, noninvasive, and easy to use method for identifying obesity in children. Thus, BMI is an appropriate surrogate measurement of fatness in children. Therefore, for the purpose this study overweight was defined as BMI percentile greater than or equal to the $85^{\text {th }}$; whereas, obesity was defined as a BMI equal to or greater than the $95^{\text {th }}$ percentile for age and gender. 


\section{ATTRIBUTES}

Evidence suggests that the environment in which a person resides influences behaviors associated with obesity development (low physical activity and food choices) and that income demarcates the type of environment in which one lives. Thus, education, income, crime, and food availability are intertwined; and therefore, must be taken into consideration when examining socioeconomics as a contributing factor in the development of childhood obesity.

\section{SOCIOECONOMICS}

The role that socioeconomic factors play in obesity development is multifaceted (Wang \& Zhang, 2006). In the US, a high socioeconomic status appears to be a protective factor against the development of overweight. Such findings correspond with previous studies (Wang \& Zhang, 2006) which identified a significant association between low socioeconomic status and risk of obesity; however, the socioeconomic influence appears to vary across ethnic groups (Roberts \& Dallal, 2001; Wang \& Zhang, 2006; Zhang \& Wang, 2004). Economically the poorest states; West Virginia, Mississippi, and Kentucky, have the heaviest children with $22.4 \%$ of 10 -to-17-year-olds living below the poverty line being overweight or obese (Trust for America's Health, 2009). US findings are similar to observations among 6-year old Germany children in which a strong doseresponse relationship between social class and obesity was identified (Lamerz et al., 2005).

\section{Education}

In a study of 9 to 10 year old black and white girls, the effect of race, household income, and parental education on obesity was examined. Findings revealed that of the three variables, higher education was consistently associated with lower percentage of dietary fat and higher levels of vitamin C, calcium, and potassium (Crawford et al., 1995). Evidence suggests that population groups with the highest poverty rates and the least education have the highest obesity rates (Drewnowski \& Specter, 2004). Education attainment was often used as an alternative measure for socioeconomic status. Researchers contend that less education is a predictor of health disparities (Metzler, 2007).

\section{Economics}

According to the literature, obesity appears to disproportionately affect those with limited economic resources. A substantial number of studies demonstrate the association between childhood obesity, low household income, and food insecurity (Casey, Szeto, Lensing, Bogle, \& Weber, 2001; Crooks, 1999, 2000; Wang \& Lobstein, 2006). Eightyone percent of economically poor counties in the Appalachian region of Kentucky, Tennessee, and West Virginia have the highest rates of childhood obesity (Centers for 
Disease Control and Prevention [CDC], 2011a). When combined with poverty obesity has a greater impact upon quality life years. Obese adults (18-years or older) for example can expect to live 47 quality-adjusted life-years; whereas obese adults living under the poverty line can expect to live 43 quality-adjusted life-years. Even when adjustments were made for life style behaviors such as smoking and alcohol use, the risk of mortality in obese adults was greater in groups with incomes at the lowest thread hold (Lantz et al., 1998; Muennig, Sohler, \& Mahato, 2007).

Children living in low-income neighborhoods have limited access to physical activity facilities (Gordon-Larsen, Nelson, Page, \& Popkin, 2006). Poverty and food insecurity are associated with lower food expenditures, low fruit and vegetable consumption (Roos, Johansson, Kasmel, Klumbiené, \& Prättälä, 2000), and lower-quality diets (Drewnowski \& Specter, 2004). Investigators examining social determinants of health have proposed that poverty is a "fundamental" cause of disease (Metzler, 2007; Wilkinson \& Marmot, 2003).

\section{Crime}

Within the literature, associations between obesity and neighborhood crime are limited. The association is most commonly examined according to the effect of crime on physical activity most notably the relationship between physical activity and crime perception of parents (Carver, Timperioa, \& Crawford, 2008). Parents who perceive their community to be unsafe may be less likely to permit their children to play outside (Nestle $\&$ Jacobson, 2000). In fact, parental concern about crime is among the leading reasons why parents keep their children indoors (Gordon-Larsen, McMurray, \& Popkin, 2000; Molnar, Gortmaker, Bull, \& Buka, 2004). Indoor sedentary behavior; computer gaming and television viewing, is perceived to contribute to low physical activity and has been positively associated with community crime and sex offender rates (Brown, Perez, Mirchandani, Hoelscher, \& Kelder, 2008). Such findings support similar studies in which perceived safety was positively associated with parental reports of child participation in physical activity (Molnar et al., 2004). Girls who perceived their neighborhood to be safe were more likely to participate in outdoor physical activity as compared to girls reporting unsafe perceptions (Gomez, Johnson, Selva, \& Sallis, 2004). Sallis and Glanz (2006) contend that access to safe places affects activity behavior, which may influence obesity development. However, the effect that crime has on physical activity is not clearly delineated within the literature. Several studies report no association between safety perception and physical activity (Adkins, Sherwood, Story, \& Davis, 2004; Sallis, Taylor, Dowda, Freedson, \& Pate, 2002).

Poverty within one given community may influence personal crime rates of nearby locations (Wilson \& Kelling, 1982). Relationships associated with spatial interaction are due to movement of people from one given location to another. For example, the "journey to crime" theory argues that criminal activity is the result of accessibility between the crime event and the criminal's home location (Sampson, 1985). 
In conclusion, crime is viewed as a contributing factor for obesity development in childhood. A commonality noted within the literature was that parents perceive children to be less vulnerable to crime indoors and that indoor sedentary behaviors appears to contribute to the epidemic of childhood obesity (Carver et al., 2008; Weira, Etelsonb, \& Brandb, 2006).

\section{OBESOGENIC ENVIRONMENT}

People who lived when food was sporadically available benefited from genes that predisposed them to obesity since these genes provided a protective advantage during times of famine (Bonner, 2003) ; however, according to Friedman, these genes in a modern day environment result in significant health consequences, such as obesity, diabetes, and heart disease (Bonner, 2003). Baranowski (1996) contends that the modern obesogenic environment places individuals with ancestral energy conserving genes at the greatest risk for overweight and obesity. According to the literature, an obesogenic environment is the totality of the surroundings, opportunities, or conditions (Bray, 1990) that promote an imbalance between energy intake and energy expenditure (Baranowski, 1996). Energy balance is based on one of the two 'Laws of Obesity': intake must be in excess of expenditure (Trayhurn, 2005). Personal behavior and biology are perceived to have a direct influence on energy intake and expenditure; whereas, the environment is perceived to influence personal behavior. Children today are being raised in environments non-conductive of physical activity (Frank \& Engelke, 2001) in which the food industry promotes convenient, inexpensive, and low-nutrient food (Brownell \& Horgen, 2004; Nestle \& Jacobson, 2000).

\section{PHYSICAL ENVIRONMENT}

Research findings indicate that obesity is in part the result of influential interactions of the community environment, diet, and physical activity (Papas et al., 2007; Sallis \& Glanz, 2006). An association between elements of the physical (recreational activities, mixed land use, green space and safety for pedestrian and bicyclists) and obesity (Cervero \& Duncan, 2003; Ellaway, Macintyre, \& Bonnefoy, 2005; Li, Fisher, Brownson, \& Bosworth, 2005) have been identified. Changes in the community environment including greater dependence on convenience store style foods and fast food combined with a lack of access to fruits and vegetables are perceived to contribute to obesity in childhood (Sallis \& Glanz, 2006). However, Sallis and Glanz (2006) suggest that no conclusive evidence exists that aspects of the physical environment promote obesity in children.

\section{Food Deserts}

Within the literature food store, availability has been linked with negative outcomes such as obesity (Beaulac, Kristjansson, \& Cummins, 2009; Blanchard \& 
Lyson, 2006; Moore, 2003). Poorer areas tend to have limited access to fruit and vegetable markets, natural food stores (Beaulac et al., 2009) and fewer chain supermarkets (Powell, Slater, Mirtcheva, Bao, \& Chaloupka, 2007). Blanchard and Lyson (2003) contend that the establishment of "supercenter" grocery stores produce "food deserts" for the rural population creating physical and economic barriers to healthy food.

\section{Fruit and Vegetable Markets}

According to Trust for America's Health (2011), only 18.2\% of WV students and $18.6 \%$ of WV adults regularly consume the recommended daily allowance of fruits and vegetables; ranking WV the $16^{\text {th }}$ state for the lowest fruit and vegetable consumption in school children and $4^{\text {th }}$ for adults. Fruit and vegetable consumption is associated with the presence of supermarkets and supermarkets are more likely to be located in wealthier neighborhoods (Morland, Wing, \& Diez, 2002). Families who have easy access to affordable, fruits and vegetables report higher levels of fruit and vegetable consumption (Sallis \& Glanz, 2006). However, regardless of availability per calorie intake, lowdensity, high-nutrient food such as fruits and vegetables cost more; therefore, economically the purchase of low-nutrient foods is a feasible alternative for low-income families (Drewnowski \& Specter, 2004).

\section{Fast Food Establishments}

In the late 1970s, fast food meals accounted for $2 \%$ of total energy intake in children, whereas by the 1990 s, fast food meals contributed to $10 \%$ of overall energy intake (American Heart Association, 2011). Generating approximately $\$ 120$ billion in sales, the fast food restaurant business is one of the largest segments of the food industry in the U.S. (Hoover Inc., 2010).

The number of and proximity to fast-food restaurants have been associated with significant increases in the risk of obesity in children (Currie, Vigna, Moretti, \& Pathania, 2010; Kipke et al., 2007; Kwate, Yau, Loh, \& Williams, 2009; Li, Hamer, Cardinal, Bosworth, \& Johnson-Shelton, 2009; Powell et al., 2007). For children, having a fast food restaurant within 0.10 miles of school increases the probability of obesity by $5.2 \%$ (Currie et al., 2010). Proximity to fast food was found to be greater among less educated women and African-American adult females; with predominantly black neighborhoods having 2.4 fast food restaurants per square mile compared to 1.5 restaurants in predominantly white neighborhood (Kwate et al., 2009). The findings support an earlier study (Block, Scribner, \& DeSalvo, 2004) documenting a geographic correlation between exposure of black and low-income neighborhoods to fast food restaurants. Powell et al. (2007) found that fast food restaurants are more concentrated in poor neighborhoods nationwide. Caution is warranted however as "no cause-and-effect" data on fast food and overweight/obesity in children currently exists (Mullen \& Shield, 2004). 


\section{Convenience Stores}

The number of convenience stores (Galvez et al., 2009; Powell et al., 2007) has been associated with a higher BMI and lower levels of fruit and vegetable consumption (Timperio, Ball, Roberts, Andrianopoulous, \& Crawford, 2009) in children. However, the literature is sparse.

\section{Recreational Facilities}

The relationship between obesity, levels of physical activity, and access to recreational facilities has been well researched (Gordon-Larsen et al., 2000; GordonLarsen et al., 2006; Trost et al., 1997; Tucker et al., 2009). Tucker et al. (2009) found that recreational opportunities and physical activity were positively associated; thus as recreational opportunities increased physical activity increased. Physical activity is most notably connected to obesity development; thus, obesity is often examined in context with access to recreational facilities. (2006)Gordon-Larsen et al. (2006) found that availability of physical activity facilities was associated with overweight patterns and that the inequality in availability contributed to decreased activity and an increase in overweight. Children living in low-income neighborhoods have limited access to physical activity facilities (Gordon-Larsen et al., 2006).

\section{CONCLUSION}

In conclusion, an obesogenic physical environment is associated with limited availability of and access to fresh produce and healthy foods. People living in resource poor communities demonstrate the greatest risk for obesity development. The number and proximity to food sources including grocery stores, fruit and vegetable markets, fast food establishments, and convenience stores appear to influence (negatively and positively) obesity development.

\section{PERSONAL ENVIRONMENT}

States with adult obesity rates exceeding $25 \%$ doubled in the past year from four to eight - Alabama, Arkansas, Kentucky, Louisiana, Mississippi, Oklahoma, Tennessee, and West Virginia (Trust for America's Health, 2009). West Virginia is the third most obese state in the nation with an adult obesity rate exceeding 30\% (Trust for America's Health, 2011). As a result, many WV children are living in households in which obesity is a common occurrence. Among children, heredity and maturation influence fitness (Armstrong \& Welsman, 2000; Pangrazi \& Corbin, 1990). A child with a hereditary predisposition for fitness may be less active but yet score better on fitness assessments than younger physically active children who lack the hereditary predisposition (Armstrong \& Welsman, 2000; Pangrazi \& Corbin, 1990). 


\section{Family History}

Understanding the dynamics of the family in relation to obesity related behaviors including; history of cardiovascular disease and/or diabetes, may provide clues to childhood obesity risk factors. Children with parents with early heart disease are at an increased risk for obesity (Slyper, 1998). Children who are overweight, have a family member with type 2 diabetes, and are over 10 years of age are at increased risk for developing type 2 diabetes during childhood, adolescence, or adulthood. Type 2 diabetes observed in youth is perceived to be a "first consequence" of the obesity epidemic in children (Fagot-Campagna, 2000; National Diabetes Education Program, 2008).

\section{Fitness}

Physical fitness and physical activity are not one in the same. Physical fitness is a characteristic or attribute defined according to the ability to carry out work (Claessens et al., 2008). Although fitness encompasses many dimensions, the most referenced relate to aerobic capacity (fitness) and musculoskeletal fitness (Armstrong \& Welsman, 2000).

Associations between body mass index and aerobic fitness in children have been noted within the literature with the majority of studies focusing on cardiovascular risk factors. Variations in cardiovascular risk factors are most notably due to the degree of body fatness (Boreham et al., 2001; Hubert, Feinleib, McNamara, \& Castelli, 1993). Individuals classified with low fitness and high BMI demonstrated the greatest degree of cardiovascular disease (CVD) risk factors including: higher blood lipids and glucose (Eisenmann, Welk, Ihmels, \& Dollman, 2007). However, the literature reliably demonstrates that fatness is a major confounding variable when examining the relationship between fitness and metabolic and/or cardiovascular risk factors (Armstrong \& Van Mechelen, 2008; Armstrong \& Welsman, 2001; Bergstrom, Hernall, \& Persson, 1997; Fripp et al., 1985; Hansen, Hyldebrandt, Frober, \& Nielsen, 1990; Sallis, Patterson, Buono, \& Nadder, 1988).

The methodology for measuring fitness components in children could influence fitness outcomes and falsely elevate or diminish a child's fitness level. Measurement normalization of exercise performance data is a process utilized to accommodate for physiological functional differences in children as a result of body size (related to growth and maturation). The method assists in controlling body size as a confounder; therefore, the aim is to remove body size as an influence thus formulating a size-free variable. A variety of scaling methods have been derived to assist in the formulation of a size-free variable. Scaling methods utilized include ratio scaling (per body mass ratios thus size dependent); linear regression scaling and algometric scaling (allows for size adjusted ratios and the examination of different growth rates as part of the growth process). Longitudinal scaling methods include ontogenetic allometry which allows for the examination of different growth rates as part of the individual growth process and multilevel modeling (Armstrong \& Van Mechelen, 2008; Armstrong, Welsman, \& Kirby, 1998; Bar-Or \& Rowland, 2004; Nevill, 1997; Nevill \& Holder, 1994; Nevill, Rowland, Goff, Martel, \& Ferrone, 2004). 
Maximal $\mathrm{VO}_{2}$ is considered to be the single best indicator of aerobic fitness (Armstrong \& Van Mechelen, 2008). $\mathrm{VO}_{2}$ is based upon the ability to measure the volume of expired air per unit time and the fractions of oxygen and carbon dioxide in expired air. Barometric pressure, gas temperature and water vapor pressures of the gases are required for the measurement. The calculation/formula is based upon volume of expired air per minute and fraction of oxygen and carbon dioxide work (Armstrong \& Van Mechelen, 2008). Some researchers advocate that "peak" $\mathrm{VO}_{2}$ rather than maximal $\mathrm{VO}_{2}$ is more appropriate term for utilization in children due to the small percentage of children and adolescents who fail to demonstrate the $\mathrm{VO}_{2}$ plateau (Banquet, Van Praagh, \& Berthoin, 2003; Bar-Or \& Rowland, 2004; Cooper, Weiler-Ravell, Whipp, \& Wasserman, 1984; Rowland, 2005).

Due to various issues such as equipment cost; complexity of test administration; and time; direct peak $\mathrm{VO}_{2}$ testing is not always practical. As a result, numerous field tests of aerobic fitness are now utilized and have been found to produce reliable and valid results in comparison to lab testing work (Armstrong \& Van Mechelen, 2008). The three main aerobic fitness tests discussed in the literature include distance run, timed run and endurance shuttle run. Running tests require maximal effort and are appropriate methods of measuring aerobic fitness in children. Other field tests that produce maximal effort discussed in the literature include jumping tests and sprinting tests. Although less prominently discussed anaerobic fitness has been associated with health and function in children (Armstrong \& Welsman, 2001) and should also be considered when examining child fitness.

Among children, heredity predisposition and maturation have more influence on fitness than does physical activity (Armstrong \& Van Mechelen, 2008; Pangrazi \& Corbin, 1990). For example, a child who is older with a hereditary predisposition for fitness may be less active, yet score better on fitness assessments than younger physically active children who lack the hereditary predisposition (Armstrong \& Welsman, 2000; Pangrazi \& Corbin, 1990). As children become adults, maturation and age become less important factors (Armstrong \& Van Mechelen, 2008; Bar-Or \& Rowland, 2004; BaxterJones, Eisenmann, \& Sherar, 2005). The relationship between children's aerobic fitness and fatness are unclear.

Findings regarding the relationship between fitness and obesity are inconclusive. A review by Marrow \& Freedson (1994) examining the relationship between physical activity and aerobic fitness concluded that a small to moderate relationship between activity and fitness in children and youth existed. Observation studies have more commonly identified a relationship between activity, fitness, and fatness. In a sample of 8 to 10 year old children, low fitness level and increased fatness were associated with decreased physical activity (Rowlands, Eston, \& Ingledew, 1999). Researchers suggested; however, that the degree of fatness may moderate fitness and physical activity findings due to an increase in heart rate threshold in response to degree of child fatness (Rowlands et al., 1999). 


\section{GEOGRAPHICAL DISTRIBUTION OF OBESITY}

Socioeconomic factors, as well as obesity are closely associated with geographic disparities. South-central regions of the US have the highest prevalence (18\%) of childhood obesity and the Mountain region the lowest prevalence (11.4\%) (Singh, Kogan, \& Van Dyck, 2008). Children living in West Virginia, Kentucky, Texas, Tennessee, and North Carolina are at twice the odds of being obese than children living in the Mountain regions of the US (Singh et al., 2008). Therefore, geographic disparity must be taken into consideration when examining obesity. Behavioral Risk Factor Surveillance System data identified obesity prevalence rates being lowest (below 20 percent of population) in Colorado, Hawaii, Vermont, and Connecticut but highest in Louisiana, Mississippi, and West Virginia with a prevalence of $30 \%$ or higher (Centers for Disease Control and Prevention [CDC], 2011b). Geographically, 16.5\% of rural kids qualify as obese as compared with $14.4 \%$ of urban kids (Trust for America's Health, 2009).

\section{WEST VIRGINIA}

According to Trust for America's Health (2011), WV ranks tenth in the nation for childhood obesity and third for adult obesity. Over the past decade, the rate of obesity has increased in virtually all WV counties, with the highest prevalence found in the southern and western regions of the state (West Virginia Health Statistic Center [HSC], 2002). As stated previously, low socioeconomic status families and children in southern Appalachian states appear to have higher rates of obesity than the rest of the population (Cochran, 2008). West Virginia is the only state that lies wholly within Appalachia and is both rural and economically disadvantaged (Bureau of Economic Analysis, 2007). For the last three years, WV has consistently ranked as the $6^{\text {th }}\left(2007\right.$ and 2008) or $7^{\text {th }}(2009)$ poorest state in the US (U.S. Census Bureau [Data file], 2010). The state has been described as having poor accessibility with a large degree of urban mountainous sprawl resulting in a heavy reliance on automotive transportation (Amarasinghe et al., 2006).

A spatial analysis of the potential impact of obesogenic factors on obesity development in WV adults found that a $1 \%$ increase in poverty would raise the county prevalence of obesity by $0.13 \%$ and a one-minute increase in transportation/ commute time to work increased the incidence of obesity by $0.3 \%$ (Amarasinghe et al., 2006). Additional findings revealed a reduction in obesity rates by $3 \%$ for each unit increase in the number of food stores per thousand population and a $0.2 \%$ decrease in obesity rates for each $1 \%$ increase in the percentage of the population completing a college education (Amarasinghe et al., 2006). To date, researchers have not examined the potential impact of these obesogenic factors to obesity risk in children.

The sum effect of these environmental pressures on promoting obesity and related consequences in the community are evident: In the United States (U.S.), WV ranks number one in terms of diabetes, number three for hypertension, and number four for total medical costs for obesity related health care treatment (Trust for America's Health, 2009). West Virginia $5^{\text {th }}$ grade children were identified to have elevated total 
cholesterol, elevated systolic blood pressures, and elevated systolic blood pressures as compared to non-overweight (Demerath et al., 2003). Such findings are similar to other communities with high childhood obesity rates. Throughout WV, there are counties in which children are expected to die at a younger age than their parents (Ezzati, Friedman, Kulkarni, \& Murray, 2008). Life expectancy among men and women within rural counties of WV dropped between 1983 and 1999 with the most significant decline occurring in southern WV counties of Lincoln, Logan, and especially McDowell counties (Ezzati et al., 2008). In McDowell County, life expectancy has fallen to third-world levels (Finn, Higgins, \& Lilly, 2011). The average age of death among WV residents declined by 6 months between the years of 1996 to 2006 to slightly more than 72 years; however, in Wyoming and McDowell counties the average age of death decreased by four years in one decade to 67 years of age (Ezzati et al., 2008; Finn et al., 2011; West Virginians for Affordable Health Care [WVAHC], 2008). Findings indicate that WV youth are disproportionately at greater risk for obesity and obesity related consequences because of an obesogenic environment.

\section{GEOTECHNIQUES}

Geo-techniques such as spatial analysis using geographic information systems (GIS), are emerging as powerful tools in the investigation of disease determinants. GIS is a computer database that stores geographic data (Aronoff, 1989). Through spatial analysis techniques, researchers can examine the distribution of and relationships between GIS geographic data and health events.

GIS spatial analysis of health/disease is a phenomenon that first emerged in the 1980s but did not take hold until the 1990s. However, the diffusion of GIS into the mainstream of health and/or disease research has been slow and is described as being in the early expansion stage of research applicability (Albert, Gesler, \& Whittie, 1995).

Within health and/or disease literature, GIS usage is very diverse (Sallis \& Glanz, 2006). The most cited usage was among medical geographers and epidemiologists examining temporal and spatial patterns of environmental health hazards and infectious diseases (Cromley \& McLafferty, 2002). From a public health perspective, GIS has played a pivotal role in disease prevention and health promotion. Yet, few studies have utilized GIS in the examination of childhood obesity at the zip code level; especially, the socioeconomic environment of childhood obesity. There are virtually no childhood obesity studies geocoded at the zip code level for an entire state.

Geomapping demands data that contains a geographical identifier such as state, county, census tract, or zip code which impacts the type of relationships and inferences that can be made in a study (Albert et al., 1995; Cromley \& McLafferty, 2002). The prevalence of obesity is most often portrayed at the county or state level, which is not necessarily representative of a community and could potentially conceal patterns of obesity occurrence. 
To utilize GIS methods, the geographical scale must be carefully defined and associated data geocoded. How scale is defined can critically impact the types of inferences that can be made (Albert et al., 1995; Cromley \& McLafferty, 2002;

Drewnowski, Rehm, \& Solet, 2007). Albert, Gesler, and Levergood (2005) point out that spatial patterns and /or variable associations may vary significantly at different scales of analysis; therefore, investigations of disease and health should be carried out at different geographical levels. Additionally, spatial boundaries may have no inherent meaning in the real world; therefore, may result in the formation of artificial relationships (Fotheringham, Densham, \& Curtis, 1995). Replication of study findings at different scale levels could help identify and define clusters of disease (Albert et al., 1995; Cromley \& McLafferty, 2002).

Data at the ZIP code scale can be problematic for spatial analysis (Drewnowski et al., 2007). Population counts per ZIP code area can vary and be too small to provide areabased prevalence estimates (Drewnowski et al., 2007), especially in rural communities. Zip code boundaries are also arbitrary in regards to what defines a community in the traditional sense. However, zip code areas do "provide a geographical frame of reference to which other data layers are tied" (Cromley \& McLafferty, 2002, p. 68); thus, allows data to be examined at a neighborhood or community level vs. a county or state.

Identifiers and scales pose unique statistical challenges. For example, according to Tobler's first law of geography, everything is related to everything else (Miller, 2004); thus, correlated. The closer communities are proximally, the stronger the spatial dependency and the stronger the similarities in community characteristics (Miller, 2004). Spatial dependency leads to the statistical problem of spatial autocorrelation and violates the statistical assumption of independence among observations. However, despite the statistical challenges, spatial analysis techniques provide a valid means to visualize spatial patterns.

\section{CONCLUSION}

The childhood obesity epidemic appears to disproportionately affect some communities greater than others. The development of childhood overweight and/or obesity is multifactorial resulting from a complex interaction of many factors. Contributing factors identified include: genetics, behavior, environment, and socioeconomic; as well as socio-demographic influences. When combined, such factors are perceived to create an environment conducive for obesity development - an obesogenic environment. The literature supports the linkage between the individual environmental risks factors of the socioeconomic, physical, and personal environment. However, there is a paucity of information on the effect of cumulative environmental factors on overweight and obesity in children, and whether the spatial distribution of these factors is associated with childhood obesity within communities. Additionally, demographic statistics regarding the distribution of childhood obesity demonstrates that the epidemic appears to disproportionately affect some communities greater than others. 


\section{CHAPTER 3. PREDICTORS OF OVERWEIGHT AND OBESITY AMONG WV $5^{\text {TH }}$ GRADE CHILDREN}

\section{INTRODUCTION}

Childhood obesity, defined as a body mass index (BMI) at or above the $95^{\text {th }}$ percentile for children of the same age and sex, is considered an epidemic in the United States (Centers for Disease Control and Prevention [CDC], 2011b). In the last 30 years, the prevalence of childhood obesity (children aged 6 to 11 ) has increased from $6.5 \%$ in 1980, to 19.6\% in 2008 (Ogden et al., 2010). Biology and lifestyle behaviors have been identified as important factors in the development of childhood obesity; however, researchers are beginning to place more emphasis upon the impact that continual environmental exposures have upon obesity development. Environmental risk factors associated with obesity are distributed continuously over space; yet, evidence suggests that the burden of risk may not be evenly dispersed across a community. Additionally, the obesity epidemic appears to disproportionately affect some communities greater than others. Examination of spatial distribution may help provide answers to fundamental childhood obesity questions related to environmental risks. Such methods may provide a means to identify geographical obesity patterns and offer the ability to filter information to identity obesity related events.

While it is well documented that the physical environment is associated with obesity development (Galvez et al., 2010; Papas et al., 2007), there is a paucity of information on the effect of cumulative environmental factors on overweight and obese children. The literature supports the linkages between individual environmental risk factors including the built, home, and socioeconomic environment. Obesity has been associated with limited community physical resources such as recreational activities, mixed land use, green space, and safety for pedestrians and bicyclists (Cervero \& Duncan, 2003; Ellaway et al., 2005; Li et al., 2005). Access to food sources including grocery stores and fruit and vegetable markets, appear to reduce the risk of obesity, while higher numbers of fast food establishments and convenience stores are linked to obesity development (Beaulac et al., 2009; Blanchard \& Lyson, 2006; Currie et al., 2010; Kipke et al., 2007; Kwate et al., 2009; Li et al., 2009; Moore, 2003; Powell et al., 2007).

Community socioeconomic factors including poverty and educational level (Drewnowski \& Specter, 2004), is a fundamental factor perceived to influence child weight. Socioeconomically individuals who are less educated and/or make less money have higher obesity rates (Trust for America's Health, 2011). Economically, the poorest states: West Virginia, Mississippi, and Tennessee have the heaviest children (Trust for America's Health, 2011).

While crime rates tend to be higher in low socioeconomic communities, studies examining the relationship between neighborhood community crime rates and obesity development have yielded equivocal results (Burdette \& Whitaker, 2004). Community crime and sex offender rates have been positively associated with indoor sedentary 
behavior (Brown et al., 2008); as has gender, with girls participating in less physical activity in areas perceived to have higher rates of crime (Gomez et al., 2004). Whether crime, particularly violent crime, contributes to obesity development through greater psychological stress, overeating, or more indoor, sedentary activity remains unclear.

West Virginia, a rural Appalachia community has the $3^{\text {rd }}$ highest adult and $10^{\text {th }}$ highest youth obesity rates $(32.2 \%$ and $18.9 \%$ respectively) in the nation (Trust for America's Health, 2011). The study design proposed that childhood overweight and obesity are the consequence of exposure to environmental attributes. The purposes of this study of WV $5^{\text {th }}$ graders were threefold: 1) To determine which socioeconomics, physical, and personal environment attributes contribute to overweight (BMI equal to or greater than the $85^{\text {th }}$ percentile for age and gender) and 2) to determine which socioeconomics, physical, and personal environment attributes contribute to overweight (BMI equal to or greater than the $5^{\text {th }}$ percentile for age and gender).

\section{PROCEDURES AND METHODS}

A secondary data analysis of cross-sectional statewide representative data was performed to examine the proposal that overweight and obesity are the consequence of exposure to environmental attributes. Data compiled were gathered from various secondary data sources for the academic school years of 2007/2008 and 2008/2009.

The study sample consisted of $5^{\text {th }}$ grade children participating in The Coronary Artery Risk Detection in Appalachian Communities (CARDIAC) (Coronary Artery Risk Detection In Appalachian Communities [CARDIAC], 2010) project during the academic school years of 2007/2008 and 2008/2009. The CARDIAC project, initiated in 1998, is a disease surveillance and intervention program designed to combat the high prevalence of heart disease and diabetes in WV. All $5^{\text {th }}$ grade students enrolled in WV public schools were eligible to participate in the CARDIAC project.

Active consent of a parent or guardian and child assent was required for CARDIAC project participation. Parents were provided a consent packet, which described the purpose of the screening, screening procedures, reporting procedures, and protocol elements associated with participating in the screening project. The study protocol was approved by the West Virginia University Institutional Review Board for the Protection of Human Subjects and written permission was obtained from the county school superintendents (Coronary Artery Risk Detection In Appalachian Children project [CARDIAC], 2010). The current study was approved by the Institutional Review Board of the University of Tennessee. The study sample was drawn from 53 of the 55 counties in WV and consisted of 12,194 fifth grade children enrolled in WV public schools during the 2007/2008 and 2008/2009 academic school years. 


\section{OPERATIONALIZATION OF SECONDARY DATA VARIABLES}

Study indicators used to quantify socioeconomic, physical, and personal environmental attributes were derived from various data sources including the CARDIAC project; WV Board of Education; US Census Bureau,; and WV State Police Crime in WV website. Geolytics compiled US Census Bureau data, a data resource management company experienced in US Census Bureau data retrieval (GeoLytics, 2010). Prior to performing the secondary data analysis, permission was obtained from the Institutional Review Board (IRB) for the University of Tennessee.

\section{Socioeconomic Environment}

The socioeconomic environment was defined according to attributes of education (aggregate total of population 25+ with high school diploma or higher), median household income, aggregate student population classified as low socioeconomic status and aggregate total of violent crime in the county. Socioeconomic data were derived from various secondary data sources including U.S. Census Bureau, WV Board of Education, and WV State Police.

\section{Physical Environment}

The physical environment included the attributes consisting of the aggregate total of: fast food, convenience store, supermarket, and grocery establishments; fruit and vegetable markets; and fitness and recreational sports centers. The North American Industry Classification System (NAICS) was utilized to define and classify food services and recreational facilities at the zip code and county for 53 of the $55 \mathrm{WV}$ counties: 722211 limited-service restaurants; 445120, convenience stores; 445110, supermarkets; 445230, fruit and vegetable markets; and 713940, fitness recreation and sports (U.S. Census Bureau [Data file], 2007).

\section{Personal Environment}

Attributes of the personal environment included a positive or negative family history of diabetes and heart disease and child fitness status (in the healthy fitness zone or needs improvement). Family history was parental self-reported data; whereas, child fitness was aggregate $5^{\text {th }}$ grade data at the school level.

\section{Secondary Data Sources}

Study indicators used to quantify socioeconomic, physical, and personal environmental attributes were derived from various data sources including the CARDIAC project; WV Board of Education; the United States (U.S.) Census Bureau; and WV State 
Police. US Census Bureau data at the zip code and county level was compiled by Geolytics a data resource management company experienced in US Census Bureau data retrieval. Secondary data sources are described below.

CARDIAC project: BMI and family history. The Coronary Artery Risk Detection in Appalachian Communities project (CARDIAC) is a disease surveillance and intervention program, designed to combat the high prevalence of heart disease and diabetes in WV. The program has been implemented in all WV public schools. Since 1998 , team members of the CARDIAC project have screened more than 46,078 fifth graders for cardiovascular disease (Coronary Artery Risk Detection In Appalachian Children project [CARDIAC], 2010). For the purpose of this study, data from a sample of 12,194 fifth grade children for academic school years 2007/2008 and 2008/2009 were examined.

WV Board of Education: Fitnessgram and low socioeconomic status. Fitnessgram was implemented in WV schools in the spring of 2006 in response to WV state fitness level reporting requirements. Each school is responsible for reporting data by grade level and class. Students enrolled in grades four through eight are tested annually. The fitness evaluation protocol was approved by the WV Board of Education and mandated by WV House Bill 2816 in 2005, serving as a replacement to the President's Physical Fitness Challenge (West Virginia Department of Education [Data file], 2011). Socioeconomic status was based on free and reduced lunch percentage eligibility rate for the academic school years 2007 and 2008 as reported by the WV Department of Education.

U.S. Census Bureau: Education and median household income. The U.S. Census Bureau is funded by the U.S. government and is widely utilized by researchers as a source for demographic data such as education and income. For the purpose of this study, data obtained through Geolytics consisted of WV business patterns and WV demographics at the zip code and county level.

U.S. Census Bureau: WV business patterns. Physical data of interest was sorted and retrieved according to the North American Industry Classification System (NAICS). NAICS is the standard used by federal statistical agencies in classifying business establishments for the purpose of collecting, analyzing, and publishing statistical data related to the U.S. business economy (U.S. Census Bureau [Data file], 2007).

WV State Police: Crime. WV crime data were available through the WV Crime Statistics report (2008 \& 2009) and accessible by county and/or district. All crime incidents identified within the state are chronicled. WV crime data is certified by the National Incident Based Reporting Systems (NIBRS) and crime data is submitted to the Federal Bureau of Investigations (FBI) (West Virginia State Police [Data file], 2008, 2009) . 


\section{STUDY MEASURES}

Socioeconomic, physical, and personal environmental attributes were derived from various data sources including the CARDIAC project; WV Board of Education; the United Stated (U.S.) Census Bureau; and the WV State Police. United States Census Bureau data at the zip code and county level was compiled by Geolytics, a data resource management company experienced in U.S. Census Bureau data retrieval.

\section{Socioeconomic Environment}

Median household income and education data were obtained from the U.S. Census Bureau one-year estimates derived from the American Community Survey (ACS). U.S. Census Data were compiled by Geolytics and obtained at the zip code and county level for the years 2007 and 2008. Low socioeconomic status data were gathered from the WV Department of Education data website for the academic years 2007/2008 and 2008/2009 school year. Violent crime data were gathered from the WV State Police data website (Crime in WV) for the years of 2007 \& 2008. Socioeconomic indicators of number of persons $25+$ years completing high school, median household income was examined at the zip code level. Aggregate $5^{\text {th }}$ grade student population classified as Low socioeconomic status (LSES) was examined by $5^{\text {th }}$ grade class. Violent crime was examined at the county level.

Education. Data were available as aggregate total for total population $25+$ years and total population of high school graduates age $25+$ years. Data estimates were derived from the census long form in which approximately one in every six households received this sample questionnaire. The data estimates are subject to sampling variability levels.

Household income. Household income was recorded as the sum of money income including wage or salary income; net self-employment income; interest, dividends, or net rental or royalty income or income from estates and trusts; Social Security or Railroad Retirement income; Supplemental Security Income (SSI); public assistance or welfare payments; retirement, survivor, or disability pensions; and all other income, received by all household members 15 years of age and older. All household members included unrelated household members such as household members not related to the householder, people living alone, and other nonfamily household members (U.S. Census Bureau [Data file], 2010) .

Both direct survey-based estimates and regression predictions from administrative records, population estimates, and decennial census data are utilized to create estimates of income. Bayesian techniques are employed to create estimates of income for different geographic levels (U.S. Census Bureau [Data file], 2010). For this study, median household income at the zip code level was used as the measure of household income.

Low socioeconomic status (LSES). Defined as the aggregate total of students eligible for free or reduced lunch as based on the National School Lunch Program 
standards. Children from families with incomes at or below $130 \%$ of the poverty level were eligible for free meals; whereas children from families between $130 \%$ and $185 \%$ of the poverty level were eligible for reduced-price meals (West Virginia Department of Education [Data file], 2011). Eligibility was determined by school district and criteria established by the Child Nutrition Act and National School Lunch Act. The application process for availability varies with most children submitting an application containing information regarding household income and size information or proof of participation in a federally subsidized Medicaid program (West Virginia Department of Education [Data file], 2011). School level data for the 2007/2008 and 2008/2009 school years were used in the analysis.

Violent crime. WV crime data were available through the National Incident Based Reporting System (NIBRS). An "incident" was defined as an offense committed by the same offender, or group of offenders acting in concert, at the same time and place (West Virginia State Police [Data file], 2008, 2009). Crimes were categorized by means of a standardized procedure in which survey questionnaire data were entered into a computer system by the investigating officer. The computer program utilized a hierarchy approach to classify the crime event as a: rape, sexual assault, robbery, assault, burglary, motor vehicle theft, and theft. For each offense known to police incident, victim, property, offender and arrest information was gathered and entered by the investigating officer (West Virginia State Police [Data file], 2008, 2009). All crime incidents identified within the state were chronicled. Incident data were available per county, per agency, per category and per offense.

Aggregate crime data (rate per 100) rape, sexual assault, robbery, assault, burglary, motor vehicle theft, and theft, were collected from the WV State Police website for the years 2007-2008 at the county level. Crime data were available for 52 of the 55 WV counties.

\section{Physical Environment}

The physical environment was defined according to attributes of convenience stores, supermarkets and other grocery, fast food, and recreational/fitness centers supplied by Geolytics. Physical data of interest was sorted and retrieved according to the 6 digit North American Industry Classification System (NAICS) code: 722211 limitedservice restaurants; 722110 full service restaurants; 445120, convenience stores; 445110, supermarkets; 445230, fruit and vegetable markets; and 713940, fitness recreation and sports (U.S. Census Bureau [Data file], 2007). An aggregate total of NAICS data at the zip code and county level for each 6-digit level was derived. NAICS data at the zip code level for the year 2008 were used for binary logistic regression.

Fast food. Data at the six level classification system 722211 (Limited-Service

Restaurants) was utilized to calculate the aggregate number of fast food restaurants by zip code. Limited-service restaurants were defined as food services (except snack and nonalcoholic beverage bars) where patrons generally pay before eating. Food and drink 
may be consumed on premises, taken out, or delivered to the customer's location. Some establishments in this industry may provide these food services in combination with selling alcoholic beverages (U.S. Census Bureau [Data file], 2010). NAICS fast food aggregate data were obtained for the year 2008 at the zip code and county level.

Convenience stores. Convenience stores were defined according to the 6 level classification code 445120 (Convenience Stores) as an industry comprising establishments engaged in retailing a limited line of goods generally including milk, bread, soda, and snacks (U.S. Census Bureau [Data file], 2010). An aggregate total of NAICS convenience store data for the year 2008 was derived at the zip code level.

Supermarkets and other grocery. Defined at the 6 digit level 445110 as an establishment known as supermarkets and grocery stores (excluding convenience) engaged primarily in retailing a general line of food and delicatessen-type establishments primarily engaged in retailing a general line of food (U.S. Census Bureau [Data file], 2010). An aggregate total of NAICS supermarkets and other grocery data for the year 2008 were derived at the zip code level.

Fruit and vegetable markets. The fruit and vegetable market classified at the 445230 level comprised establishments primarily engaged in retailing fresh fruits and vegetables (Trust for America's Health, 2009). An aggregate total of NAICS fruit and vegetable markets for the year 2008 were derived at the zip code level.

Fitness and recreational sports centers. The six level classification 713940 (Fitness and Recreational Sports Centers) was utilized to calculate the aggregate number of fitness and recreational sports center by zip code. Fitness and recreational sports centers were defined as an establishment engaged primarily in featuring exercise and other active physical fitness conditioning or recreational sports activities, such as swimming, skating, or racquet sports (U.S. Census Bureau [Data file], 2010) . An aggregate total of NAICS fitness and recreational sports center data at the zip code level for the year 2008 was derived for logistic regression analysis.

\section{Personal Environment}

Personal environment variables of interest included family history of diabetes, family history of heart disease, and child fitness. Family history data were derived from the CARDIAC Project and examined at the zip code, school, and county level. Child fitness was examined at the school and county level.

Family history. As part of the CARDIAC project, parents completed a comprehensive risk screening which included family history of heart disease and diabetes. The presence or absence of heart disease and diabetes was reported as yes, no or do not know. 
Child fitness. Child fitness data were derived from WV FITNESSGRAM. FITNESSGRAM ${ }^{\circledR}$ is a comprehensive fitness assessment and reporting program for youth developed by the Cooper Institute (Welk \& Meredith, 2008). The comprehensive assessment included physical fitness tests to assess aerobic capacity, muscular strength, muscular endurance, and flexibility. To determine child's overall physical fitness scores are assigned to a Healthy Fitness Zone ${ }^{\circledR}$ (Welk \& Meredith, 2008).

Healthy Fitness Zone ${ }^{\circledR}$ standards are age and gender criterion-referenced standards representing required fitness levels for good health. Based on performance, students are categorized as being in the healthy fitness zone or needing improvement (Welk \& Meredith, 2008). The FITNESSGRAM and Health Fitness Zone ${ }^{\circledR}$ standards have established validity and reliability in multi-ethnic groups of children (Welk \& Meredith, 2008).

Physical education teachers were trained to administer and report grade level FITNESSGRAM ${ }^{\circledR}$ data through the West Virginia Education Information System (WVEIS) Tenth Month Report. The grade level report included the number of students tested and the number of students performing in the "healthy zone" for each category (aerobic and musculoskeletal) as defined by the FITNESSGRAM ${ }^{\circledR}$ (West Virginia Department of Education [Data file], 2011). For the purpose of this study, only $5^{\text {th }}$ grade level aerobic fitness data were examined.

\section{Body Mass Index (BMI)}

Anthropometric measurement of height and weight were obtained as part of the CARDIAC project. The child height $(\mathrm{cm})$ and weight $(\mathrm{kg})$ was measured using the SECA 840 Personal Digital Scale. Children removed any foot wear or headgear that might alter the height measurements. Children's height was measured to the nearest centimeter while standing with feet together and head level. The digital scale was calibrated before each child was weighed. Children removed shoes, socks, and any heavy outerwear prior to stepping on the scale. The weight was recorded in pounds to the nearest one tenths of a pound as displayed. Trained health professionals and health professional students collected height and weight data. Training was provided by the CARDIAC staff and local school nurses trained to collect anthropometric measurements (Coronary Artery Risk Detection In Appalachian Children project [CARDIAC], 2010). The equation weight $(\mathrm{kg}) / \mathrm{height}(\mathrm{cm})^{2} * 10,000$ was utilized to calculate BMI.

BMI percentiles derived from CARDIAC project data were assigned to cut points of overweight defined as a BMI $\geq 85^{\text {th }}$ percentile for age and gender and obesity defined as a BMI $\geq 95^{\text {th }}$ percentile for age and gender (Barlow \& Dietz, 1998; Dietz \& Bellizi, 1999). All weight percentile cut points: overweight (BMI $\geq 85^{\text {th }}$ ), obese (BMI $\geq 95^{\text {th }}$ percentile), were based on age and gender-specific growth charts recommended by the CDC (Centers for Disease Control and Prevention [CDC], 2000). 
Percentile measurements taken using the BMI method have produced reliable estimates of body fat with results correlating with body fat percentage, skin fold test, and is only weakly associated with height (Himes \& Dietz, 1994). BMI correlates well with body fat in adults (Bertakis \& Azari, 2005) and children (Velasquez-Mieyer et al., 2007) and is recommended as the preferred methods for determining obesity. Data from the CARDIAC (2010) project was available by both BMI and BMI percentiles. Data of interest was obtained for the academic years 2007/2008 and 2008/2009 at the zip code level.

\section{STATISTICAL ANALYSIS PLAN}

De-identified data for this secondary data analysis were stored on separate Microsoft Excel spreadsheets and then merged by zip code onto one spreadsheet. SPSS Statistical Software Package (Version 17) was used for statistical analyses. Descriptive statistics were used to portray demographic characteristics for $5^{\text {th }}$ grade child participants. Frequency distributions were obtained for categorical data such as race and gender, while means and standard deviations were reported for continuous variables. Logistic regression analysis was performed to explore the relationship of socioeconomic, physical, and personal attributes to overweight $\left(\mathrm{BMI} \geq 85^{\text {th }}\right.$ percentile) and obesity $\left(\mathrm{BMI} \geq 95^{\text {th }}\right.$ percentile). The significance level was set at 0.05 for the final regression model.

\section{Aim One}

To determine which socioeconomic, physical, and personal environment attributes contribute to overweight (BMI equal to or greater than the $85^{\text {th }}$ percentile for age and gender) in WV $5^{\text {th }}$ graders. Hypotheses:

1.a. Socioeconomic attributes (lower level of education, lower household income, and higher level of violent crime in the county) will be associated with a BMI equal to or greater than the $85^{\text {th }}$ percentile (overweight).

1.b. BMI equal to or greater than the $85^{\text {th }}$ percentile (overweight) will be inversely associated with physical attributes of the number of grocery stores, fruit and vegetable markets, and the number of recreational facilities.

1.c. BMI equal to or greater than the $85^{\text {th }}$ percentile (overweight) will be positively associated with physical attributes of the number of fast food restaurants and convenience stores.

1.d. BMI equal to or greater than the $85^{\text {th }}$ percentile (overweight) will be positively associated with personal attributers of a family history of cardiovascular disease and diabetes.

1.e. BMI equal to or greater than the $85^{\text {th }}$ percentile (overweight) will be inversely associated with the personal attribute of child aerobic fitness at the school level. 


\section{Aim Two}

To determine which socioeconomic, physical, and personal environment attributes contribute to obesity (BMI equal to or greater than the $95^{\text {th }}$ percentile for age and gender) in WV $5^{\text {th }}$ graders. Hypotheses:

2.a. Socioeconomic attributes (lower level of education, lower household income, and higher level of violent crime in the county) will be associated with a BMI equal to or greater than the $95^{\text {th }}$ percentile (obese).

2.b. BMI equal to or greater than the $95^{\text {th }}$ percentile (obese) will be inversely associated with physical attributes of the number of grocery stores, fruit and vegetable markets, and the number of recreational facilities.

2.c. BMI equal to or greater than the $95^{\text {th }}$ percentile (obese) will be positively associated with physical attributes of the number of fast food restaurants and convenience stores.

2.d. BMI equal to or greater than the $95^{\text {th }}$ percentile (obese) will be positively associated with personal attributers of a family history of cardiovascular disease and diabetes.

2.e. BMI equal to or greater than the $95^{\text {th }}$ percentile (obese) will be inversely associated with the personal attribute of child aerobic fitness at the school level.

For both aim one and aim two, binary logistic regression methods were employed to determine which attributes (socioeconomics, physical, and personal environment) contributed to overweight (BMI equal to or greater than the $85^{\text {th }}$ percentile for age, and gender) and obesity (BMI equal to or greater than the $95^{\text {th }}$ percentile for age, and gender). For analysis purposes, the dependent variable BMI percentile was categorized as discrete variables $(0,1)$; whereas, a BMI less than the $85^{\text {th }}$ percentile $(84.99)=0$ and a BMI greater than or equal the $85^{\text {th }}$ percentile $=1$. A second BMI category was categorized as BMI less the $95^{\text {th }}$ percentile $(94.99)=0$ and a BMI equal to or greater than the $95^{\text {th }}$ percentile $=1$. A variety of regression models were constructed: 1 ) unadjusted odds ratios (ORs) to determine which independent variables in the model were most predictive and 2) a Forward LR analysis to examine which term combination significantly affected the dependent variables of overweight and obesity. Univariate variables within each environmental attribute category found to be significant at the $\mathrm{p}<.10$ were retained and included in the multivariate analysis (Forward LR). Variables that were significant $(\mathrm{p}<.10)$ in the Forward LR analysis of socioeconomic, physical, and personal attribute categories were retained and analyzed using multivariate techniques; therefore, the final analysis included all significant socioeconomic, physical, and personal variables identified in the Forward LR analysis. Variables at the $p<.05$ were considered significant in the final model. See Figure 3-1.

To test the statistical significance of each coefficient $(\beta)$ in the model, a Wald test was performed. A Wald test calculates a $Z$ statistic. The $Z$ value is squared, yielding a Wald statistic with a chi-square distribution. Wald significant values less than 0.10 were Retained during model testing; values less than 0.05 were considered significant in the 




Figure 3-1. Analysis Plan: Progression of Model Exploration 
final analysis. The $\operatorname{Exp}(\beta)$ value was used to measure the corresponding influence between one unit change in the IV and odds of overweight and / or obesity occurrence. Direction of influence of $\operatorname{Exp}(\beta)$ was interrupted as values exceeding one increased odds of overweight or obesity occurrence and values less than one decreased odds (Menard, 2001; Peng, Lee, \& Ingersoll, 2002; Peng, Manz, \& Keck, 2001).

Standardized residuals for outliers (ZResid) and residuals were examined; whereas cases exceeding 2.58 (outliers at the 0.01 level) were removed. The H-L goodness-of-fit test statistic was examined to evaluate the overall fit of the model. A $\mathrm{p}>0.05$ indicated insignificance suggesting that the model was fit to the data well. Nagelkerke's $R$ was examined to evaluate the strength of the relationship between the DV and IV. The Nagelkerke's $R$ is the most reported R-squared estimate and is reflective of the relationship between the predictors and the prediction (Peng, et al., $2001 \& 2002$ ). The overall significance of each model was tested using the Model Chi square, as well as the Wald statistic.

To validate the accuracy of the final model a training sample was derived using the $\mathrm{R}^{2}$. Through examination of the classification tables and variable in the equations, output the training model was compared to the binary logistic regression forward LR model. Criteria to support the classification accuracy of the model was an accuracy rate of the holdout sample that was no more than $10 \%$ lower than the accuracy rate for the training sample.

\title{
FINDINGS
}

The sample consisted of $12,194 \mathrm{WV}$ students who were enrolled in $5^{\text {th }}$ grade during the $2007 / 2008$ or 2008/2009 academic year. Approximately $30 \%$ of all WV $5^{\text {th }}$ graders are represented in the study sample. Forty-eight percent of the subjects had a $\mathrm{BMI} \geq 85^{\text {th }}$. percentile of which 3483 were considered obese (BMI $\geq 95^{\text {th }}$ percentile). Similar to statewide racial demographics, the majority of subjects were white. Study demographic characteristics are presented in Table 3-1.

\begin{abstract}
AIM ONE
Aim one: To determine which socioeconomics, physical, and personal environment attributes contributed to overweight (BMI equal to or greater to the $85^{\text {th }}$ percentile for age, and gender) in WV $5^{\text {th }}$ graders a univariate analysis followed by forward regression modeling was undertaken. To validate the accuracy of the final model for generalizability of the findings, a training sample was derived using the $\mathrm{R}^{2 .}$ Through examination of the classification tables and variables in the equations output, the training model was compared to the binary logistic regression model. An accuracy rate of the holdout sample no more than $10 \%$ lower than the accuracy rate for the training sample was utilized to support the classification accuracy of the model.
\end{abstract}


Table 3-1. Study Demographics $(\mathrm{N}=12,194)$

\begin{tabular}{lrr}
\hline Characteristics & Mean (SD) & \multicolumn{1}{c}{ N (\%) } \\
\hline Age (yrs) & $10.99(.467)$ & \\
Female (\%) & & $6557(54)$ \\
Male (\%) & $5637(46)$ \\
Race (\%) & \\
Black & & $325(.03)$ \\
White & $11,011(.90)$ \\
Asian & $48(.004)$ \\
Hispanic & $94(.008)$ \\
Bi-Racial & $316(.02)$ \\
Other & $44(.003)$ \\
Unidentified & $3546(.03)$ \\
BMI $\geq$ equal to $85^{\text {th }}$ percentile & $5851(48)$ \\
BMI $\geq$ equal to $95^{\text {th }}$ percentile & $3483(29)$ \\
\hline
\end{tabular}

\section{SOCIOECONOMIC ENVIRONMENTAL PREDICTORS}

Univariate analysis was undertaken to examine the relationship of each socioeconomic factor (income, education, LSES, and violent crime) to BMI equal to or greater than the $85^{\text {th }}$ percentile. Socioeconomic variables that were significantly associated $(\mathrm{p} \leq$ 0.10 ) with a BMI equal to or greater than the $85^{\text {th }}$ percentile, were then entered for Forward (LR) Stepwise regression. Socioeconomic variables that were significant were then included in the final model of socioeconomic, physical, and personal environment.

\section{Univariate Analysis of Socioeconomic Environmental Predictors}

Significant variables of the univariate analysis of socioeconomic predictors of overweight (BMI $\geq 85^{\text {th }}$ percentile) included education, household income, socioeconomic status, and violent crime $(\mathrm{p}<0.10)$. The odds of a child being overweight increased significantly $(p<0.05)$ in association with socioeconomic variables of lower levels of education, median household income and socioeconomic status. For each unit increase in percentage of the population age 25 years or older with a high school education or greater, the odds of a child being overweight decreased by $56 \%$. Each $\$ 10,000$ dollar increase in income decreased the odds of overweight by $11 \%$. For each percentage increase in child classified as low socioeconomic status defined as receiving free or reduced lunch; the odds of being overweight increased by $135 \%$. Crime increases the odds of being overweight by $14.6 \%$. See Table 3-2. The significant variables ( $\mathrm{p} \leq$ 0.10 ) of education, income, socioeconomic status, and crime were then entered for Forward (LR) Stepwise regression analysis. 
Table 3-2. Univariate Analysis: Socioeconomic Environmental Predictors of BMI Equal to or Greater than the $85^{\text {th }}$ Percentile in WV $5^{\text {th }}$ Grade Children

\begin{tabular}{lcccc}
\hline & & & \multicolumn{2}{c}{ 95\% C.I. for EXP(B) } \\
Predictor & $\mathbf{p}$ & Odds Ratio & Lower & Upper \\
\hline Education & .000 & .434 & .298 & .633 \\
Household Income & .000 & .884 & .841 & .930 \\
Socioeconomic Status & .006 & 2.350 & 1.865 & 2.961 \\
Violent Crime & .076 & 1.146 & .986 & 1.333 \\
\hline
\end{tabular}

\section{Forward (LR) Stepwise Analysis of Socioeconomic Environmental Predictors}

The socioeconomic variables of education and socioeconomic status $(p<0.05)$ were the most significant of the Forward Stepwise LR analysis and was included in the final model of socioeconomic, physical, and personal environment. Among the variables of significance, each unit increase in education decreased overweight by $48.3 \%$; whereas, overweight increased by $102.8 \%$ for each unit increase in low socioeconomic classification. See Table 3-3.

\section{PHYSICAL ENVIRONMENTAL PREDICTORS}

Univariate logistic regression was done to examine the association between the physical factors of supermarket, convenience stores, fitness and recreational facilities, fruit and vegetable markets, and fast food establishments with overweight (BMI $\geq 85^{\text {th }}$ percentile). Physical variables that were significantly associated $(p \leq 0.10)$ with a BMI greater than the $85^{\text {th }}$ percentile, were then entered for Forward (LR) Stepwise regression. Physical variables that were significant were then included in the final model of socioeconomic, physical, and personal environment.

\section{Univariate Analysis of Physical Environmental Predictors}

The odds of having a BMI equal to or greater than the $85^{\text {th }}$ percentile were associated with lower numbers of supermarket, convenience stores, fitness and recreational facilities, fruit and vegetable markets, and fast food. The number of grocery stores, convenience stores, fitness and recreational facilities, fruit and vegetable markets, and fast food restaurants were inversely associated with a child being overweight. For a one facility, increase in the number of grocery stores the odds of being overweight decreased by $1.9 \%$. An increase of one fruit and vegetable market was associated with a decrease in overweight by $11.8 \%$. An increase of one recreational facility decreased overweight by $2.9 \%$; whereas, an increase of 1 convenience store decreased the odds of being overweight by $3.4 \%$. A 1 facility increase in fast food restaurants decreased the odds of overweight by $0.4 \%$. See Table 3-4. 
Table 3-3. Forward (LR) Stepwise Analysis: Adjusted Model of Socioeconomic Environmental Predictors of BMI Equal to or Greater than the $85^{\text {th }}$ Percentile in WV $5^{\text {th }}$ Grade Children

\begin{tabular}{lcccc}
\hline & & & \multicolumn{2}{c}{ 95\% C.I. for EXP(B) } \\
\cline { 4 - 5 } Predictor & $\mathbf{p}$ & Odds Ratio & Lower & Upper \\
\hline Education & .002 & .517 & .343 & 1.459 \\
Socioeconomic Status & .000 & 2.028 & 1.574 & 2.613 \\
\hline
\end{tabular}

Table 3-4. Univariate Analysis: Physical Environmental Predictors of BMI Equal to or Greater than the $85^{\text {th }}$ Percentile in WV $5^{\text {th }}$ Grade Children

\begin{tabular}{|c|c|c|c|c|}
\hline \multirow[b]{2}{*}{ Predictor } & \multirow[b]{2}{*}{ p } & \multirow[b]{2}{*}{ Odds Ratio } & \multicolumn{2}{|c|}{ 95\% C.I. for EXP(B) } \\
\hline & & & Lower & Upper \\
\hline $\begin{array}{l}\text { Supermarkets and Other } \\
\text { Grocery }\end{array}$ & .002 & .981 & .969 & .993 \\
\hline Fruit and Vegetable Markets & .018 & .882 & .794 & .979 \\
\hline $\begin{array}{l}\text { Fitness and Recreational } \\
\text { Centers }\end{array}$ & .032 & .971 & .946 & .997 \\
\hline $\begin{array}{l}\text { Convenience Store } \\
\text { Establishments }\end{array}$ & .001 & .966 & .949 & .986 \\
\hline Fast Food Establishments & .019 & .996 & .993 & .999 \\
\hline
\end{tabular}




\section{Forward (LR) Stepwise Analysis of Physical Environmental Predictors}

The physical variable of convenience stores was the most significant variable $(\mathrm{p}<.005)$ of the Forward Stepwise LR analysis (see Table 3-5). Therefore, number of convenience stores was included in the final model of socioeconomic, physical, and personal environment.

\section{PERSONAL ENVIRONMENTAL PREDICTORS}

Three personal environmental variables (family history of diabetes, family history of heart disease, and child aerobic fitness per fifth grade class) were examined as predictors of overweight $\left(\mathrm{BMI} \geq 85^{\text {th }}\right.$ percentile) in $5^{\text {th }}$ grade children residing in WV. Univariate analysis was undertaken to examine the relationship of each personal environmental factor (family history of heart disease, family history of heart disease, and aerobic fitness) to BMI equal to or greater than the $85^{\text {th }}$ percentile. Personal environmental variables that were significantly associated $(\mathrm{p} \leq 0.10)$ with a BMI equal to or greater than the $85^{\text {th }}$ percentile, were then entered for Forward (LR) Stepwise regression. Socioeconomic variables that were significant were then included in the final model of socioeconomic, physical, and personal environment.

\section{Univariate Analysis of Personal Environmental Predictors}

A family history of diabetes or heart disease was associated with a greater likelihood of the child being overweight $\left(\mathrm{BMI} \geq 85^{\text {th }}\right.$ percentile). Higher fitness was associated with lower odds of having a BMI above the $85^{\text {th }}$ percentile. For each increase of 1 child with a family history of heart disease, the odds of overweight increased by $21 \%$; while an increase of 1 child with a family history of diabetes increased the odds by $36 \%$. Aerobic fitness was inversely associated with overweight with a $38 \%$ decrease in odds for each unit increase in fitness. See Table 3-6. Univariate variables retained for the block analysis included family history of diabetes and heart disease, as well as aerobic fitness.

Table 3-5. Forward (LR) Stepwise Analysis: Adjusted Model of Physical Environmental Predictors of BMI Equal to or Greater than the $85^{\text {th }}$ Percentile in WV $5^{\text {th }}$ Grade Children

\begin{tabular}{lcccc}
\hline & & & \multicolumn{2}{c}{$\mathbf{9 5 \%}$ C.I. for EXP(B) } \\
Predictor & $\mathbf{p}$ & Odds Ratio & Lower & Upper \\
\hline Convenient Store & .001 & .966 & .946 & .986 \\
\hline
\end{tabular}


Table 3-6. Univariate Analysis: Personal Environmental Predictors of BMI Equal to or Greater than the $85^{\text {th }}$ Percentile in WV $5^{\text {th }}$ Grade Children

\begin{tabular}{lcccc}
\hline & & & \multicolumn{2}{c}{ 95\% C.I. for EXP(B) } \\
\cline { 5 - 6 } Predictor & p & Odds Ratio & Lower & Upper \\
\hline Family History of Heart Disease & .000 & 1.213 & 1.121 & 1.314 \\
Family History of Diabetes & .000 & 1.364 & 1.268 & 1.466 \\
Aerobic Fitness: $5^{\text {th }}$ Grade Class & .000 & .619 & .491 & .781 \\
\hline
\end{tabular}

\section{Forward (LR) Stepwise Analysis of Personal Environmental Predictors}

According to the Forward (LR) Stepwise analysis, a family history of heart disease increased the odds of overweight by $12.9 \%$, while a family history of diabetes increased the odds by $31.7 \%$. Aerobic fitness was inversely associated with a BMI greater than the $85^{\text {th }}$ percentile with a $39.6 \%$ decrease in obesity for each unit increase in aerobic fitness. See Table 3-7. All three personal environmental factors were retained for the final model.

\section{FINAL MODEL}

A logistic regression analysis was conducted to predict overweight using socioeconomic status; family history of heart disease and diabetes; convenience stores; and aerobic fitness factors as predictors. A test of the full model against a constant only model was statistically significant, indicating that the predictors as a set reliably distinguished between overweight and non-overweight (chi square $=94.730, \mathrm{p}<0.000$ with $d f=5)$. The Hosmer-Lemeshow (H-L) inferential goodness-of-fit test yielded a $\chi^{2}$ (8) of 6.384 and was insignificant $(p>0.05)$ with a $p$ value of 0.604 , suggesting that the model was fit to the data well.

Nagelkerke's $\mathrm{R}^{2}$ of 0.015 indicated a weak relationship between prediction and the multivariate grouping. Prediction success overall was $54.5 \%$ (65.8\% for nonoverweight and $43.2 \%$ for overweight) which exceeded the constant prediction success of 52. The Wald criterion demonstrated that socioeconomic status; family history of heart disease; family history of diabetes; child aerobic fitness; and the number of convenience stores made a significant contribution to predicting $(\mathrm{p}<0.05)$ BMI equal to or equal to the $85^{\text {th }}$ percentile.

A percentage increase in $5^{\text {th }}$ grade children classified as low socioeconomic status increased the child's odds of overweight by $72 \%$; whereas, an increase in family history of heart disease or diabetes increased a child's odds of overweight by 12 and $30 \%$ respectively. An increase in the percentage of children classified as aerobic fit decreased the odds of overweight by $26 \%$, while each 1 facility increase in the number of convenience stores decreased the odds of overweight by $4 \%$. See Table 3-8. 
Table 3-7. Forward (LR) Stepwise Analysis: Adjusted Model of Personal Environmental Predictors of BMI Equal to or Greater than the $85^{\text {th }}$ Percentile in WV $5^{\text {th }}$ Grade Children

\begin{tabular}{lccrc}
\hline & & & \multicolumn{2}{c}{$\mathbf{9 5 \%}$ C.I. for EXP(B) } \\
\cline { 3 - 5 } Predictor & $\mathbf{p}$ & Odds Ratio & Lower & Upper \\
\hline Heart Disease & .010 & 1.129 & 1.030 & 1.237 \\
Diabetes & .000 & 1.317 & 1.208 & 1.433 \\
Aerobic Fitness & .000 & .604 & .473 & .773 \\
\hline
\end{tabular}

Table 3-8. $\quad$ Final Model: Forward (LR) Stepwise Analysis of Environmental Predictors of BMI Equal to or Greater than the $85^{\text {th }}$ Percentile in WV $5^{\text {th }}$ Grade Children

\begin{tabular}{lccrr}
\hline & & & \multicolumn{2}{c}{$\mathbf{9 5 \%}$ C.I. for EXP(B) } \\
\cline { 3 - 5 } Predictor & $\mathbf{p}$ & Odds Ratio & Lower & Upper \\
\hline Socioeconomic Status & .000 & 720 & 1.296 & 2.282 \\
Family History of Heart Disease & .014 & 124 & 1.024 & 1.231 \\
Family History of Diabetes & .000 & 399 & 1.202 & 1.426 \\
Aerobic Fitness & .024 & 744 & .575 & .961 \\
Convenience Stores & .002 & 963 & .941 & .986 \\
\hline
\end{tabular}


The Forward LR Stepwise binary logistic regression of the training model resulted in the same number of steps as the full sample model: socioeconomic status; family history of heart disease; family history of diabetes; child aerobic fitness; and the number of convenience stores. The accuracy for the validation sample was larger (55.1) than the classification accuracy for the training sample (54.2), implying a better fit than obtained for the training sample. Thus, the validation analysis supported the generalizability of the final model findings to the population represented by the study sample.

\begin{abstract}
AIM TWO
Aim two: To determine which socioeconomics, physical, and personal environment attributes contribute to obesity (BMI equal to or greater to the $95^{\text {th }}$ percentile for age, and gender) in WV $5^{\text {th }}$ graders univariate analysis, followed by forward regression modeling were undertaken. To validate the accuracy of the final model for generalizability of the findings, a training sample was derived using the $\mathrm{R}^{2}$. Through examination of the classification tables and variables in the equations output, the training model was compared to the binary logistic regression model. An accuracy rate of the holdout sample no more than $10 \%$ lower than the accuracy rate for the training sample was utilized to support the classification accuracy of the model. Findings from the validation sample were used to evaluate the generalizability of the final model to the population represented by the study sample.
\end{abstract}

\title{
SOCIOECONOMIC ENVIRONMENTAL PREDICTORS
}

Four socioeconomic variables (income, education, LSES, and violent crime) were examined as predictors of obesity $\left(\mathrm{BMI} \geq 95^{\text {th }}\right.$ percentile) in $5^{\text {th }}$ grade children residing in WV. Univariate analysis was undertaken to examine the relationship of each socioeconomic variable to BMI equal to or greater than the $95^{\text {th }}$ percentile. Socioeconomic variables that were significantly associated $(p \leq 0.10)$ with a BMI greater than the $95^{\text {th }}$ percentile, were then entered for Forward (LR) Stepwise regression. Significant variables were then included in the final model of socioeconomic, physical, and personal environment.

\section{Univariate Analysis of Socioeconomic Environmental Predictors}

The odds of a child being obese increased significantly $(p<0.05)$ in association with education, median household income, and socioeconomic status. For each unit increase in percentage of the population age 25 years or older with a high school diploma or greater, the odds of a child being obese decreased by $78.5 \%$. Each $\$ 10,000$ dollar increase in income decreased the odds of obese by $17.8 \%$. For each percentage increase in children classified as low socioeconomic status defined as being eligible to receive free or reduced lunch; the odds of being obese increased by $260 \%$. Crime increased the odds 
of being obese by $20 \%$ for each unit increase in county crime rate per 100 persons. See Table 3-9.

\section{Forward (LR) Stepwise Analysis of Socioeconomic Environmental Predictors}

The socioeconomic variables of socioeconomic status, education, and crime $(\mathrm{p}<$ 0.10) were the most significant variables of the Forward Stepwise LR analysis and were included in the final model of socioeconomic, physical, and personal environment. For each unit increase in the percentage of $5^{\text {th }}$ grade children classified as low socioeconomic status, obesity increased by $182 \%$; whereas, each percentage unit increase in high school education among the population aged $25+$ years, the odds of obesity decreased by $63.9 \%$. For each unit increase in the rate of county crime per 100 persons, the odds of a child being obese increased by $22.7 \%$. See Table 3-10. All three socioeconomic variables were included in the final Forward (LR) Stepwise Analysis.

\section{PHYSICAL ENVIRONMENTAL PREDICTORS}

Univariate logistic regression was done to examine the association between the physical factors of supermarket, convenience stores, fitness and recreational facilities, fruit and vegetable markets and fast food with BMI equal to or greater than the $95^{\text {th }}$ percentile. Physical variables that were significantly associated $(\mathrm{p} \leq 0.10)$ with a BMI equal to or greater than the $95^{\text {th }}$ percentile, were then entered for Forward (LR) Stepwise.

\section{Univariate Analysis of Physical Environmental Predictors}

The odds of having a BMI equal to or greater than the $95^{\text {th }}$ percentile were inversely associated with the number of supermarkets, convenience stores, fitness and recreational facilities, fruit and vegetable markets, and fast food establishments. For a one facility increase in number of grocery stores, the odds of a child being obese decreased by $1.6 \%$. An increase of one fruit and vegetable market was associated with a decreased odd of being overweight of $16.4 \%$; while an increase of one recreation facility decreased the odd of being overweight by $3.8 \%$. An increase in one convenience store decreased the odds of being overweight by $3 \%$ percent, while for a one facility increase in the number of fast food restaurants the odds of obesity decreased by $0.4 \%$. See Table 3-11.

\section{Forward (LR) Stepwise Analysis of Physical Environmental Predictors}

The physical variable of fruit and vegetable markets was the most significant variable $(\mathrm{p}<.10)$ of the Forward (LR) Stepwise analysis and was included in the final Model. See Table 3-12. 
Table 3-9. Univariate Analysis: Socioeconomic Environmental Predictors of BMI Equal to or Greater than the $95^{\text {th }}$ Percentile in WV $5^{\text {th }}$ Grade Children

\begin{tabular}{lccrc}
\hline & & & \multicolumn{2}{c}{$\mathbf{9 5 \%}$ C.I. for EXP(B) } \\
Predictor & $\mathbf{p}$ & Odds Ratio & Lower & Upper \\
\hline Education & .000 & .215 & .144 & .321 \\
Household Income & .000 & .822 & .776 & .871 \\
Socioeconomic Status & .000 & 3.602 & 2.784 & 4.660 \\
Violent Crime & .026 & 1.206 & 1.022 & 1.424 \\
\hline
\end{tabular}

Table 3-10. Forward (LR) Stepwise Analysis: Adjusted Model of Socioeconomic Environmental Predictors of BMI Equal to or Greater than the $95^{\text {th }}$ Percentile in WV $5^{\text {th }}$ Grade Children

\begin{tabular}{lccrc}
\hline & & & \multicolumn{2}{c}{ 95\% C.I. for EXP(B) } \\
Predictor & $\mathbf{p}$ & Odds Ratio & Lower & Upper \\
\hline Socioeconomic Status & .010 & 2.821 & 2.125 & 3.744 \\
Education & .000 & .369 & .236 & .576 \\
Violent Crime & .020 & 1.227 & 1.032 & 1.459 \\
\hline
\end{tabular}

Table 3-11. Univariate Analysis: Physical Environmental Predictors of BMI Equal to or Greater than the $95^{\text {th }}$ Percentile in WV $5^{\text {th }}$ Grade Children

\begin{tabular}{|c|c|c|c|c|}
\hline \multirow[b]{2}{*}{ Predictor } & \multirow[b]{2}{*}{ p } & \multirow[b]{2}{*}{ Odds Ratio } & \multicolumn{2}{|c|}{ 95\% C.I. for $\operatorname{EXP}(B)$} \\
\hline & & & Lower & Upper \\
\hline $\begin{array}{l}\text { Supermarkets and Other } \\
\text { Grocery }\end{array}$ & .019 & .984 & .970 & .997 \\
\hline Fruit and Vegetable Markets & .003 & .836 & .743 & .942 \\
\hline $\begin{array}{l}\text { Fitness and Recreational } \\
\text { Centers }\end{array}$ & .010 & .962 & .934 & .991 \\
\hline $\begin{array}{l}\text { Convenience Store } \\
\text { Establishments }\end{array}$ & .012 & .970 & .948 & .993 \\
\hline Fast Food Establishments & .016 & .996 & .992 & .999 \\
\hline
\end{tabular}


Table 3-12. Forward (LR) Stepwise Analysis: Adjusted Model of Physical Predictors of BMI Equal to or Greater than the $95^{\text {th }}$ Percentile in $\mathrm{WV}^{\text {th }}$ Grade Children

\begin{tabular}{lcccc}
\hline & & & \multicolumn{2}{c}{ 95\% C.I. for EXP(B) } \\
Predictor & p & Odds Ratio & Lower & Upper \\
\hline Fruit and Vegetable Markets & .003 & .836 & .743 & .942 \\
\hline
\end{tabular}

\section{PERSONAL ENVIRONMENTAL PREDICTORS}

Three personal environmental variables were examined as predictors of BMI greater than the $95^{\text {th }}$ percentile in $5^{\text {th }}$ grade children residing in WV. Univariate analysis was undertaken to examine the relationship of each personal environmental factor (family history of heart disease, family history of diabetes, and aerobic fitness) to BMI equal to or greater than the $95^{\text {th }}$ percentile. Personal environmental variables that were significantly associated $(\mathrm{p} \leq 0.10)$ with a BMI equal to or greater than the $95^{\text {th }}$ percentile, were then entered for Forward (LR) Stepwise regression. Personal environmental variables that were significant were then included in the final model of socioeconomic, physical, and personal environment.

\section{Univariate Analysis of Personal Environmental Predictors}

A family history of diabetes or heart disease was associated with a greater likelihood of the child being obese (BMI $\geq 95^{\text {th }}$ percentile). Higher aerobic fitness was associated with lower odds of having a BMI above the $95^{\text {th }}$ percentile. For each increase of 1 child reporting a family history of diabetes, the odds for obesity increased by $41.1 \%$, while an increases in 1 child reporting a family history of heart disease increased the odds of obesity by $24.6 \%$. Aerobic fitness was inversely associated with obesity with a $50.3 \%$ decrease in odds for each unit increase in fitness. See Table 3-13. Univariate variables retained for the Forward (LR) analysis included family history of diabetes and heart disease, as well as aerobic fitness.

\section{Forward (LR) Stepwise Analysis of Personal Environmental Predictors}

The odds for obesity increased for each unit increase in family history of heart disease and diabetes $(15.7 \%$, and $35.4 \%)$. For each unit increase in the percentage of $5^{\text {th }}$ grade, children classified as aerobic fit ("healthy zone"), the odds of obesity decreased by 50.6\%. See Table 3-14. All three predictors were included in the final Forward Stepwise Analysis. 
Table 3-13. Univariate Analysis: Personal Environment Predictors of BMI Greater than the $95^{\text {th }}$ Percentile in $5^{\text {th }}$ Grade Children

\begin{tabular}{lccrc}
\hline & & & \multicolumn{2}{c}{$\mathbf{9 5 \%}$ C.I. for EXP (B) } \\
Predictor & $\mathbf{p}$ & Odds Ratio & Lower & Upper \\
\hline Heart Disease & .000 & 1.246 & 1.143 & 1.358 \\
Diabetes & .000 & 1.411 & 1.302 & 1.529 \\
Aerobic Fitness & .000 & .497 & .385 & .640 \\
\hline
\end{tabular}

Table 3-14. Forward Stepwise Analysis: Adjusted Model of Personal Environmental Predictors of BMI Equal to or Greater than the $95^{\text {th }}$ Percentile in WV $5^{\text {th }}$ Grade Children

\begin{tabular}{lcccc}
\hline & & & \multicolumn{2}{c}{ 95\% C.I. for EXP (B) } \\
\cline { 4 - 5 } Predictor & $\mathbf{p}$ & Odds Ratio & Lower & Upper \\
\hline Heart Disease & .004 & 1.157 & 1.047 & 1.279 \\
Diabetes & .000 & 1.354 & 1.232 & 1.489 \\
Aerobic Fitness & .000 & .494 & .378 & .645 \\
\hline
\end{tabular}




\section{FINAL MODEL}

The Forward LR Stepwise binary logistic regression of the training sample failed to result in the same number of steps as the full sample model. The Forward LR Stepwise binary logistic model was rerun excluding the suspect variables of aerobic fitness and fresh fruit and vegetable markets. Education, socioeconomic status, crime, family history of heart disease and diabetes were included in the final analysis. The modified model resulted in the same variables selected in the forward logistic regression of the training sample: education, socioeconomic status, family history of heart disease, family history of diabetes, and crime. The accuracy for the validation sample was larger (72.1) than the classification accuracy for the training sample (71.5), implying a better fit than obtained for the training sample. Thus, the validation analysis supported the generalizability of the modified final model findings to the population represented by the study same.

A test of the modified model against a constant only model was statistically significant, indicating that the predictors as a set reliably distinguished between overweight and non-overweight (chi square $=175.363, \mathrm{p}<0.000$ with $d f=5$ ). The Hosmer-Lemeshow (H-L) inferential goodness-of-fit test yielded a $\chi^{2}(8)$ of 5.889 and was insignificant ( $p>0.05)$ with a $p$ value of 0.660 , suggesting that the model was fit to the data well. Nagelkerke's $\mathrm{R}^{2}$ of .023 indicated a weak relationship between prediction and the multivariate grouping. Prediction success overall was $71.6 \%$ which was equivalent to the constant prediction success. The Wald criterion demonstrated that education, socioeconomic status; family history of heart disease; family history of diabetes, and crime made a significant contribution to predicting $(\mathrm{p}<0.05)$ BMI greater or equal to the $95^{\text {th }}$ percentile.

Findings indicated a $1 \%$ increase in the percentage of the population age 25 years or older with a high school degree, decreased the odds of obesity by $60 \%$. A $1 \%$ increase in $5^{\text {th }}$ grade children eligible for free or reduced lunch increased the child's odds of obesity by $179 \%$; whereas, a family history of heart disease or diabetes increased a child's odds of obesity by 16 and $35 \%$ respectively. For each unit increase in county crime rate per 100 persons, the odd of obesity increased by 27\%. See Table 3-15.

Table 3-15. Final Model: Forward (LR) Stepwise Analysis of Predictors of BMI Equal to or Greater than the $95^{\text {th }}$ Percentile in WV $5^{\text {th }}$ Grade Children

\begin{tabular}{lcccc}
\hline & & & \multicolumn{2}{c}{ 95\% C.I. for EXP (B) } \\
\cline { 5 - 6 } Predictor & $\mathbf{p}$ & Odds Ratio & Lower & Upper \\
\hline Education & .000 & .394 & .247 & .630 \\
Socioeconomic Status & .000 & 2.796 & 2.073 & 3.771 \\
Family History of Heart Disease & .002 & 1.159 & 1.058 & 1.269 \\
Family History of Diabetes & .000 & 1.353 & 1.229 & 1.449 \\
Crime & .009 & 1.273 & 1.232 & 1.463 \\
\hline
\end{tabular}




\section{DISCUSSION}

Within the state of WV, overweight and obesity appear to disproportionately affect those with limited economic resources as defined by free or reduced lunch eligibility. Seventy-two percent of overweight/obese subjects attended schools in which $50 \%$ or more of the $5^{\text {th }}$ grade population was eligible for free or reduced lunch; in other words, living in households with an annual income below $130 \%$ to $185 \%$ of the poverty line. Household income was less of a determinant of overweight or obesity with low socioeconomic status being the strongest predictor. Such findings could attest to the fact that median household income is an estimate of the general population (larger geographical scale); thus subject to greater fluctuations due to community dynamics. In comparison, low socioeconomic status as defined according to the percentage of $5^{\text {th }}$ grade children (by school) eligible for free or reduced lunch more closely represents a child's household income; a stronger predictor of poverty. Therefore, free or reduced lunch eligibility may be a stronger social determinant of childhood overweight and obesity than other socioeconomic measures. Education was found to be a significant predictor of obesity, but not for overweight. This, theoretically, could be due to the difference in parental and child behavior. Parents with less than a high school education may lack the knowledge necessary to prevent the transition from overweight to obesity. Nayga (2000) contends that diet-disease knowledge decreases the probability of obesity. Findings are similar to work by Drewnowki \& Specter (2004), indicating that population groups with the highest poverty rates and the least education have the highest obesity rates.

A substantial number of studies demonstrate the association between childhood obesity, low household income, and food insecurity (Casey et al., 2001; Crooks, 1999, 2000; Wang \& Lobstein, 2006). As hypothesized, findings from this study were similar to those reported in the literature, in that an inverse relationship between overweight and obesity and attributes of the physical environment including number of supermarket and other grocery stores, fruit and vegetable markets, and the number of recreational facilities was observed. Among the physical attributes, fruit and vegetable markets played the most significant role in obesity development. Within the literature, food store availability has been linked with negative outcomes such as obesity (Beaulac et al., 2009; Blanchard \& Lyson, 2006; Moore, 2003); with poorer communities having limited access to fruit and vegetable markets and natural food stores. Additionally, fruit and vegetable consumption has been associated with the presence of supermarkets, and supermarkets are more likely to be located in wealthier neighborhoods (Morland et al., 2002). However, the increase in odds was non-significant when examined within the context of other study variables (socioeconomics and personal environment). Findings indicate that as an independent predicator attributes of the physical environment may play a role in overweight and obesity development; but when combined with an environment consisting of low education attainment and/or low socioeconomics, their influence is less. Nevertheless, examining the impact that the physical environment has upon overweight/obesity development as independent predictors is reasonable due to the complexities of the socioeconomic environment.

According to researchers, the number of convenience stores (Galvez et al., 2009; Powell et al., 2007) within a community is associated with a higher BMI and lower levels 
of fruit and vegetable consumption in children (Timperio et al., 2009). Contrary to our hypothesis, this study revealed an inverse association in that as the number of convenience stores increased the odds of overweight decreased. However, this relationship was not observed, among obese children. Such findings are perplexing and the dearth of the literature fails to aid in providing an explanation for the observed phenomenon.

Sallis and Glanz (2006) contend that access to safe places affects activity behavior, which may influence obesity development. Findings from this study indicate that the odds of obesity increase in association to crime; however, how crime influences behavior was not examined. Nevertheless, researchers contend that parents who perceive their community to be unsafe may be less likely to permit their children to play outside (Nestle \& Jacobson, 2000). In fact, parental concern about crime is among the leading reasons why parents keep their children indoors (Gordon-Larsen et al., 2000; Molnar et al., 2004). Therefore, findings from this study warrant additional investigation regarding crime perception, safety, physical activity, and obesity.

West Virginia is the $4^{\text {th }}$ most obese state in the nation with an adult obesity rate exceeding 30\% (Trust for America's Health, 2011). As a result, many WV children are living in households in which obesity is a common occurrence. Parental obesity increases the risk of obesity development in children (Freeman et al., 2011; Pryor et al., 2011) with the odds of a child becoming obese as an adult increasing threefold if one parent is obese and tenfold if both parents are obese (Summerbell et al., 2005). Parental BMI was not available for the current study; however, family history of heart disease and diabetes were self-reported by parents of subjects. Studies support increased risk of obesity among offspring of parents with a history of heart disease (Youssef, Valdez, Elkasabany, Srinivasan, \& Berenson, 2002) or diabetes (Kim, England, Sharma, \& Njoroge, 2011; Malcolm, Lawson, Gaboury, Lough, \& Keely, 2006).

Understanding the dynamics of the family in relation to obesity related behaviors; history of cardiovascular disease and/or diabetes, may provide clues to childhood obesity risk factors. As hypothesized, this study indicates that WV children are at greater odds of overweight/obesity due to family history of heart disease and/or diabetes. Such findings are similar to reports in the literature indicating that children with parents with early heart disease are at an increased risk for obesity (Slyper, 1998). Furthermore, children who are overweight, have a family member with type 2 diabetes, and are over 10 years of age are at increased risk for developing type 2 diabetes during childhood, adolescence, or adulthood Type 2 diabetes observed in youth is perceived to be a "first consequence" of the obesity epidemic in children (Fagot-Campagna, 2000; Fagot-Campagna et al., 2000; National Diabetes Education Program, 2008).

Associations between BMI and aerobic fitness in children were noted within the literature with the majority of studies focusing on contribution of BMI and fitness to cardiovascular risk factors (DuBose, Eisenmann, \& Donnelly, 2007; Eisenmann, Welk, Wickel, \& Blair, 2007; Eisenmann, Welk, Ihmels, et al., 2007). Individuals classified with low fitness and high BMI demonstrate the greatest degree of cardiovascular disease (CVD) risk factors including: higher blood lipids and glucose (Eisenmann, Welk, 
Ihmels, et al., 2007). Findings from this study demonstrate a significant association between overweight and aerobic fitness; whereas, a one-percentage increase in $5^{\text {th }}$ grade children classified as aerobic fit decreased the odds of overweight by $24 \%$. Interestingly, fitness was not retained in the final prediction model for obesity. The relationship may have been attenuated by the use of aggregate, school level fitness data rather than individual fitness data. Thus, fitness levels in this study may be more reflective of the community in which the students reside rather than a measure of personal attributes. Nevertheless, further exploration of the association between BMI and aerobic fitness is imperative; as previous research indicated that overweight and obese WV children had elevated total cholesterol and elevated systolic blood (Demerath et al., 2003).

\section{SIGNIFICANCE AND RECOMMENDATIONS}

This is the first study to explore the relationship of continual environmental attributes to childhood obesity in a large, state-wide sample of $\mathrm{WV} 5^{\text {th }}$ graders. Results of the binary logistic regression analysis of environmental attributes identified that free or reduced lunch eligibility significantly increased a child's odds for overweight or obesity; whereas, household income as defined on a global scale using census tract data was found to be insignificant. Such findings indicate that low socioeconomic status defined according to free or reduced lunch eligibility may be a stronger social predictor for negative health outcomes such as obesity. According to the criteria, children must reside in a household in which incomes are at or below $130 \%$ for free lunch and between 130 and $185 \%$ for reduced lunch (West Virginia Department of Education [Data file], 2011). Thus, eligibility is not only associated with increased odds of overweight or obesity, but also a reflection of poverty status.

Education attainment is often used within the literature as an alternate measure for socioeconomic status. Less education is viewed by many researchers as a predictor of health disparities and seen as a contributing factor for poverty and unemployment (Metzler, 2007). Therefore, interventions aimed to enhance educational attainment may play a vital role in childhood obesity prevention.

Food inaccessibility; lack of access to grocery stores and fruit and vegetable markets, appeared to play a significant role in overweight and obesity occurrence independently. However, when examined within the context of other socioeconomic attributes; education and socioeconomic status, food inaccessibility failed to play a significant role in overweight and obesity development. Yet the spatial inaccessibility of food facilities warrants further investigation. Additionally, findings suggest that more attention should be placed upon urban planning and local food accessibility and availability. 


\section{CONCLUSION}

The purpose of this study was to determine which socioeconomics, physical, and personal environmental attributes contributed to overweight (BMI equal to or greater than the $85^{\text {th }}$ percentile for age, and gender) and obesity (BMI equal to or greater than the $95^{\text {th }}$ percentile) in $\mathrm{WV} 5^{\text {th }}$ graders. Socioeconomic status of the community and a positive family history of heart disease and diabetes, consistently increased the odds of being overweight $\left(\mathrm{BMI} \geq 85^{\text {th }}\right.$ percentile) or obese (BMI $\geq 95^{\text {th }}$ percentile). Findings from this study may be useful in determining allocation of physical and financial resources to improve intervention strategies at the community level, specifically targeting students who attend schools where a high percentage of students are eligible for free or reduced lunches. Additionally, cumulative findings of community level data may help develop obesity predictive models. 


\section{CHAPTER 4. SPATIAL ANALYSIS}

\section{INTRODUCTION}

Researchers contend that an obesogenic environment is a major explanation for the increased incidence of overweight and obesity (Boehmer et al., 2006; Giskes et al., 2011; Michimi \& Wimberly, 2010); however, what constitutes an environment that promotes obesity is not well understood. West Virginia, a rural Appalachian community, has the $10^{\text {th }}$ highest youth obesity rate $(18.9 \%)$ in the nation (Trust for America's Health, 2011), yet few studies have examined childhood overweight and obesity among Appalachian children from an obesogenic environmental perspective. Our preliminary analysis of $5^{\text {th }}$ grade WV children who participated in the CARDIAC project identified socioeconomic, personal, and physical environmental attributes associated with childhood obesity and overweight. Additionally, the literature supports the linkages between environmental risk factors and obesity development (Papas et al., 2007). However, there is a paucity of information on the effect of cumulative environmental factors on overweight and obese children. Environmental risk factors associated with obesity are perceived to be distributed continuously over space, yet the obesity epidemic appears to disproportionately affect some communities greater than others (Cochran, 2008). Analysis of spatial distribution may help provide answers to fundamental childhood obesity questions related to environmental risks. Such methods may provide a means to identify geographical obesity patterns and offer the ability to filter information to identify obesity related events.

\section{PROCEDURES AND METHODS}

A merged database incorporated de-identified individual child data (BMI and family history of heart disease and diabetes) from the CARDIAC project and publically accessible socioeconomic, physical, and personal environmental data. Using the merged database relationships among the environmental attributes (socioeconomic, physical, and personal) and childhood obesity and overweight were previously analyzed by means of binary logistic regression methods. Individual variables were examined for significance and final models of childhood overweight and obesity were derived through multivariate analysis. The merged database was then utilized to assess the geographic distribution of attributes (socioeconomic, physical, and personal) in relation to overweight (BMI equal to or greater than the $85^{\text {th }}$ percentile for age, and gender) and obesity (BMI equal to or greater than the $95^{\text {th }}$ percentile for age, and gender). The study was approved by the Institutional Review Board of the University of Tennessee Health Science Center.

CARDIAC data (subject data: BMI and family history) layers and environment variable layers were integrated using ARCH GIS 9.3. CARDIAC data contained geographical indicators of county, school, and zip code per subject. Therefore, for spatial analysis purposes, each subject zip code served as the link between data sources and data layers; thus, each subject zip code could be linked to participant's school and each 
participant's school linked to a county. Five-digit ZIP Code Tabulation Areas (ZCTAs) and Fipscode for the state and county (FIPSSTCO) served as the spatial link for data mapping.

The study sample consisted of 12,194 fifth grade children (48\% overweight; $29 \%$ obese) participating in the CARDIAC project during the academic school years of 2007/2008 and 2008/2009. The sample was drawn from 53 of the state's 55 counties. All $5^{\text {th }}$ grade students enrolled in WV public schools were eligible to participate. Community demographic characteristics are presented in Table 4-1.

\section{INSTRUMENTS}

\section{Socioeconomics}

Household income and education data were obtained from the U.S. Census Bureau one-year estimates derived from the American Community Survey (ACS). U.S. Census Data were compiled by Geolytics and obtained at the zip code and county level for the years 2007 and 2008. Education data (the number of persons 25+ years completing high school) was examined at the zip code level for years 2007 and 2008. The percentage of $5^{\text {th }}$ grade students in a class eligible for free or reduced lunch, based on the National School Lunch Program standards, was used as the measure low socioeconomic status (LSES) for the academic years 2007/2008 and 2008/2009 and was coded by school and county. County violent crime data (rate per 100) for rape, sexual assault, robbery, assault, burglary, motor vehicle theft, and theft were gathered from the WV State Police data website for the years of $2007 \& 2008$. See Table 4-2.

\section{Physical Environment}

The physical environment was defined according to attributes of convenience stores, supermarkets and other grocery, fast food restaurants and fitness/recreational facilities and supplied by Geolytics. The level of spatial analysis and data source are presented in Table 4-3. Physical data of interest was sorted and retrieved according to

Table 4-1. Community Demographic Characteristics

\begin{tabular}{lr}
\hline Characteristics & N (\%) \\
\hline Counties & $53(96)$ \\
Zip Codes & $730(88)$ \\
Schools $\left(5^{\text {th }}\right.$ grade class) & $315(80)$ \\
Students $\left(5^{\text {th }}\right.$ graders $)$ & $12,194(30)$ \\
\hline
\end{tabular}


Table 4-2. Socioeconomic Environmental Variables, Data Level, and Source

\begin{tabular}{|c|c|c|}
\hline Socioeconomic & Level & Source \\
\hline $\begin{array}{l}\text { Total Population } 25+\text { Years } \\
\text { with High School Diploma or } \\
\text { Higher. }\end{array}$ & $\begin{array}{l}\text { Zip Code and } \\
\text { County }\end{array}$ & $\begin{array}{l}\text { Geolytics: US Census (2007 } \\
\& 2008 \text { estimates) }\end{array}$ \\
\hline Median Household Income & $\begin{array}{l}\text { Zip Code and } \\
\text { County }\end{array}$ & $\begin{array}{l}\text { Geolytics: US Census } \\
\text { (2007 \& } 2008 \text { estimates) }\end{array}$ \\
\hline $\begin{array}{l}\text { Total } 5^{\text {th }} \text { Grade Student } \\
\text { Population Classified as Low } \\
\text { Socioeconomic Status (Free or } \\
\text { Reduced Lunch Eligibility) }\end{array}$ & $\begin{array}{l}\text { School and } \\
\text { County }\end{array}$ & $\begin{array}{l}\text { WV Board of Education } \\
(2007 \& 2008 \text { academic } \\
\text { years) }\end{array}$ \\
\hline Total Violent Crime & County & $\begin{array}{l}\text { WV State Police }(2007 \& \\
\text { 2008) }\end{array}$ \\
\hline
\end{tabular}

Table 4-3. Physical Environmental Variables, Data Level, and Source

\begin{tabular}{|c|c|c|}
\hline Physical & Spatial Level & Source \\
\hline $\begin{array}{l}\text { Fast Food Establishments } \\
\text { (NAICS code 722211) }\end{array}$ & $\begin{array}{l}\text { Zip Code and } \\
\text { County }\end{array}$ & $\begin{array}{l}\text { Geolytics: US Census } \\
\text { (2008): WV County } \\
\text { Business Patterns }\end{array}$ \\
\hline $\begin{array}{l}\text { Convenience Store } \\
\text { Establishments } \\
\text { (NAICS code } 445120)\end{array}$ & $\begin{array}{l}\text { Zip Code and } \\
\text { County }\end{array}$ & $\begin{array}{l}\text { Geolytics: US Census } \\
\text { (2008): WV County } \\
\text { Business Patterns }\end{array}$ \\
\hline $\begin{array}{l}\text { Supermarket and Other } \\
\text { Grocery Establishments } \\
\text { (NAICS code } 445110 \text { ) }\end{array}$ & $\begin{array}{l}\text { Zip Code and } \\
\text { County }\end{array}$ & $\begin{array}{l}\text { Geolytics: US Census } \\
\text { (2008): WV County } \\
\text { Business Patterns }\end{array}$ \\
\hline $\begin{array}{l}\text { Fruit and Vegetable Markets } \\
\text { (NAICS code } 445230 \text { ) }\end{array}$ & $\begin{array}{l}\text { Zip Code and } \\
\text { County }\end{array}$ & $\begin{array}{l}\text { Geolytics: US Census } \\
\text { (2008): WV County } \\
\text { Business Patterns }\end{array}$ \\
\hline $\begin{array}{l}\text { Fitness and Recreational } \\
\text { Sports Centers (NAICS code } \\
713940 \text { ) }\end{array}$ & $\begin{array}{l}\text { Zip Code and } \\
\text { County }\end{array}$ & $\begin{array}{l}\text { Geolytics: US Census } \\
\text { (2008): WV County } \\
\text { Business Patterns }\end{array}$ \\
\hline
\end{tabular}


the 6 digit North American Industry Classification System (NAICS) code: 722211 limited-service restaurants; 722110 full service restaurants; 445120, convenience stores; 445110, supermarkets; 445230, fruit and vegetable markets; and 713940, fitness recreation and sports (U.S. Census Bureau [Data file], 2007). An aggregate total of NAICS data at the zip code and county level for each 6-digit level was derived. NAICS data at the zip code level for the years 2007 and 2008 were used for spatial mapping.

\section{Personal Environment}

Personal environment variables of interest included family history of diabetes, family history of heart disease, and child fitness. Parents self-reported the presence or absence of heart disease and disease as yes, no, or do not know. Family history data were derived from the CARDIAC Project and examined at the zip code, school, and/or county level. Child fitness was derived from WV FITNESSGRAM ${ }^{\circledR}$ data. Fifth grade students were categorized as being in the healthy fitness zone for aerobic fitness or as needing improvement based upon age-and gender - criterion standards. Fitness data was examined as the school level (percentage of total $5^{\text {th }}$ grade class achieving healthy fitness zone) but mapped at the county level. See Table 4-4.

\section{Body Mass Index}

Anthropometric measurement of height and weight were obtained as part of the CARDIAC project. See Equation 3-1.

$$
\mathrm{BMI}=\text { weight in } \mathrm{kg} /\left(\text { height in } \mathrm{cm}^{2} * 10,000\right)
$$

BMI percentiles were determined based on age and gender-specific growth chart recommendations by the CDC (Centers for Disease Control and Prevention [CDC], 2000). Fifth graders with a BMI $\geq 85^{\text {th }}$ percentile were classified as overweight; while those with a BMI $\geq 95^{\text {th }}$ percentile were considered obese (Barlow \& Dietz, 1998; Centers for Disease Control and Prevention [CDC], 2000; Dietz \& Bellizi, 1999).

Table 4-4. Personal Environmental Variables, Data Level, and Source

\begin{tabular}{lll}
\hline Personal Environment & Spatial Level & Source \\
\hline Family History of Diabetes & Zip Code & CARDIAC Project \\
Family History of Heart Disease & Zip Code & CARDIAC Project \\
& & \\
Aerobic Fitness & School \& County & $\begin{array}{l}\text { WV Board of Education: } \\
\end{array}$ \\
\hline
\end{tabular}




\title{
DATA MANAGEMENT
}

Data for spatial analysis were stored on Microsoft Excel spreadsheets. ArcGIS 9.3; a geodatabase, was utilized to compile the geographic data.

\section{SPATIAL MAPPING PLAN}

Individual subject data (BMI, family history, zip code of residency, school of attendance, and county for which the school resided) was joined to aggregated data (socioeconomic status, crime, supermarkets and other grocery establishments, convenience stores, fast food facilities, fruit/vegetable markets, sports/recreational centers, and aerobic fitness) using a geographical indicator: zip code, school, and/or county. Zip code and county polygons were downloaded from Environmental Systems Research Institute (ESRI) and utilized as base maps for which data were joined. See Figure 4-1.

Polygons were formulated into choropleth maps (colored coded theme maps) and point density for variables of interest. Contrasting map colors were utilized to differentiate variations in values of independent variables (socioeconomic, physical, and personal) and to visually represent the data. BMI percentile values equal to or greater than the $85^{\text {th }}$ and $95^{\text {th }}$ percentiles were mapped utilizing dot density. Each dot on the map represented a single case/occurrence or a defined number of cases/occurrences per zip code area or county and fixed placement was utilized.

To discern the percentage of total $5^{\text {th }}$ grade enrollment represented in the study, subject participation was mapped into choropleth and the distribution inspected. The study sample and BMI percentile values were than mapped using dot density to allow for visual inspection of the statewide distribution of the sample at the zip code level. Choropleth maps layered with dot density were utilized to assess the geographic distribution of attributes (socioeconomic, physical, and personal) in relation to the distribution of overweight and obesity.

\section{FINDINGS}

\begin{abstract}
Aim Three
To assess the geographic distribution of attributes (socioeconomic, physical, and personal) in relation to overweight $\left(\mathrm{BMI} \geq 85^{\text {th }}\right.$ percentile) and obesity (BMI $\geq 95^{\text {th }}$ percentile) among WV $5^{\text {th }}$ graders the distribution of the entire study sample was mapped and examined in comparison to the distribution of overweight and obese children. Choropheth maps were overlayed with point density of BMI percentile values equal to or greater than the $85^{\text {th }}$ and $95^{\text {th }}$ to allow for examination of the association between socioeconomic, physical, and personal attributes and BMI percentile events.
\end{abstract}






Figure 4-1. Spatial Analysis Plan 
Study sample. To discern the total percentage of $5^{\text {th }}$ graders represented in the study (in comparison to total county enrollment) choropleth maps were utilized. Of the 53 counties, examined nine counties had a sample population that represented $51 \%$ or more of the total $5^{\text {th }}$ grade enrollment for that county; in total thirty-seven counties had a $5^{\text {th }}$ grade participation rate greater than $31 \%$. Only five counties had a participation rate below $30 \%$ with the lowest being at 13\%. See Figure A-1. To visually inspect the spatial distribution of the study sample at the zip code level, subjects were mapped using point density; whereas, 1 dot $=1 \mathrm{BMI}$ percentile event. Findings indicate that the study sample was evenly distributed across the state of WV. See Figure 4-2.

Distribution of overweight and obese $5^{\text {th }}$ grade children. A visual inspection of the distribution of $5^{\text {th }}$ grade children was done; whereas, 1 dot $=1 \mathrm{BMI}$ event equal to or greater than the $85^{\text {th }}$ percentile and $1 \mathrm{dot}=1 \mathrm{BMI}$ event equal to or greater than the $95^{\text {th }}$ percentile revealed clusters of overweight (Figure 4-3) and obesity (Figure 4-4) in regions throughout the state. Spatial patterns indicated that obesity tended to be lowest in the mid and east central parts of WV relative to other regions. Findings support the hypothesis that the geographic distribution of children with a BMI equal to or greater than the $85^{\text {th }}$ and $95^{\text {th }}$ percentile is disproportionately dispersed across the state.

\section{Socioeconomic Environment}

To visually represent the data, contrasting map colors (choropleth maps) were utilized to differentiate variations in values of socioeconomic attributes (education, income, low socioeconomic status, and crime). Choropheth maps were overlayed with point density of BMI percentile values equal to or greater than the $85^{\text {th }}$ and $95^{\text {th }}$ to allow for examination of the association between socioeconomic attributes and BMI percentile events. Each dot on the map represented a single case/occurrence or a defined number of cases/occurrences per zip code area or county.

Education. The percentage of the population age 25 years or greater with a high school diploma or more varied across the state with zip code regions ranging from $35 \%$ to $93 \%$. The lowest percentages (less than $60 \%$ of the population) of high school graduates were distributed mainly in the south/south western zip code regions of the state; as well as east central. Findings support the hypothesis that levels of education are disproportionately distributed across the state of WV.

A visual inspection of the distribution of overweight and obese $5^{\text {th }}$ grade children was done; whereas, $1 \mathrm{dot}=1 \mathrm{BMI}$ event equal to or greater than the $85^{\text {th }}$ or $95^{\text {th }}$ percentile at the zip code level, revealed a greater intensity of occurrence in association to the distribution of low levels of education most notably in the southern and south western regions of the state. The majority of overweight (91\%) and obese (90\%) children lived in communities in which less than $75 \%$ of the population had a high school diploma. See Table 4-5. 




Figure 4-2. Spatial Distribution of Study Sample at the Zip Code Level

Note: 1 Dot $=1$ Child Sample Participant. 




Figure 4-3. Distribution of Overweight at the Zip Code Level

Note: 1 Dot $=1$ Child Sample Participant. 


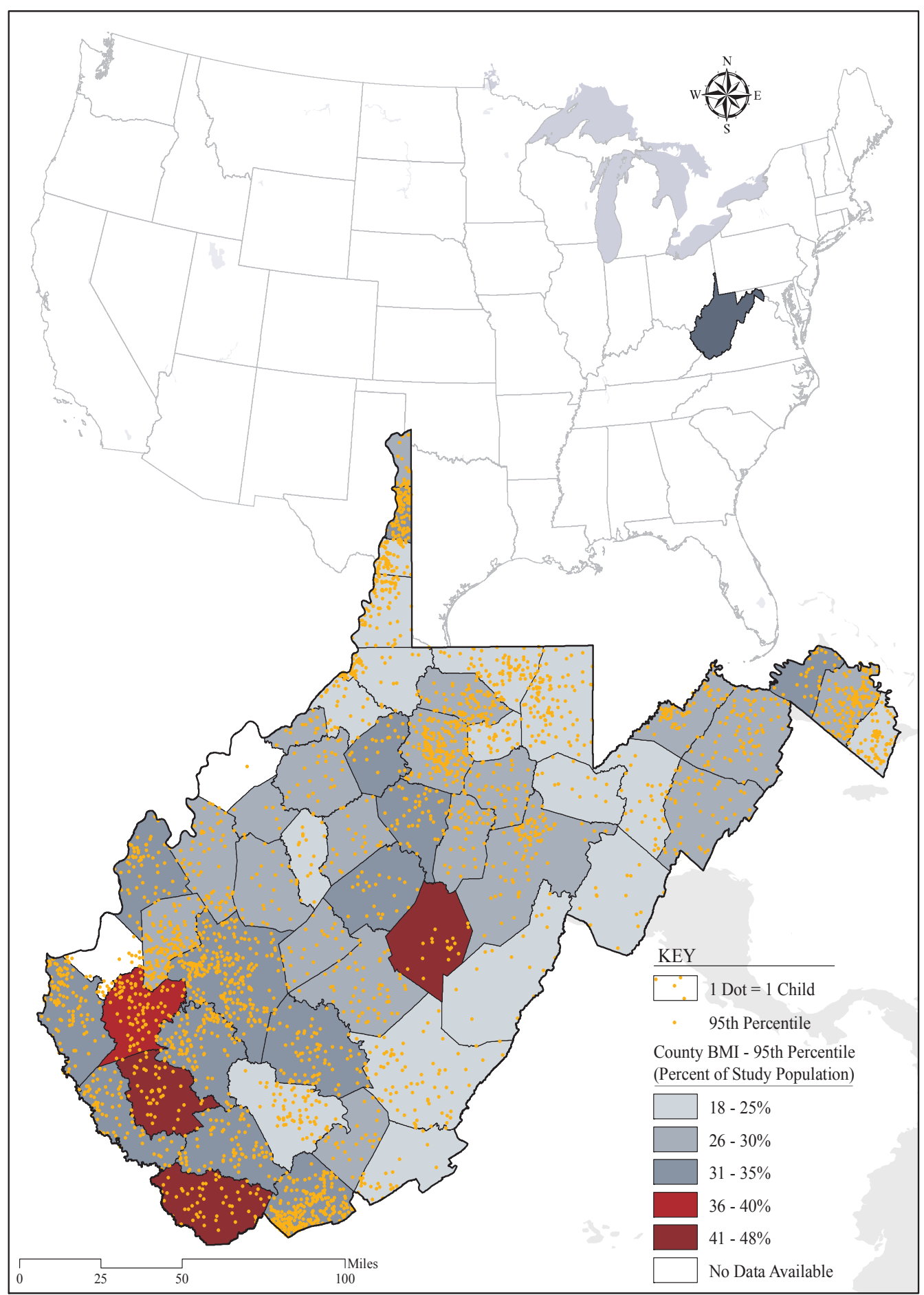

Figure 4-4. Distribution of Obese $5^{\text {th }}$ Graders at the Zip Code Level

Note: 1 Dot $=1$ Child Sample Participant. 
Table 4-5. Percentage of Overweight and Obese $5^{\text {th }}$ Graders Living in Communities Where Less than 75\% of the Population Aged 25 Years or Older Had a High School Diploma or Greater

\begin{tabular}{lll}
\hline BMI Percentile & $\begin{array}{l}\text { Less than 75\% of } \\
\text { Community Members } \\
\text { by Zip Code Had a } \\
\text { High School Degree } \\
\text { N (\%) }\end{array}$ & $\begin{array}{l}\text { Greater than 75\% of } \\
\text { Community } \\
\text { Members by Zip } \\
\text { Code Had a High } \\
\text { School Degree N (\%) }\end{array}$ \\
\hline $\begin{array}{l}\text { BMI Equal to or Greater than } \\
\text { the } 85^{\text {th }} \text { Percentile }(\mathrm{N}=5851)\end{array}$ & $5327(91)$ & $524(9)$ \\
$\begin{array}{l}\text { BMI Equal to or Greater than } \\
\text { the } 95^{\text {th }} \text { Percentile }(\mathrm{N}=3483)\end{array}$ & $3142(90)$ & $341(10)$ \\
\hline
\end{tabular}

Spatially, southern zip code regions had a higher percentage of overweight and obese $5^{\text {th }}$ graders relative to the percentage of the population 25 years or older without a high school diploma. However, such associations were not observed amongst other regions of the state exhibiting clusters of overweight or obese $5^{\text {th }}$ graders. Therefore, findings failed to support the hypothesis that overweight and obesity is spatially patterned in association to the distribution of socioeconomic environmental attribute of education. See Figures A-2 and A-3.

Low socioeconomic status. The percentage of $5^{\text {th }}$ grade children classified as low socioeconomic status ranged from 17 to $91 \%$ in the schools. Among overweight and obese children, $66-69 \%$ attended schools in which $50 \%$ or more of the $5^{\text {th }}$ grade population was defined as being low socioeconomic status; in other words, living in households with an annual income below $130 \%$ to $185 \%$ of the poverty line. See Table 4-6.

A visual inspection of the distribution of overweight and obese $5^{\text {th }}$ grade children was done; whereas, 1 dot $=10 \mathrm{BMI}$ events equal to or greater than the $85^{\text {th }}$ or $95^{\text {th }}$ percentile at the zip code level, revealed a greater intensity of occurrence in association to the distribution of low socioeconomic status most notably in the southern, west central, and eastern panhandle regions of the state. Zip code regions exhibiting the lowest socioeconomic status followed a similar pattern of distribution to that of BMI equal to or greater than the $85^{\text {th }}$ and $95^{\text {th }}$ percentiles; therefore, supporting the hypothesis that overweight and obesity is spatially patterned in association to the distribution of low socioeconomic status. See Figures 4-5 and A-4.

Income. Within the study sample, the distribution of income as compiled by Geolytics at the zip code level range from $\$ 233$ to $\$ 74,000$; in which, $83 \%$ of overweight and $86 \%$ of obese children lived in zip code regions with a median household income below the state median income of \$37,494 in 2007 and \$37,989 in 2008 (U.S. Census Bureau [Data file], 2010). See Table 4-7. 
Table 4-6. Percentage of Overweight and Obese $5^{\text {th }}$ Graders Attending Schools in Which $50 \%$ or More of the $5^{\text {th }}$ Grade Population Was Defined as Low Socioeconomic Status

\begin{tabular}{lll}
\hline BMI Percentile & $\begin{array}{l}\text { 50\% or More 5 } \\
\text { Grade School } \\
\text { Population Defined as } \\
\text { LSES (\%) }\end{array}$ & $\begin{array}{l}\text { Less than 50\% 5 }^{\text {th }} \\
\text { Grade School } \\
\text { Population Defined as } \\
\text { LSES (\%) }\end{array}$ \\
\hline $\begin{array}{l}\text { BMI Equal to or Greater than } \\
\text { the 85 }\end{array}$ & $3865(66)$ & $1987(34)$ \\
$\begin{array}{l}\text { BMI Equal to or Greater than } \\
\text { the 95 }\end{array}$ & $2393(69)$ & $1090(31)$ \\
\hline
\end{tabular}






Figure 4-5. Distribution of the Percentage of $5^{\text {th }}$ Grade Children Classified as Low Socioeconomic Status According to Free or Reduced Lunch Eligibility

Note: 1 Dot $=1$ Child Sample Participant. 
Table 4-7. Percentage of Overweight and Obese $5^{\text {th }}$ Graders Living in Zip Code Regions with Incomes below the State Median Household Income

\begin{tabular}{lll}
\hline BMI Percentile & $\begin{array}{l}\text { Income Less than } \\
\mathbf{\$ 3 7 , 0 0 0} \text { for Years } \\
\mathbf{2 0 0 7} \& \mathbf{2 0 0 8} \text { at the } \\
\text { Zip Code Level }\end{array}$ & $\begin{array}{l}\text { Income Greater than } \\
\mathbf{\$ 3 7 , 0 0 0} \text { for Years } \\
\mathbf{2 0 0 7} \boldsymbol{\&} \mathbf{2 0 0 8} \text { at the Zip } \\
\text { Code Level }\end{array}$ \\
\hline $\begin{array}{l}\text { BMI Equal to or Greater than } \\
\text { the 85 }\end{array}$ & $4845(83)$ & $1006(17)$ \\
$\begin{array}{l}\text { BMI Equal to or Greater than } \\
\text { the 95 }\end{array}$ & 3012 Percentile $(\mathrm{N}=3483)$ & \\
\hline
\end{tabular}

Pockets of low income; however, were observed throughout all regions of the state failing to support the proposed hypothesis that income was disproportionately distributed across the state of WV. See Figures A-5 and A-6.

Crime. Visual inspection of the distribution of violent crime revealed a greater intensity of violent crime across regions of the state. Fifteen counties exhibited county violent crime rates greater than 6 per 100 persons (see Table 4-8). The central region of the state demonstrated the lowest occurrence. Findings support the proposed hypothesis that the socioeconomic attribute violent crime is disproportionately distributed across the state of WV.

Violent crime rates at the county level demonstrated a similar pattern of distribution to that of overweight and obesity. Regions with the highest percentages of overweight or obese $5^{\text {th }}$ graders were clustered in regions with higher rates of violent crime. Obesity demonstrated the strongest spatial relationship to violent crime. Findings supported the hypothesis that overweight and obesity is spatially pattered in association to the distribution of socioeconomic environmental attribute crime. See Figure 4-6.

\section{Physical Environment}

The physical environment was examined according to the distribution of: supermarkets, convenience stores; fruit and vegetable markets; and fitness recreation and sport establishments. To visually represent the data, contrasting map colors (choropleth maps) were utilized to differentiate variations in values of the physical environment (supermarkets and other grocery stores, convenience store, fruit and vegetable markets, recreational facilities and fast food). Choropheth maps were overlayed with point density of BMI percentile values equal to or greater than the $85^{\text {th }}$ and $95^{\text {th }}$ to allow for examination of the association between socioeconomic attributes and BMI percentile events. Each dot on the map represented a single case/occurrence or a defined number of cases/occurrences per zip code area or county. 
Table 4-8. Percentage of Overweight and Obese $5^{\text {th }}$ Graders Living in Counties with a Crime Rate Greater than 6 per 100 Persons

\begin{tabular}{lll}
\hline BMI Percentile & $\begin{array}{l}\text { County Crime Rate }> \\
\text { than } 6 \text { per } \mathbf{1 0 0} \text { Persons }(\%)\end{array}$ & $\begin{array}{l}\text { County Crime Rate }<\text { than } \\
\mathbf{6} \text { per 100 Persons (\%) }\end{array}$ \\
\hline $\begin{array}{l}\text { BMI } \geq 85^{\text {th }} \text { Percentile } \\
(\mathrm{N}=5851)\end{array}$ & $2797(48)$ & $3054(52)$ \\
$\mathrm{BMI} \geq 95^{\text {th }}$ Percentile & $1641(47)$ & $1842(53)$ \\
$(\mathrm{N}=3483)$ & & \\
\hline
\end{tabular}




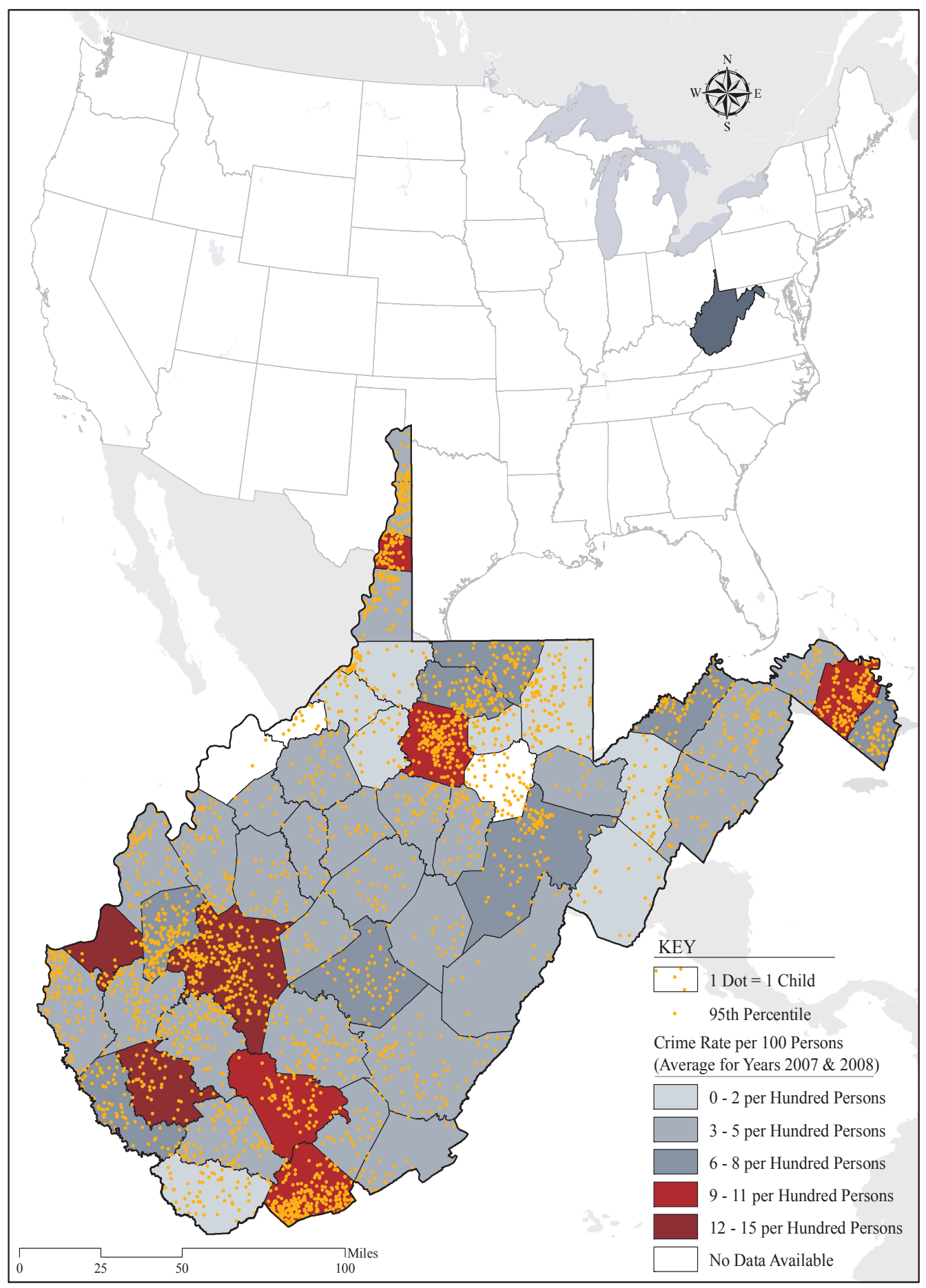

Figure 4-6. Distribution of Violent Crime at the County Level and Obese $5^{\text {th }}$ Grade Children

Note: 1 Dot $=1$ Child Sample Participant. 
Supermarkets and other grocery. A visual inspection of the spatial distribution of supermarkets identified pockets of zip code regions with a higher density of no supermarkets or 1-4 supermarkets per zip code. Few zip code regions had greater than five supermarkets with only one zip code having greater than thirteen. Among overweight/obese children, 33\% (overweight) and 32\% (obese) failed to have a supermarket and other grocery store within their zip code region. See Table 4-9.

A visual inspection of the distribution of overweight and obese $5^{\text {th }}$ grade children whereas; $1 \mathrm{dot}=10 \mathrm{BMI}$ events equal to or greater than the $85^{\text {th }}$ or $95^{\text {th }}$ percentile at the zip code level, revealed a greater intensity of occurrence in association to the distribution of supermarkets in the south western regions of the state. Communities with the least number of supermarkets followed a similar pattern of distribution to that of BMI equal to or greater than the $85^{\text {th }}$ and $95^{\text {th }}$ percentiles excluding in the northern region of the state. See Figures A-7 and A-8.

Convenience stores. A visual inspection of the spatial distribution of convenience stores identified pockets of zip code regions with no convenience stores per zip code. Few zip code regions had greater than three convenience stores. Findings supported the hypothesis that the physical environement attribute of convenience stores is disproportionately distributed across the state of WV.

A visual inspection of the distribution of overweight and obese $5^{\text {th }}$ grade children whereas; 1 dot $=10 \mathrm{BMI}$ events equal to or greater than the $85^{\text {th }}$ or $95^{\text {th }}$ percentile at the zip code level, revealed a greater intensity of occurrence in association to the distribution of convenience stores. Sixty-three percent of overweight and sixty-two percent of obese children lived in zip code regions without convenience stores (see Table 4-10). Statewide overweight and obese $5^{\text {th }}$ graders were less likely to have a grocery store within their zip code

Communities with the least number of convenience stores followed a similar pattern of distribution to that of BMI equal to or greater than the $85^{\text {th }}$ and $95^{\text {th }}$ percentiles; supporting the hypothesis that overweight and obesity is spatially patterned in association to the distribution of physical environmental attributes. See Figures A-10 and A-11.

Table 4-9. Percentage of Overweight and Obese $5^{\text {th }}$ Graders Living in Zip Code Regions with No Grocery Stores

\begin{tabular}{lll}
\hline BMI Percentile & $\begin{array}{l}\text { No Supermarkets or } \\
\text { Other Grocery }(\%)\end{array}$ & $\begin{array}{l}\text { No Supermarkets or } \\
\text { Other Grocery (\%) }\end{array}$ \\
\hline $\begin{array}{l}\mathrm{BMI} \geq 85^{\text {th }} \text { Percentile } \\
(\mathrm{N}=5851)\end{array}$ & $1902(33)$ & $3949(67)$ \\
$\mathrm{BMI} \geq 95^{\text {th }}$ Percentile & $1113(32)$ & $2370(68)$ \\
$(\mathrm{N}=3483)$ & & \\
\hline
\end{tabular}


Table 4-10. Percentage of Overweight and Obese $5^{\text {th }}$ Graders Living in Zip Code Regions with No Convenience Stores

\begin{tabular}{lll}
\hline BMI Percentile & $\begin{array}{l}\text { No Convenience } \\
\text { Stores (\%) }\end{array}$ & $\begin{array}{l}\text { Greater than 1 } \\
\text { Convenience Store (\%) }\end{array}$ \\
\hline $\begin{array}{l}\text { BMI } \geq 85^{\text {th }} \text { Percentile } \\
(\mathrm{N}=5851)\end{array}$ & $3695(63)$ & $2156(37)$ \\
& & \\
BMI $\geq 95^{\text {th }}$ Percentile & $2168(62)$ & $1315(38)$ \\
$(\mathrm{N}=3483)$ & & \\
\hline
\end{tabular}

Fast food restaurants. Visual inspection of the distribution of fast food restaurants revealed statewide distribution with clusters of zip code regions containing 14-54 facilities per zip code region. A visual inspection of the distribution of overweight and obese $5^{\text {th }}$ grade children whereas; 1 dot $=10$ BMI events equal to or greater than the $85^{\text {th }}$ or $95^{\text {th }}$ percentile at the zip code level, revealed a greater intensity of occurrence in association to the distribution of fast food facilities. Among the study sample, $66 \%$ of overweight/obese children lived in zip code regions with at least one fast food facility. See Table 4-11.

Zip code regions with the greatest number of fast food facilities followed a similar pattern of distribution to that of BMI equal to or greater than the $85^{\text {th }}$ and $95^{\text {th }}$ percentiles; supporting the hypothesis that overweight and obesity is spatially patterned in association to the distribution of physical environmental attributes. See Figures 4-7 and A-12.

Fruit and vegetable markets. Visual inspection revealed a sparse distribution of fruit and vegetable markets statewide with the majority of communities at the zip code level lacking access to fruit and vegetable markets. A visual inspection of the distribution of overweight and obese $5^{\text {th }}$ grade children was done; whereas, $1 \mathrm{dot}=10$ BMI events equal to or greater than the $85^{\text {th }}$ or $95^{\text {th }}$ percentile at the zip code level, failed to support the hypothesis that overweight and obesity were spatially patterned in association to zip code regions with the least number of fruit and vegetable markets. The sparse distribution of fruit and vegetable markets was observed in areas with a low prevalence of overweight/non-obese children, as well as in areas with a high prevalence of overweight an obese youth. Findings failed to support the propsed hypothesis. See Figures A-11 and A-12.

Fitness and recreational facilities. Visual inspection revealed a sparse distribution of fitness and recreational facilities statewide with the majority of communities at the zip code level lacking a facility. A visual inspection of the distribution of overweight and obese $5^{\text {th }}$ grade children, whereas; 1 dot $=10 \mathrm{BMI}$ events equal to or greater than the $85^{\text {th }}$ or $95^{\text {th }}$ percentile at the zip code level, failed to support the hypothesis that overweight and obesity were spatially patterned in association to zip code regions with the least fitness and recreational facilities. The sparse distribution of 
Table 4-11. Percentage of Overweight and Obese $5^{\text {th }}$ Graders Living in Zip Code Regions with One or More Fast Food Facilities

\begin{tabular}{lll}
\hline BMI Percentile & $\begin{array}{l}\text { Greater than 1 Fast } \\
\text { Food Facility }(\%)\end{array}$ & $\begin{array}{l}\text { No Fast Food } \\
\text { Facilities }(\%)\end{array}$ \\
\hline $\begin{array}{l}\mathrm{BMI} \geq 85^{\text {th }} \text { Percentile } \\
(\mathrm{N}=5851)\end{array}$ & $3858(66)$ & $1993(34)$ \\
& & $1183(34)$ \\
$\mathrm{BMI} \geq 95^{\text {th }}$ Percentile & $2300(66)$ & \\
$(\mathrm{N}=3483)$ & & \\
\hline
\end{tabular}




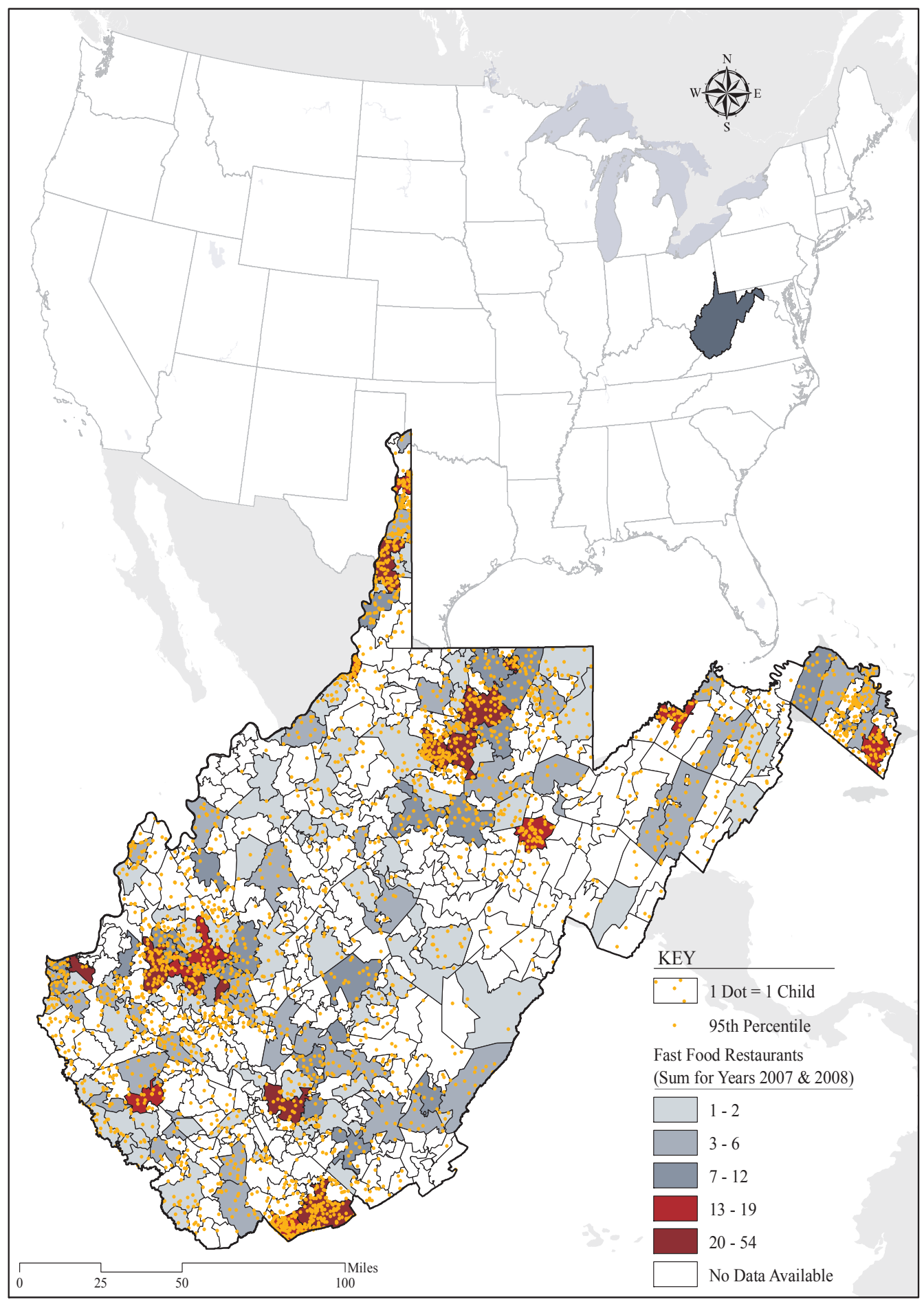

Figure 4-7. Distribution of Fast Food Facilities at the Zip Code Level and Obesity

Note: 1 Dot $=1$ Child Sample Participant. 
recreational facilities was observed among communities with a low prevalence of overweight and obese children, as well as areas where there were a high prevalence of obese and overweight youth Findings failed to support the proposed hypothesis that overweight and obesity is spatially associated with the distribution or lack thereof of recreational facilities. See Figures A-13 and A-14.

\section{Personal Environment}

To visually represent the data contrasting map colors (choropleth maps) were utilized to differentiate variations in values of personal attributes (family history of heart disease, family history of diabetes, and child fitness). Choropheth maps were overlayed with point density of BMI percentile values equal to or greater than the $85^{\text {th }}$ and $95^{\text {th }}$ to allow for examination of the association between socioeconomic attributes and BMI percentile events. Each dot on the map represented a single case/occurrence or a defined number of cases/occurrences per zip code area or county.

Family history. A visual inspection of the distribution of family history of heart disease and/or diabetes indicates a greater intensity of occurrence in some regions of the state. Among overweight children, $32 \%$ reported a family history of heart disease; whereas, $62 \%$ reported a family history of diabetes. Thirty-two percent of obese children reported a family history of heart disease and 54\% reported a family history of diabetes. See Tables 4-12 and 4-13. The pattern of distribution is similar to those observed for overweight and obesity. See Figures 4-8 and 4-9 and Figures A-15 and A-16.

Aerobic fitness. Forty percent of overweight and $42 \%$ of obese children attended schools in which less than $70 \%$ of the $5^{\text {th }}$ grade population failed to be aerobic fit. Several schools failed to report data for both years with some $5^{\text {th }}$ grade classes lacking data. See Table 4-14. As a result, conclusions regarding the distribution of aerobic fitness in association to overweight or obesity distribution could not be made. See Figures A-17 and A-18. Findings failed to support the hypothesis that overweight and obesity is spatially patterned in association to the distribution of the physical environmental attribute of aerobic fitness.

\section{SPATIAL CHALLENGES AND LIMITATIONS}

Geocoding data at the zip code level proved to be problematic initially. Several children shared the same zip code but attended different schools. Therefore, to adequately describe the individual child's low socioeconomic environment and the percentage of $5^{\text {th }}$ graders classified as aerobic fit - "healthy zone" each individual child zip code had to be matched to the child's school of attendance which in turn was matched to the county the school belonged to. This allowed different levels of data to be matched to each individual child zip code for the purpose of describing the individual child's environment. 
Table 4-12. Percentage of Overweight and Obese $5^{\text {th }}$ Graders Reporting a Family History of Heart Disease

\begin{tabular}{lll}
\hline BMI Percentile & $\begin{array}{l}\text { Family History of } \\
\text { Heart Disease }(\%)\end{array}$ & $\begin{array}{l}\text { No Family History of } \\
\text { Heart Disease (\%) }\end{array}$ \\
\hline $\begin{array}{l}\mathrm{BMI} \geq 85^{\text {th }} \text { Percentile } \\
(\mathrm{N}=5851)\end{array}$ & $1842(31)$ & $4009(69)$ \\
& & \\
$\mathrm{BMI} \geq 95^{\text {th }}$ Percentile & $1134(32)$ & $2349(68)$ \\
$(\mathrm{N}=3483)$ & & \\
\hline
\end{tabular}

Table 4-13. Percentage of Overweight and Obese $5^{\text {th }}$ Graders Reporting a Family History of Diabetes

\begin{tabular}{lll}
\hline BMI Percentile & $\begin{array}{l}\text { Family History of } \\
\text { Diabetes (\%) }\end{array}$ & $\begin{array}{l}\text { No Family History of } \\
\text { Diabetes (\%) }\end{array}$ \\
\hline $\begin{array}{l}\mathrm{BMI} \geq 85^{\text {th }} \text { Percentile } \\
(\mathrm{N}=5851)\end{array}$ & $062(52)$ & $789(48)$ \\
$\mathrm{BMI} \geq 95^{\text {th }}$ Percentile & $896(54)$ & $587(46)$ \\
$(\mathrm{N}=3483)$ & & \\
\hline
\end{tabular}




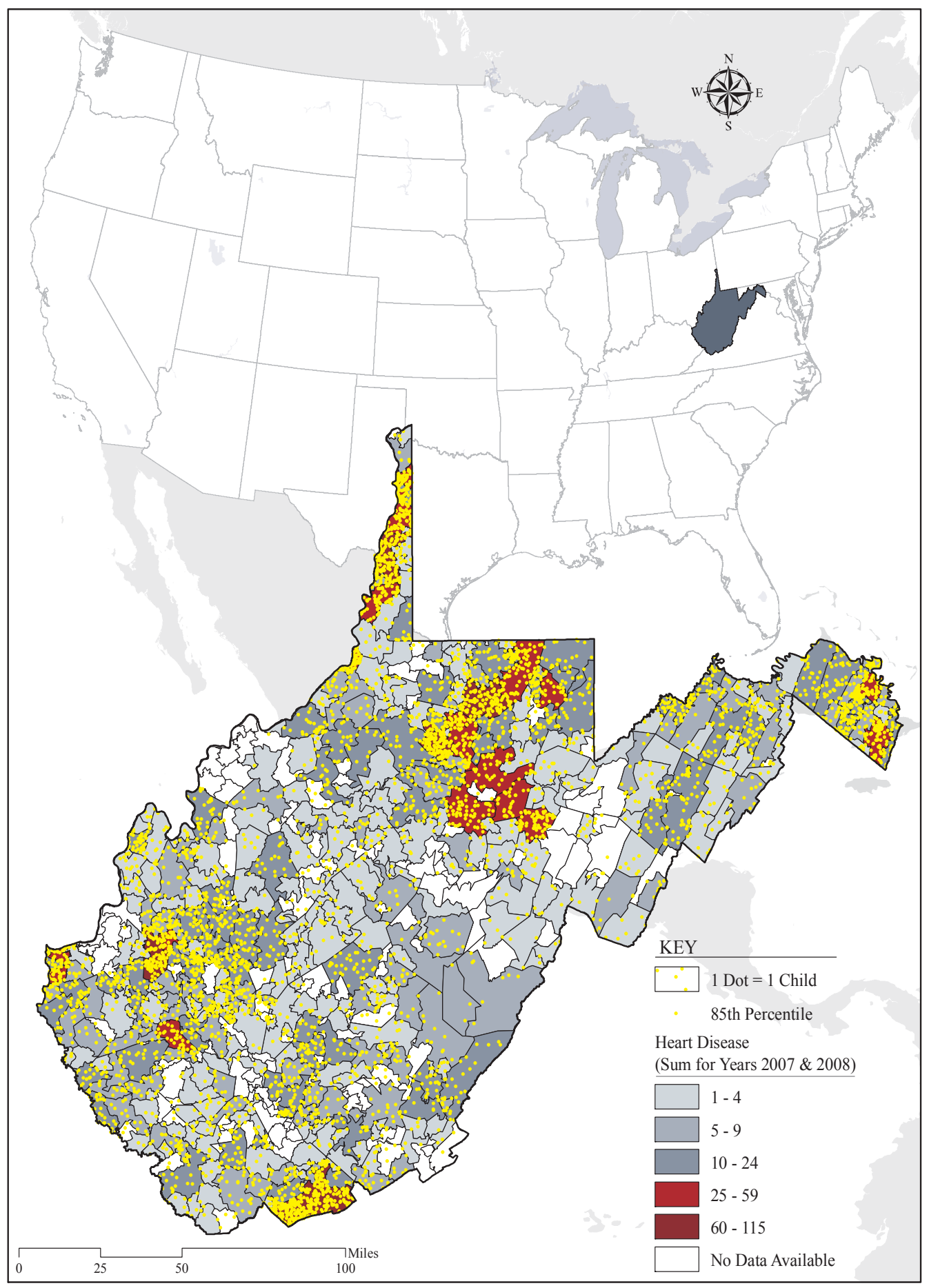

Figure 4-8. Distribution of Child's Family History of Heart Disease at the Child's Zip Code Level

Note: 1 Dot $=1$ Child Sample Participant. 




Figure 4-9. Distribution of Child's Family History of Diabetes at the Child's Zip Code Level

Note: 1 Dot $=1$ Child Sample Participant. 
Table 4-14. Percentage of Overweight and Obese $5^{\text {th }}$ Graders Attending Schools Where $70 \%$ or More of $5^{\text {th }}$ Graders Were in the Healthy Zone for Aerobic Fitness

\begin{tabular}{lll}
\hline BMI Percentile & $\begin{array}{l}\text { More than 70\% of } \\
\mathbf{5}^{\text {th }} \text { Graders } \\
\text { Aerobic Fitness (\%) }\end{array}$ & $\begin{array}{l}\text { Less than 70\% of } \\
\mathbf{5}^{\text {th }} \text { Graders } \\
\text { Aerobic Fitness (\%) }\end{array}$ \\
\hline $\begin{array}{l}\mathrm{BMI} \geq 85^{\text {th }} \text { Percentile } \\
(\mathrm{N}=5851)\end{array}$ & $2370(41)$ & $3481(59)$ \\
$\mathrm{BMI} \geq 95^{\text {th }}$ Percentile & $1476(42)$ & $2007(58)$ \\
$(\mathrm{N}=3483)$ & & \\
\hline
\end{tabular}

The enumeration units of variables of interest within zip code regions had a great deal of variation, most notably amongst rural and urban regions, resulting in cells with small sample sizes. Therefore, the dot density units were adjusted / set to allow visualization of patterns in both urban and rural regions and zip code regions with small sample sizes. A disadvantage was that the more populated regions formed a solid fill of indiscernible dots.

Dots used for density were randomly placed within zip code regions due to the nature of the GIS software utilized. Therefore, dot locations displayed within each zip code unit were approximate in regards to location. Additionally, land cover data was not utilized to discern location of geographical barriers influencing habitability of a region.

The purpose of this exploratory study was to visually inspect the spatial arrangement of overweight, obesity, and associated risk factors throughout the state of WV; therefore, the significance of the distribution and identified "clusters" were not examined statistically using GIS software. Findings can only attest to the relative magnitude of the problem.

Proximity between subject and physical environmental attributes (supermarket and other grocery, convenience stores, fruit and vegetable markets, recreation facilities, and fast food establishments) was not examined. Access was discerned according to the presence or absence of attributes within zip code regions and adjacent zip code communities.

The use of NACIS classification codes according to the U.S. Economic Census Bureau is not without controversy. How variables of the physical environment; supermarket and other grocery stores, convenience stores, fast food restaurants, fruit and vegetable markets, and fitness and recreational facilities, were defined may result in over or under estimations. Data gathered by Geolytics was based on census estimates for the years 2007 and 2008 . 


\section{DISCUSSION}

Attributes associated with overweight/obesity development appear to be disproportionality distributed across the state but spatially grouped. Findings indicate that many WV children are at an increased risk for overweight or obesity development due to the cumulative impact of attributes of the socioeconomic, physical, and personal environment. However, the cumulative impact of risk appears to disproportionately impact some regions of the state greater than others. Zip code regions impacted by the greatest number of risk factors were disproportionately distributed in the southern and southwestern regions of the state.

Spatially, overweight and obese children were more likely to have a family history of heart disease or diabetes and attend schools with a high percentage of low socioeconomic status classmates. Multivariate regression also indicated that family history and low socioeconomic status had a significant impact on the prevalence of overweight and obesity. Whereas, the number of $5^{\text {th }}$ grade children reporting a family history of heart disease or diabetes was positively and significantly correlated with overweight or obesity, as was the percentage of $5^{\text {th }}$ grade children eligible for free or reduced lunch.

Education was spatially associated with overweight and obesity in the southern zip code communities of the state but not the northern. Spatially southern zip code regions had a higher percentage of obese fifth graders and relatively lower levels of education. The northern region of the state also demonstrated a high concentration of obese children yet demonstrated amongst the highest percentages of individuals over the age of 25 with a high school diploma or greater. Multivariate binary regression indicated that educational level had a significant impact on the prevalence of obesity; whereas, the number of residents with at least a high school diploma was negatively and significantly correlated with obesity. However, such a relationship was not observed in children classified as overweight. Findings indicate that although statistically significant in association to obesity education may be spatially auto correlated with other environmental risk factors.

Crime was disproportionately distributed but spatially associated with overweight and obesity. Multivariate binary regression also indicated that county crime rate had a significant impact on obesity. Findings indicated that crime was positively and significantly associated with obesity. A visual inspection of crime and low socioeconomic status indicated similar distribution patterns signifying that crime may be an environmental element that when combined with poverty increases a child's risk for obesity. According to Wilson \& Kelling (1982) poverty within one given community may influence personal crime rates of nearby locations. Therefore, understanding the spatial distribution of crime in relation to poverty and the influence on obesity development is defensible.

Geographically, the distribution of fresh fruit and vegetable markets was sparse; indicating WV residents lack access. Such findings support previous research indicating 
that only $18.2 \%$ of WV students and $18.6 \%$ of WV adults regularly consume the recommended daily allowance of fruits and vegetables; ranking WV the $16^{\text {th }}$ state for the lowest fruit and vegetable consumption in school children and $4^{\text {th }}$ for adults (Trust for America's Health, 2011). Fruit and vegetable consumption is associated with the presence of supermarkets and supermarkets are more likely to be located in wealthier neighborhoods (Morland et al., 2002). Families who have easy access to affordable fruits and vegetables report higher levels of fruit and vegetable consumption (Sallis \& Glanz, 2006). Findings from this study indicate a lack of access to grocery facilities and an association between lack of access and income. Such findings are similar to previous reports by Halverson et al. (2004) and Amarasinghe and D'Souza (2010) indicating many WV communities do not have enough supermarket and other grocery stores. Univariate analysis of the number of supermarket /other grocery stores and fruit / vegetable markets found a significantly negative association. Thus, as the number of facilities increased, overweight and obesity decreased.

Gordon-Larsen et al. (2006) found that availability of physical activity facilities was associated with overweight patterns and that the inequality in availability contributed to decreased activity and an increase in overweight. Tucker et al. (2009) found that recreational opportunities and physical activity were positively associated; thus as recreational opportunities increased, physical activity increased. However, findings from this study indicate that the lack of access is a problem throughout the state; thus, inferences to the impact on overweight/obesity development are difficult to assess.

Regardless of the distribution of overweight and obese children, findings indicate the spatial distribution of supermarket / other grocery stores, fruit / vegetable markets, and recreational facilities appear to be unequally dispersed across the state. Spatial findings suggest that WV communities have pockets of "food deserts". According to Blanchard and Lyson (2006), food deserts are the result of physical and economic barriers to healthy food.

Findings from this study support earlier works documenting the geographic correlation between the number of and proximity to fast-food and the risk of obesity in children (Currie et al., 2010; Kipke et al., 2007; Kwate et al., 2009; Li et al., 2009; Powell et al., 2007). Within the state, the ratio of fast food to supermarket and other grocery was 3.5 to 1 . Across the state, there were 5.45 fast food facilities per 100 study participants vs. 1.5 supermarket and other grocery stores. Such findings are reflective of research by Schwartz \& Brownell (2005) which identified that over the last 35 years, the number of fast food establishments has doubled, whereas the number of supermarkets has declined by $15 \%$. Evidence from this investigation indicates that communities have greater access to fast food in comparison to supermarket and other grocery establishments; as well as fruit and vegetable markets. However, proximity to fast food and other physical attributes was not examined.

Results of spatial mapping indicate that WV youth are disproportionately at greater risk for obesity and obesity related consequences because of an obesogenic environment. As noted in the literature, obesity when combined with poor economic 
conditions has a greater impact upon quality life years. For example, obese adults (18years or older) can expect to live 47 quality-adjusted life-years; whereas obese adults living under the poverty line can expect to live 43 quality-adjusted life-years (Muennig, Lubetkin, Haomial, \& Franks, 2006).

\section{SIGNIFICANCE AND RECOMMENDATIONS}

Food inaccessibility; including lack of access to supermarket and other grocery stores and fruit and vegetable markets, appears to play a significant role in overweight and obesity occurrence. The spatial inaccessibility of food facilities warrants further investigation. Additionally, findings suggest that more attention should be placed upon urban planning and local food accessibility and availability.

Spatially clustering of overweight and obesity was observed, as well as clustering of identified risk factors. However, the significance of the clustering was not examined statistically. Findings from this study support the need for additional research to examine the significance of spatial clusters and associated risk factors. Additionally, the health consequences of childhood obesity would be of interest in light of the strong association between family history of heart disease and diabetes.

The distribution of overweight and obese children correlates with previous research that indicates that life expectancy in counties such as McDowell has fallen to third world levels. Children within these communities are expected to die at a younger age than their parents (West Virginians for Affordable Health Care [WVAHC], 2008). Findings from this study indicate that overweight and obesity may play a role in the decline in life expectancy in these WV communities.

Findings from this study may be useful in determining allocation of physical and financial resources to improve intervention strategies at the community level. Analysis of risk factors at smaller geographical increments beyond county mapping may prove useful in targeting communities at greatest risk. Additionally, cumulative findings of community level data may help develop obesity predictive models.

Findings from this study support the hypothesis that overweight and obesity are the consequence of the cumulative impact of environmental factors that are disproportionately distributed across the state. Findings warrant further examination of the spatial significance of overweight and obese children in the state of WV.

\section{CONCLUSION}

Findings from this study demonstrate the impact cumulative environmental risks have upon obesity development. Although the phenomenon of an obesogenic environment is not well understood within the literature, evidence from this study supports the theory that obesity risk factors are spatially but disproportionately dispersed in association with overweigh and obesity. The binary logistic regression analysis aided 
in identifying environmental attributes associated with increasing the odds of overweight and obesity; whereas, spatial mapping techniques allowed for a visual inspection of the distribution of overweight/obesity and associated risk factors.

Results of the binary logistic regression analysis of environmental attributes identified that free or reduced lunch eligibility significantly increased a child's odds for overweight or obesity; whereas, household income as defined on a global scale using census tract data was found to be insignificant. Such findings indicate that low socioeconomic status defined according to free or reduced lunch eligibility may be a stronger social predictor for negative health outcomes such as obesity. According to the criteria, children must reside in a household in which incomes are at or below $130 \%$ for free lunch and between 130 and 185\% for reduced lunch (WV Board of Education, 2010). Thus, the criterion is a reflection of poverty status. A positive family history or heart disease of diabetes, lack of aerobic fitness, and lack of access to convenience stores was also associated with an increased risk for overweight; whereas, low education, high prevalence of crime, and positive family history of heart disease or diabetes placed a child at greater risk for being obese.

Results of spatial mapping indicated that WV youth are disproportionately at greater risk for obesity and obesity related consequences because of an obesogenic environment. As noted in the literature, obesity when combined with poor economic conditions has a greater impact upon quality life years. For example, obese adults (18-yolds) can expect to live 47 quality-adjusted life-years; whereas, obese adults living under the poverty line can expect to live 43 quality-adjusted life-years (Muennig et al., 2006). The distribution of overweight and obese children correlates with previous research that indicates that life expectancy in counties such as McDowell has fallen to third world levels. Children within these communities are expected to die at a younger age than their parents (West Virginians for Affordable Health Care [WVAHC], 2008). Findings from this study indicate that overweight and obesity may play a role in the decline in life expectancy in these WV communities.

An examination of the spatial distribution of environmental attributes in association with overweight and obesity events support the view that the more obesogenic the environment, the stronger the influence towards obesity (Kirk et al., 2010; Papas et al., 2007). Communities with combined risks demonstrated more dense populations of overweight or obese children. Findings warrant further investigation to identify if there is any statistical significant association between overweight and obesity prevalence clusters at the zip code level and to define the significant association to environmental attributes; as well as to further delineate the observed geographically differences between the northern and southern regions of the state.

In conclusion, over the last 5 years WV has consistently ranked among the top 10 most obese states in the nation for both adults and children and residents experience among the highest rates of chronic conditions associated with obesity including diabetes and hypertension (Trust for America's Health, 2011). Obese children are more likely to become obese adults (Biro \& Wien, 2010; Serdula et al., 1993; Trust for America's Health, 2011) and are at increased risk of morbidity, mortality , (Flegal et al., 2010; 
Flegal et al., 2005; Fontaine et al., 2003; Franks et al., 2010) disability, and premature death due to cardiovascular disease (Freedman et al., 1999; Freedman et al., 2005; Mokdad et al., 2001; Must et al., 1999; Must \& Strauss, 1999) increased insulin resistance and type 2 diabetes in adulthood (Whitlock et al., 2005). Medical expenditures associated with overweight and obesity in WV were estimated to be \$668 million in 2008 and if current trends continue is estimated to be between $\$ 1,556-3,212$ million by 2018 (Thorpe, 2009). Therefore, findings from this study warrant urgent attention. Although this research does not address all the complexities involved in the development of childhood obesity, it does help us understand the spatial distribution of childhood obesity prevalence in WV and associated risk factors. Findings from this exploratory analysis may provide greater insight into the spatial epidemiology of childhood obesity, lead to modeling of environmental attributes that are predictive of childhood obesity, and aid in targeting at risk communities based on spatial distribution. 


\section{LIST OF REFERENCES}

Adkins, S., Sherwood, N. E., Story, M., \& Davis, M. (2004). Physical activity among African-American girls: The role of parents and the home environment. Obesity Research, 12(Supplement), 38S - 45S.

Albert, D. P., Gesler, W. M., \& Levergood, B. (2005). Spatial analysis, GIS and remote sensing applications in the health sciences. Retrieved January 12, 2011, from http://books.google.com/books?hl=en\&lr=\&id=Abj0LW4BlU0C\&oi=fnd\&pg=PP $1 \& \mathrm{dq}=$ Spatial + Analysis,+ GIS + and + Remote + Sensing + Applications + in + the + Heal th+Sciences:\&ots=VhCVBNg2EJ\&sig=3EzDS7DcUR1_22NCecCmb22ERxQ\#v =onepage \&q\&f=false.

Albert, D. P., Gesler, W. M., \& Whittie, P. S. (1995). Geographic information systems and health: An educational resource. Journal of Geography, 94(2), 350-356.

Amarasinghe, A., \& D'Souza, G. E. (2010). Economics of health, obesity and the built environment: Empirical investigations and policy implications. Saarbrucken, Germany: VDM Verlag.

Amarasinghe, A., D'Souza, G. E., Brown, C., \& Borisova, T. (2006). A spatial analysis of obesity in West Virginia. Retrieved January 10, 2010, from http://ideas.repec.org/p/ags/aaea06/21159.html.

American Heart Association. (2011). Understanding childhood obesity: 2011 Statistical sourcebook. Retrieved August 13, 2011, from https://www.heart.org/idc/groups/heartpublic/@wcm/@,fc/documents/downloadable/ucm_428180.pdf.

Armstrong, N., \& Van Mechelen, W. (2008). Paediatric exercise science and medicine (2nd ed.). Oxford: Oxford University Press.

Armstrong, N., \& Welsman, J. R. (2000). Development of aerobic fitness during childhood and adolescence. Pediatric Exercise Science, 12, 128-149.

Armstrong, N., \& Welsman, J. R. (2001). Peak oxygen uptake in relation to growth and maturation in 11-17 year olds. European Journal of Applied Physiology and Occupational Physiology, 85, 546-551.

Armstrong, N., Welsman, J. R., \& Kirby, B. J. (1998). Peak VO2 and maturation in 12-yr olds. Medicine and Science in Sports and Exercise, 30, 165-169.

Aronoff, S. (1989). Geographic information systems: A management perspective. Ottawa: WDL Publications.

Banquet, G., Van Praagh, E., \& Berthoin, S. (2003). Endurance training and aerobic fitness in young people. Sports Medicine, 33(15), 1127-1143. 
Bar-Or, O., \& Rowland, T. W. (2004). Pediatric exercise medicine: From physiologic principles to health care application. Champaign, IL: Human Kinetics Publishers.

Baranowski, T. (Ed.). (1996). Families and health action (Vol. 1). New York: Plenum.

Barlow, S. E., \& Dietz, W. H. (1998). Obesity evaluation and treatment: Expert committee recommendations. Pediatrics, 102(3), e29. doi:

10.1542/peds.102.3.e29.

Barlow, S. E., \& Expert Committee. (2007). Expert committee recommendations regarding the prevention, assessment, and treatment of child and adolescent overweight and obesity: Summary report. 120, S164-192. doi: 10.1542/peds.2007-2329C.

Baxter-Jones, A. D., Eisenmann, J. C., \& Sherar, L. B. (2005). Controlling for maturation in pediatric exercise science. Pediatric Exercise Science, 17, 18-30.

Beaulac, J., Kristjansson, E., \& Cummins, S. (2009). A systematic review of food deserts, 1966-2007. Preventing Chronic Disease, 6(3), A105. Retrieved January 12, 2011, from http://www.ncbi.nlm.nih.gov/pubmed/19527577.

Bergstrom, E., Hernall, O., \& Persson, L. A. (1997). Endurance running performance in relation to cardiovascular risk indicators in adolescents. International Journal of Sports Medicine, 18, 300-307.

Bertakis, K. D., \& Azari, R. (2005). The impact of obesity on primary care visits. Obesity Research, 13(9), 1615-1623.

Biro, F. M., \& Wien, M. (2010). Childhood obesity and adult morbidities. American Society for Nutrition, 91(5), 1499s-1505s.

Björntorp, P. (1998). Obesity: A chronic disease with alarming prevalence and consequences. Journal of Internal Medicine, 244(4), 267-269.

Blanchard, T., \& Lyson, T. (2003, November 21-22.). Access to low cost groceries in nonmetropoliton counties: Large retailers and the creation of food deserts. Paper presented at the Rural Diversity Conference, Washington, DC.

Blanchard, T., \& Lyson, T. (2006). Food availability \& food deserts in the nonmetropolitan south: Food assistance needs of the south's vulnerable populations. Retrieved October 1, 2011, from http://srdc.msstate.edu/publications/other/foodassist/2006 04 blanchard.pdf.

Block, J. P., Scribner, R. A., \& DeSalvo, K. B. (2004). Fast food, race/ethnicity, and income: A geographic analysis. American Journal of Preventive Medicine, 27(3), 211-217. 
Boehmer, T. K., Lovegreen, S. L., Haire-Joshu, D., \& Brownson, R. C. (2006). What constitutes an obesogenic environment in rural communities. The School of Health Promotion, 20(6), 411-421.

Bonner, J. (2003). Obesity not a personal failing, says leptin discoverer Jeffrey Friedman, but a battle against biology. New York: The Rockefeller University.

Borecki, I. B., Higgins, M., Schreiner, P. J., Arnett, D. K., Mayer-Davis, E., \& Hunt, S. C. (1998). Evidence for multiple determinants of the body mass index: The national heart, lung, and blood institute family heart study. Obesity Research, $6(2), 107-114$.

Boreham, C., Twisk, J., Murray, L., Savage, M., Strain, J. J., \& Cran, G. (2001). Fitness, fatness, and coronary heart disease risk in adolescents: The Northern Ireland Young Hearts Project. Medicine and Science in Sports and Exercise, 33(2), 270274.

Bray, G. A. (1990). Obesity: Historical development of scientific and cultural ideas. International Journal of Obesity, 14(11), 909-926.

Brown, H. S. I., Perez, A., Mirchandani, G. G., Hoelscher, D. M., \& Kelder, S. H. (2008). Crime rates and sedentary behavior among 4th grade Texas school children.

International Journal of Behavioral Nutrition and Physical Activity, 5(28), 27-34.

Brownell, K. D., \& Horgen, K. B. (2004). The toxic environment. Food fight: The inside story of the food industry, America's obesity crisis, and what we can do about it. New York: McGraw-Hill.

Burdette, H. L., \& Whitaker, R. C. (2004). Neighborhood playgrounds, fast food restaurants, and crime: Relationships to overweight in low income preschool children. Preventive Medicine, 38, 57-63. Retrieved March 6, 2011, from http://www.mathematica-mpr.com/publications/PDFs/neighborplay.pdf.

Bureau of Economic Analysis. (2007). Per-capita income of different states: Analysis. Washington, DC: U.S. Dept. of Commerce.

Burns, N. B., \& Groves, S. K. (2001). The practice of nursing research: Contact, critique \& utilization (4th ed.). Philadelphia: W.B. Saunders.

Carver, A., Timperioa, A., \& Crawford, D. (2008). Playing it safe: The influence of neighbourhood safety on children's physical activity-A review. Health \& Place, 14(2), 217-227.

Casey, P. H., Szeto, K., Lensing, S., Bogle, M., \& Weber, J. (2001). Children in foodinsufficient, low-income families prevalence, health, and nutrition status. Archives of Pediatrics and Adolescent Medicine, 155, 508-514. 
Centers for Disease Control and Prevention [CDC]. (2000). 2000 CDC growth charts for the United States: Methods and development. Vital and health statistics.

Retrieved September 1, 2011, from http://www.cdc.gov/nchs/data/series/sr_11/sr11_246.pdf.

Centers for Disease Control and Prevention [CDC]. (2011a). Obesity halting the epidemic by making life easier. Obesity 2010. Retrieved September 1, 2011, from http://www.cdc.gov/chronicdisease/resources/publications/aag/pdf/2011/Obesity AAG WEB 508.pdf.

Centers for Disease Control and Prevention [CDC]. (2011b). Overweight and obesity: Trends by state 1985-2010. Overweight and obesity. Retrieved September 1, 2011, from http://www.cdc.gov/obesity/data/trends.html.

Cervero, R., \& Duncan, M. (2003). Walking, bicycling, and urban landscapes: Evidence from the San Francisco Bay area. American Journal of Public Health, 93(9), $1478-1483$.

Claessens, A. L., Beunen, G., \& Malina, R. M. (2008). Anthropometry, physique, body composition, and maturity. In N. Armstrong \& W. Van Mechelen (Eds.), Paediatric exercise science and medicine. New York: Oxford University Press.

Cochran, J. (2008). Empowerment in adolescent obesity: State of the science. Online Journal of Rural Nursing and Health Care, 8(1), 63-73. Retrieved December 12, 2010, from http://www.rno.org/journal/index.php/online-journal/issue/view/23.

Cole, T. J. (2002). Assessment: National and international reference standards. In K. Chen \& W. H. Dietz (Eds.), Obesity in childhood and adolescence Nestle Nutrition Workshop Series Pediatric Program (pp. 1-21). Philadelphia: Lippincott Williams \& Wilkins.

Cole, T. J., Bellizzi, M. C., Flegal, K. M., \& Dietz, W. H. (2000). Establishing a standard definition for child overweight and obesity worldwide. British Medical Journal, $320,1240-1245$.

Cooper, D. M., Weiler-Ravell, D., Whipp, B. J., \& Wasserman, K. (1984). Aerobic parameters of exercise as a function of body size during growth. Journal of Applied Physiology, 56, 628-634.

Coronary Artery Risk Detection In Appalachian Children project [CARDIAC]. (2010). Morgantown: CARDIAC WV Project.

Coronary Artery Risk Detection In Appalachian Communities [CARDIAC]. (2010). CARDIAC project: Surveillance intervention research Retrieved March 9, 2011, from http://www.cardiacwv.org/contact.php. 
Crawford, P. B., Obarzanek, E., Schreiber, G. B., Barrier, P., Goldman, S., Frederick, M. M., \& Sabry, Z. I. (1995). The effects of race, household income, and parental education on nutrient intake of 9 and 10-year-old girls: NHLBI growth and health study. Annals of Epidemiology, 5, 360-368.

Cromley, E. K., \& McLafferty, S. L. (2002). GIS and public health. New York: The Guilford Press.

Crooks, D. L. (1999). Child growth and nutritional status in a high-poverty community in eastern Kentucky. American Journal of Physical Anthropology, 109(1), 129-142.

Crooks, D. L. (2000). Food consumption, activity, and overweight among elementary school children in an Appalachian Kentucky community. American Journal of Physical Anthropology, 112(2), 159-170.

Cureton, K. J., \& Plowman, S. A. (2008). Aerobic capacity assessments. Fitnessgram/activitygram reference guide. Retrieved May 9, 2011, from http://www.silvercreek.wnyric.org/107610102135438680/lib/1076101021354386 80/FITNESSGRAM ReferenceGuide.pdf.

Currie, J., Vigna, S. D., Moretti, E., \& Pathania, V. (2010). The effect of fast food restaurants on obesity and weight gain. American Economic Journal: Economic Policy, 2(3), 32-63. doi: 10.1257/pol.2.3.32.

Cutts, B. B., Darby, K. J., Boone, C. G., \& Brewis, A. (2009). City structure, obesity, and environmental justice: An integrated analysis of physical and social barriers to walkable streets and park access. Social Science and Medicine, 69, 1314-1322.

Davies-Cole, J. O., Kidane, G., Lum, G., \& Richardson, M. (2003). Spatial distribution of obesity, diabetes, and hypertension in the District of Columbia. Paper presented at the ESRI Health GIS, Washington, DC.

Demerath, E., Muratova, V., Spangler, E., Li, J., Minor, V. E., \& Neal, W. A. (2003). School-based obesity screening in rural Appalachia. Preventive Medicine, 37(6). doi: 10.1016/j.ypmed.2003.09.013.

Dietz, W. H., \& Bellizi, M. C. (1999). Introduction: The use of body mass index to assess obesity in children. American Journal of Clinical Nutrition, 70, 123s-125s. Retrieved January 13, 2010, from http://www.ajcn.org/content/70/1/123S.full.

Dietz, W. H., \& Robinson, T. N. (1998). Use of the body mass index (BMI) as a measure of overweight in children and adolescents. Journal of Pediatrics, 132, 191-193.

Drewnowski, A., Rehm, C. D., \& Solet, D. (2007). Disparities in obesity rates: Analysis by zip code area. Social Science and Medicine, 65(12), 2458-2463.

Drewnowski, A., \& Specter, S. E. (2004). Poverty and obesity: The role of energy density and energy costs. The American Journal of Clinical Nutrition, 79(1), 6-16. 
DuBose, K. D., Eisenmann, J. C., \& Donnelly, J. E. (2007). Aerobic fitness attenuates the metabolic syndrome score in normal-weight, at-risk-for-overweight, and overweight children. Pediatrics, 120. doi: 10.1542/peds.2007-044.

Eisenmann, J. C., Welk, G. J., Wickel, E. E., \& Blair, S. N. (2007). Combined influence of cardiorespiratory fitness and body mass index on cardiovascular disease risk factors among 8-18 year old youth: The Aerobics Center Longitudinal Study. International Journal of Pediatric Obesity, 2(2), 66-72.

Eisenmann, J. C., Welk, J. W., Ihmels, M., \& Dollman, J. (2007). Fatness, fitness, and cardiovascular disease risk factors in children and adolescents. Medicine and Science in Sports and Exercise, 39(8), 1251-1256.

Ellaway, A., Macintyre, S., \& Bonnefoy, X. (2005). Graffiti, greenery, and obesity in adults: Secondary analysis of European cross sectional survey. British Medical Journal, 331(7517), 611-612. doi: 10.1136/bmj.38575.664549.F7.

Ezzati, M., Friedman, A. B., Kulkarni, S. C., \& Murray, C. J. L. (2008). The reversal of fortunes: Trends in county mortality and cross-county mortality disparities in the United States. Plos Medicine, 4, 557-568. doi: 10.1371/journal.pmed.0050066.

Fagot-Campagna, A. (2000). Emergence of type 2 diabetes mellitus in children: Epidemiological evidence. Journal of Pediatric Endocrinology and Metabolism, 13(Suppl 6), 1395-1402.

Fagot-Campagna, A., Pettitt, D. J., Engelgau, M. M., Burrows, N. R., Geiss, L. S., Valdez, R., . . Narayan, K. M. (2000). Type 2 diabetes among north American children and adolescents: An epidemiologic review and a public health perspective. Journal of Pediatrics, 136(5), 664-672.

Finkelstein, E. A., Trogdon, J. G., Cohen, J. W., \& Dietz, W. (2009). Annual medical spending attributable to obesity: Payer-and service-specific estimates. Health Affairs, 28(5), w822-w831.

Finn, S., Higgins, S., \& Lilly, J. (2011). Life expectancy declining in parts of WV, rural America. WVPubcast: West Virginia Public Broadcasting.

Flegal, K. M. (1993). Defining obesity in children and adolescents: Epidemiologic approaches. Critical Reviews in Food Science and Nutrition, 331, 307-312.

Flegal, K. M., Carroll, M. D., Kuczmarski, R. J., \& Johnson, C. L. (1998). Overweight and obesity in the United States: Prevalence and trends, 1960-1994. International Journal of Obesity, 22, 39-47.

Flegal, K. M., Carroll, M. D., Ogden, C. L., \& Curtin, L. R. (2010). Prevalence and trends in obesity among US adults, 1999-2008. Journal of the American Medical Association, 303(3), 235-241. 
Flegal, K. M., Graubard, B. I., Williamson, D. F., \& Gail, M. H. (2005). Excess deaths associated with underweight, overweight, and obesity. Journal of the American Medical Association, 293(15), 1861-1867.

Fontaine, K. R., Redden, D. T., Wang, C., Westfall, A. O., \& Allison, D. B. (2003). Years of life lost due to obesity. Journal of the American Medical Association, 289(2), 187-193.

Fotheringham, A. S., Densham, P. J., \& Curtis, A. (1995). The zone definition problem and location allocation modeling. Geographical Analysis, 27, 60-77.

Frank, L. D., \& Engelke, P. O. (2001). The built environment and human activity patterns: Exploring the impacts of urban form on public health. Journal of Planning Literature, 16(2), 202-218.

Franks, P. W., Hanson, R. L., \& Knowler, W. C. (2010). Childhood obesity, other cardiovascular risk factors, and premature death. New England Journal of Medicine, 362(6), 485-493.

Freedman, D. S., Dietz, W. H., Srinivasan, S. R., \& Berenson, G. S. (1999). The relation of overweight to cardiovascular risk factors among children and adolescents: The Bogalusa Heart Study. Pediatrics, 103, 1175-1182.

Freedman, D. S., Khan, L. K., Serdula, M. K., Dietz, W. H., Srinivasan, S. R., \& Berenson, G. S. (2005). The relation of childhood BMI to adult adiposity: The Bogalusa Heart Study. Pediatrics, 115, 22 -27.

Freedman, D. S., Khan, L. K., Serdula, M. K., Ogden, C. L., \& Dietz, W. H. (2006). Racial and ethnic differences in secular trends for childhood BMI, weight, and height. Obesity, 14(2), 301-308. doi: 10.1038/oby.2006.39.

Freedman, D. S., Mei, Z., Srinivasan, S. R., Berenson, G. S., \& Dietz, W. H. (2007). Cardiovascular risk factors and excess adiposity among overweight children and adolescents: The Bogalusa Heart Study. Journal of Pediatrics, 150(1), 12-17.e12.

Freeman, E., Fletcher, R., Collins, C. E., Morgan, P. J., Burrows, T., \& Callister, R. (2011). Preventing and treating childhood obesity: Time to target fathers. International Journal of Obesity (Lond), [Epub ahead of print]. doi: 10.1038/ijo.2011.198.

Fripp, R. R., Hodgson, J. L., Kwiterovich, P. O., Werner, J. C., Schuler, H. G., \& Whitman, V. (1985). Aerobic capacity, obesity and atherosclerotic risk factors in male adolescents. Pediatrics, 75, 813-818.

Galvez, M. P., Hong, L., Choi, E., Liao, L., Godbold, J., \& Brenner, B. (2009). Childhood obesity and neighborhood food-store availability in an inner-city community. Academic Pediatrics, 9(5), 339-343. 
Galvez, M. P., Pearl, M., \& Yen, I. H. (2010). Childhood obesity and the built environment. Current Opinion in Pediatrics, 22(2), 202-207.

GeoLytics. (2010). Demographic data and estimates. Retrieved February 24, 2010, from http://www.geolytics.com/.

Giskes, K., Van Lenthe, F., Avendano-Pabon, M., \& Brug, J. (2011). A systematic review of environmental factors and obesogenic dietary intakes among adults: Are we getting closer to understanding obesogenic environments. Obesity Review, May, 12(5), e95-e106. doi: 10.1111/j.1467-789X.2010.00769.x.

Gomez, J. E., Johnson, B. A., Selva, M., \& Sallis, J. F. (2004). Violent crime and outdoor physical activity among inner-city youth. Preventive Medicine, 39(5), 876-881.

Gordon-Larsen, P., McMurray, R. G., \& Popkin, B. M. (2000). Determinants of adolescent physical activity and inactivity patterns. Pediatrics, 105(6), e83. doi: 10.1542/peds.105.6.e83.

Gordon-Larsen, P., Nelson, M. C., Page, P., \& Popkin, B. M. (2006). Inequality in the built environment underlies key health disparities in physical activity and obesity. Pediatrics, 117. doi: 10.1542/peds.2005-0058.

Halverson, J. A., Ma, L., Harner, J., Hanham, R., \& Braham, V. (2004). Adult obesity in Appalachia: An atlas of geographic disparities. Morgantown: West Virginia University.

Hamin, M. T. (1999). Constitutional types, institutional forms: Reconfiguring diagnostic and therapeutic approaches to obesity in early Twentieth-Century biomedical investigation. In J. Sobal \& D. Maure (Eds.), Weighty issues: Fatness and thinness as social problems (pp. 53-74). New York: Aldine de Gruyter.

Hansen, H. S., Hyldebrandt, N., Frober, K., \& Nielsen, J. R. (1990). Blood pressure and physical fitness in a population of children: The Odense Schoolchild Study. Journal of Human Hypertension, 4, 615-620.

Haslam, D. (2007). Obesity: A medical history. Obesity Review, 8(Suppl 1), 31-36.

Hickman, T., Briefel, R., Carroll, M., Rifkind, B., Cleeman, J., Maurer, K., \& Johnson, C. (1998). Distributions and trends of serum lipid levels among United States children and adolescents ages 4-19 years: Data from the third national health and nutrition examination survey. Preventive Medicine, 27, 879-890.

Himes, J. H., \& Dietz, W. H. (1994). Guidelines for overweight in adolescent preventive services: Recommendations from an expert committee. American Journal of Clinical Nutrition, 59(2), 307-316. 
Hoover Inc. (2010). Fast food and quick service restaurants. Retrieved September 1, 2011, from http://www.hoovers.com/industry/fast-food-quick-servicerestaurants/1444-1.html.

Hubert, H. B., Feinleib, M., McNamara, P. M., \& Castelli, W. P. (1993). Obesity as an independent risk factor for cardiovascular disease: A 26-year follow-up of participants in the Framingham Heart Study. Circulation, 67, 968-977.

Kim, S. Y., England, L., Sharma, A. J., \& Njoroge, T. (2011). Gestational diabetes mellitus and risk of childhood oberweight and obesity in offspring: A systematic review. 2011. doi: 10.1155/2011/541308.

Kipke, M. D., Iverson, E., Moore, D., Booker, C., Ruelas, V., Peters, A. L., \& Kaurman, F. (2007). Food and park environments: Neighborhood-level risks for childhood obesity in east Los Angeles. Journal of Adolescent Health, 40, 325-333.

Kirk, S. F., Penney, T. L., \& McHugh, T. L. (2010). Characterizing the obesogenic environment: The state of the evidence with directions for future research. Obesity Review, 11(12), 109-117.

Krebs, N. F., Himes, J. H., Jacobson, D., Nicklas, T. A., Guilday, P., \& Styne, D. (2007). Assessment of child and adolescent overweight and obesity. Pediatrics, 129(Suppl. 4), S193-S228. doi: 10.1542/peds.2007-2329D.

Kuczmarski, R. J., Carroll, M. D., Flegal, K. M., \& Troiano, R. P. (1997). Varying body mass index cutoff points to describe overweight prevalence among U.S. adults: NHANES III (1988 to 1994). Obesity Research, 5(6), 542-548.

Kuczmarski, R. J., \& Flegal, K. M. (2000). Criteria for definition of overweight in transition: Background and recommendations for the United States. American Journal of Clinical Nutrition Review, 72, 1074-1081.

Kuczmarski, R. J., Ogden, C., Guo, S., Himes, J., Hirshman, J., \& Roche, A. (2000). CDC growth charts for the United States: Methods and development. Vital Health Statistic, 11(246), 1-190.

Kwate, N. O. A., Yau, C. Y., Loh, J. M., \& Williams, D. (2009). Inequality in obesigenic environments: Fast food density in New York City. Health Place, 15, 364-373.

Lamerz, A., Kuepper-Nybelen, J., Wehle, C., Bruning, N., Trost-Brinkhues, G., Brenner, H., . . . Herpertz-Dahlmann, B. (2005). Social class, parental education, and obesity prevalence in a study of six-year-old children in Germany. International Journal of Obesity, 29, 373-380.

Lantz, P. M., House, J. S., Lepkowski, J. M., Williams, D. R., Mero, R. P., \& Chen, J. (1998). Socioeconomic factors, health behaviors, and mortality results from a nationally representative prospective study of US adults. Journal of the American Medical Association, 279, 1703-1708. 
Lasker, G. W. (1994). The place of anthropometry in human bioligy. In S. J. Ulijaszek \& C. G. N. Mascie-Taylor (Eds.), Anthropometry: The Individual and The Population (pp. 1-6). Cambridge: Cambridge University Press.

Li, F., Fisher, K. J., Brownson, R. C., \& Bosworth, M. (2005). Multilevel modelling of built environment characteristics related to neighbourhood walking activity in older adults. British Medical Journal, 59(7), 558-564. doi: 10.1136/jech.2004.028399.

Li, F., Hamer, P., Cardinal, B. J., Bosworth, M., \& Johnson-Shelton, D. (2009). Obesity and the built environment: Does the density of neighborhood fast-food outlets matter? American Journal of Health Promotion, 23(3), 203-209.

Mainous, A. G. I., \& Hueston, W. J. (1997). Using other people's data: The ins and outs of secondary data analysis. Family Medicine, 29, 568-571.

Malcolm, J. C., Lawson, M. T., Gaboury, I., Lough, G., \& Keely, E. (2006). Glucose tolerance of offspring of mother with gestational diabetes mellitus in a low-risk population. Diabetic Medicine, 23(5), 565-570.

Maynard, M. L., Wisemandle, W., Roche, A. F., Chumlea, W. C., Guo, S. S., \& Siervogel, R. M. (2001). Childhood body composition in relation to body mass index. Pediatrics, 107(2), 344-350. . doi: 10.1542/peds.107.2.344.

Menard, S. W. (2001). Applied logistic regression analysis (2nd ed.). Thousand Oaks: Sage.

Metzler, M. (2007). Social determinants of health: What, how, why, and now? Preventing Chronic Disease, 4(4), A85. Retrieved October 9, 2010, from http://www.ncbi.nlm.nih.gov/pmc/articles/PMC2099283/?tool=pubmed.

Michimi, A., \& Wimberly, M. C. (2010). Spatial patterns of obesity and associated risk factors in the conterminous US. American Journal of Preventive Medicine, 39(2), e1-e12

Miller, H. J. (2004). Tobler's first law and spatial analysis. Annals of the Association of American Geographers, 94, 284-289.

Moffat, T. (2010). The childhood obesity epidemic: Health crisis or social construction? Medical Anthropology Quarterly, 24(1), 1-21.

Mokdad, A. H., Bowman, B. A., Ford, E. S., Vinicor, F., Marks, J. S., \& Koplan, J. P. (2001). The continuining epidemic of obesity and diabetes in the United States. Journal of the American Medical Association, 286(10), 1195-1200. 
Molnar, B. E., Gortmaker, S. L., Bull, F. C., \& Buka, S. L. (2004). Unsafe to play? Neighborhood disorder and lack of safety predict reduced physical activity among urban children and adolescents. American Journal of Health Promotion, 18(5), 378-386.

Moore, B. J. (2003). Supersized America: Help your patients regain control of their weight: Identifying fast food as a contributor to overeating. Cleveland Clinic Journal of Medicine, 70(3), 237-240.

Morland, K., Wing, S., \& Diez, R. A. (2002). The contextual effect of the local food environment on residents' diets: The atherosclerosis risk in communities study. American Journal Public Health, 92(11), 1761-1767.

Morrow, J. R. J., \& Freedson, P. S. (1994). Relationship between habitual physical activity and aerobic fitness in adolescents. Pediatric Exercise Science, 6(4), 315329.

Muennig, P., Lubetkin, E., Haomial, J., \& Franks, P. (2006). Gender and the burden of disease attributable to obesity. American Journal of Public Health, 96(9), 16621668.

Muennig, P., Sohler, N., \& Mahato, B. (2007). Socioeconomic status as an independent predictor of physiological biomarkers of cardiovascular disease: Evidence from NHANES. Preventive Medicine, 45(1), 35-40.

Mullen, M. C., \& Shield, J. (2004). Childhood and adolescent overweight: The health professional's guide to identification, treatment, and prevention. Chicago: American Diabetes Association.

Must, A., Spandano, J., Coakley, E. H., Field, A. E., Colditz, G., \& Dietz, W. H. (1999). The disease burden associated with overweight and obesity. Journal of the American Medical Association, 282(16), 1523-1529.

Must, A., \& Strauss, R. S. (1999). Risks and consequences of childhood and adolescent obesity. International Journal of Obesity and Related Metabolic Disorders, 23(Suppl 2), S2-11.

National Diabetes Education Program. (2008). Overview of diabetes in children and adolescents. A fact sheet from the National Diabetes Education Program. Retrieved January 7, 2011, from http://ndep.nih.gov/media/diabetes/youth/youth_FS.htm.

National Research Council. (2005). Preventing childhood obesity: Health in the balance (Vol. 105). Washington, DC: The National Academies Press.

Nayga, R. M. (2000). Schooling, health knowledge, and obesity. Applied Economics, 32, 815-822. 
Nestle, M., \& Jacobson, M. (2000). Halting the obesity epidemic: A public health policy approach. Public Health Reports, 115, 12-24.

Nevill, A. M. (1997). The appropriate use of scaling techniques in exercise physiology. Pediatric Exercise Science, 9, 295-298.

Nevill, A. M., \& Holder, R. L. (1994). Modelling maximum oxygen uptake-a case-study in on-linear regression model formulation and comparison. Applied Statistics, 43(4), 653-666.

Nevill, A. M., Rowland, T. W., Goff, D., Martel, L., \& Ferrone, L. (2004). Scaling or normalizing maximum oxygen uptake to predict 1-mile run time in boys. European Journal of Applied Physiology, 92, 285-288.

Nicoll, L. H., \& Beyea, S. C. (1999). Using secondary data analysis for nursing research. Association of Operating Room Nurses, 69(2), 428-433. Retrieved September 1, 2011, from http://findarticles.com/p/articles/mi m0FSL/is 2 69/ai 53893778/?tag=content; c ol1.

Ogden, C. L., Carroll, M. D., Curtin, L. R., Lamb, M. M., \& Flegal, K. M. (2010). Prevalence of high body mass index in US children and adolescents, 2007-2008. Journal of the American Medical Association, 303(3), 242-249.

Ogden, C. L., \& Flegal, K. M. (2010). Changes in terminology for childhood overweight and obesity. National health statistics reports. Retrieved September 1, 2011, from http://www.cdc.gov/nchs/data/nhsr/nhsr025.pdf.

Ogden, C. L., Flegal, K. M., Carroll, M. D., \& Johnson, C. L. (2002). Prevalence and trends in overweight among U.S. children and adolescents, 1999-2000. Journal of the American Medical Association, 288, 1728-1732.

Olshansky, S. J., Passaro, D. J., Hershow, R. C., Layden, J., Carnes, B. A., Brody, J., . . . Ludwig, D. S. (2005). A potential decline in life expectancy in the United States in the 21st century. New England Journal of Medicine, 352(11), 1138-1145. doi: 10.1056/NEJMsr043743.

Pangrazi, R. P., \& Corbin, C. B. (1990). Age as a factor relating to physical fitness test performance. Research Quarterly for Exercise and Sport, 61, 410-414.

Papas, M. A., Alberg, A. J., Ewing, R., Helzlsouer, K. J., Gary, T. L., \& Klassen, A. C. (2007). The built environment and obesity. Epidemiologic Reviews, 29(1), 129143.

Papavramidou, N. S., Papavramidis, S. T., \& Christopoulou-Aletra, H. (2004). Galen on obesity: Etiology, effects, and treatment. World Journal of Surgery, 28(6), 631635. 
Peng, C. Y., Lee, K. L., \& Ingersoll, G. M. (2002). An introduction to logistic regression analysis and reporting. The Journal of Educational Research, 96(1), 3-14.

Peng, C. Y., Manz, B. D., \& Keck, J. (2001). Modeling categorical variables by logistic regression. American Journal of Health Behavior, 25(3), 278-284.

Powell, L. M., Slater, S., Mirtcheva, D., Bao, Y., \& Chaloupka, F. (2007). Food store availability and neighborhood characteristics in the United States. Preventive Medicine, 44, 198-195.

Pryor, L. E., Tremblay, R. E., Boivin, M., Touchette, E., Dubois, L., Genolini, C., . . . Côté, S. M. (2011). Developmental trajectories of body mass index in early childhood and their risk factors: An 8-year longitudinal study. Archives of Pediatrics and Adolescent Medicine, 165(10), 906-912.

Reilly, J. J. (2002). Assessment of childhood obesity: National reference data or international approach? Obesity Research, 10(8), 838-840.

Reilly, J. J., Dorosty, A. R., \& Emmett, P. M. (2000). Identification of the obese child: Adequacy of the BMI for clinical practice and epidemiology. International Journal of Obesity, 24, 1623-1627.

Reilly, J. J., Methven, E., McDowell, Z. C., Hacking, B., Alexander, D., Stewart, L., \& Kelnar, C. J. H. (2003). Health consequences of obesity: Systematic review. Archives of Disease in Childhood, 88, 748-752.

Reilly, J. J., Wilson, M., Summerbell, C. D., \& Wilson, D. C. (2002). Obesity diagnosis, prevention, and treatment: Evidence based answers to common questions. Archives of Disease in Childhood, 86, 392-395.

Rew, L., Koniak-Griffin, D., Lewis, M. A., Miles, M., \& O'Sullivan, A. (2000). Secondary data analysis: New perspective for adolescent research. Nursing Outlook, 48, 223-229.

Roberts, S. B., \& Dallal, G. E. (2001). The new childhood growth charts. Nutrition Review, 59(2), 31-36.

Rodgers, B. L. (1989). Concepts, analysis and the development of nursing knowledge: The evolutionary cycle. Journal of Advanced Nursing, 14, 330-335.

Roos, G., Johansson, L., Kasmel, A., Klumbiené, J., \& Prättälä, R. (2000). Disparities in vegetable and fruit consumption: European cases from the north to the south. Public Health Nutrition, 4(1), 35-43. doi: 10.1079/PHN200048.

Rothman, K. J. (2008). BMI-related errors in the measurement of obesity. International Journal of Obesity, 32, S56-S59. 
Rowland, T. W. (2005). Children's exercise physiology (2nd ed., pp. 15-16). Champaign, IL.: Human Kinetics.

Rowlands, A. V., Eston, R. G., \& Ingledew, D. K. (1999). The relationship between activity levels, aerobic fitness, and body fat in 8 to 10 yr-old children. Journal of Applied Physiology, 86, 1428-1435.

Sallis, J. F., \& Glanz, K. (2006). The role of built environments in physical activity, eating, and obesity in childhood.The future of children (Vol. 16, pp. 89-108). Princeton, NJ: Princeton University and The Brookings Institution. Retrieved from http://links.jstor.org/sici?sici=10548289\%28200621\%2916\%3A1\%3C89\%3ATROBEI\%3E2.0.CO\%3B2-H.

Sallis, J. F., Patterson, T. L., Buono, M. J., \& Nadder, P. R. (1988). Relation of cardiovascular fitness and physical activity to cardiovascular disease risk factors in children and adults. American Journal of Epidemiology, 127, 933-941.

Sallis, J. F., Taylor, W. C., Dowda, M., Freedson, P. S., \& Pate, R. R. (2002). Correlates of vigorous physical activity for children in grades 1 through 12: Comparing parent-reported and objectively measured physical activity. Pediatric Exercise Science, 14, 30-44.

Sampson, R. (1985). Neighborhood and crime: The structural determinants of personal victimization. Journal of Research in Crime and Delinquency, 22(1), 7-40.

Schwatz, M. B., \& Brownell, K. (2005). The need for courageous action to prevent obesity. In D. Crawford \& R. W. Jeffrey (Eds.), Obesity Prevention and Public Health (pp. 307-330). New York: Oxford University Press.

Serdula, M. K., Ivery, D., Coates, R. J., Freedman, D. S., Williamson, D. F., \& Byers, T. (1993). Do obese children become obese adults? A review of the literature. Preventive Medicine, 22(2), 167-177.

Siaway, G., Davies-Cole, J. O., \& Kidane, G. (2007). Quantifying spatial autocorrelation between obesity, neighborhood characteristics, high blood pressure and physical inactivity, Washington D.C. Paper presented at the The 135th APHA Annual Meeting \& Exposition of American Public Health Association, Denver, Colorado.

Singh, G. K., Kogan, M. D., \& Van Dyck, P. C. (2008). A multilevel analysis of state and regional disparities in childhood and adolescent obesity in the United States. Journal of Community Health, 33(2), 90-102.

Slyper, A. H. (1998). Childhood obesity, adipose tissue distribution and the pediatric practitioner. Pediatrics, $102(\mathrm{e} 4)$.

Stearns, P. N. (1999). Children and weight control: Priorities in the United States and France. In J. Sobal \& D. Maurer (Eds.), Weighty issues: Fatness and thinness as social problems (pp. 9-30). New York: Aldine de Gruyter. 
Summerbell, C. D., Waters, E., Edmunds, L. D., Kelly, S., Brown, T., \& Campbell, K. J. (2005). Interventions for preventing obesity in children. Cochrane Database of Systematic Reviews, July 20(3), 1-70. doi: 10.1002/14651858.CD001871.pub2.

Thorpe, K. E. (2009). The future costs of obesity: National and state estimates of the impact of obesity on direct health care expenses. Retrieved March 9, 2011, from http://www.nccor.org/downloads/CostofObesityReport-FINAL.pdf.

Timperio, A., Ball, K., Roberts, R., Andrianopoulous, N., \& Crawford, D. (2009). Children's fast food intake and availability of food outlets near home and on the way to school. Public Health Nutrition, 12, 1960-1964.

Trayhurn, P. (2005). Plenary lecture: The biology of obesity. Proceedings of the Nutrition Society, 64, 31-38. doi: 10.1079/PNS2004406.

Trost, S. G., Pate, R. R., Saunders, R., Ward, D. S., Dowda, M., \& Felton, G. (1997). A prospective study of the determinants of physical activity in rural fifth-grade children. Preventive Medicine, 26(2), 257-263.

Trust for America's Health. (2009). F as in fat: How obesity policies are failing in America. Retrieved June 1, 2011, from http://healthyamericans.org/reports/obesity2009/Obesity2009Report.pdf.

Trust for America's Health. (2011). How obesity threatens America's future 2011. Robert Wood Johnson Foundation. Retrieved June 1, 2011, from http://healthyamericans.org/reports/obesity2010/.

Tucker, P., Irwin, J. D., Gilliland, J., He, M., Larsen, K., \& Hess, P. (2009). Environmental influences on physical activity levels in youth. Health \& Place, 15(1), 357-363.

U.S. Census Bureau [Data file]. (2007). 2007 NAICS codes and titles Retrieved April 3, 2011, from http://www.census.gov/naics/2007/NAICOD07.HTM.

U.S. Census Bureau [Data file]. (2010). American community survey 1-year estimates Retrieved April 19, 2011, from http://www.census.gov/acs/www/.

U.S. Census Bureau [Data file]. (2011). Household income and persons below poverty Retrieved September 9, 2011, from http://quickfacts.census.gov/qfd/meta/long_IPE010208.htm.

U.S. Department of Health and Human Services [DHHS]. (2010). The Surgeon General's vision for a healthy and fit nation. Retrieved September 4, 2010, from http://www.ncbi.nlm.nih.gov/books/NBK44660/.

Velasquez-Mieyer, P., Neira, C. P., Nieto, R., \& Cowan, P. A. (2007). Obesity and cardiometabolic syndrome in children. Therapeutic Advances in Cardiovascular Diseases, 1(1), 61-81. 
Wang, Y., \& Lobstein, T. (2006). Worldwide trends in childhood overweight and obesity. International Journal of Pediatric Obesity, 1, 11-25.

Wang, Y., \& Zhang, Q. (2006). Are low-socioeconomic-status American children and adolescents at increased risk of obesity? Changes in the association between overweight and family income between 1971 and 2002. American Journal of Clinical Nutrition, 84, 707-716.

Weira, L. A., Etelsonb, D., \& Brandb, D. A. (2006). Parents' perceptions of neighborhood safety and children's physical activity. Preventive Medicine, 43(3), 212-217.

Welk, G. J., \& Meredith, M. D. (2008). Fitnessgram/activitygram reference guide. Dallas: The Cooper Institute.

West Virginia Department of Education [Data file]. (2011). Data. Retrieved January 7, 2011, from http://wvde.state.wv.us/.

West Virginia Health Statistic Center [HSC]. (2002). Obesity: Facts, figures, guidelines. Retrieved March 4, 2011, from http://www.wvdhhr.org/bph/oehp/obesity/default.htm.

West Virginia State Police [Data file]. (2008). Annual Report for 2007. Retrieved June 1, 2011, from http://www.wvstatepolice.com/.

West Virginia State Police [Data file]. (2009). Annual Report for 2008. Retrieved June 1, 2011, from http://www.wvstatepolice.com/.

West Virginians for Affordable Health Care [WVAHC]. (2008). Early Deaths: West Virginians have some of the shortest life expectancies in the United States. Retrieved June 1, 2011, from http://www.sludgesafety.org/health/Early Deaths wv.pdf.

Whitlock, E. P., Williams, S. B., Gold, R., Smith, P. R., \& Shipman, S. A. (2005). Screening and interventions for childhood overweight: A summary of evidence for the US prevention service task force. Pediatrics, 116(1), 125-144. doi: 10.1542/peds.2005-0242.

Wilkinson, R. G., \& Marmot, M. G. (2003). Social determinants of health: The solid facts. Retrieved June 1, 2011, from http://www.euro.who.int/_data/assets/pdf_file/0005/98438/e81384.pdf.

Wilson, J. Q., \& Kelling, G. L. (1982). Broken windows: The police and neighborhood safety. Retrieved November 9, 2010, from http://www.manhattaninstitute.org/pdf/_atlantic_monthly-broken_windows.pdf.

World Health Organization [WHO]. (2000). Obesity: Preventing and managing the global epidemic. Geneva: World Health Organization. 
Youssef, A. A., Valdez, R., Elkasabany, A., Srinivasan, S. R., \& Berenson, G. S. (2002). Time-course of adiposity and fasting insulin from childhood to young adulthood in offspring of parents with coronary artery disease: The Bolalusa Heart Study. Annals of Epidemiology, 12(8), 553-559.

Zhang, Q., \& Wang, Y. (2004). Socioeconomic inequality in obesity in the United States: Do gender, age and ethnicity matter. Social Science and Medicine, 58, 1171-1180.

Zuguo, M., Grummer-Strawn, L. M., Pietrobelli, A., Goulding, A., Goran, M. I., \& Dietz, W. H. (2002). Validity of body mass index compared with other bodycomposition screening indexes for the assessment of body fatness in children and adolescents. American Journal of Clinical Nutrition, 75(6), 978-985. 
APPENDIX A. SPATIAL DISTRIBUTION OF STUDY VARIABLES 


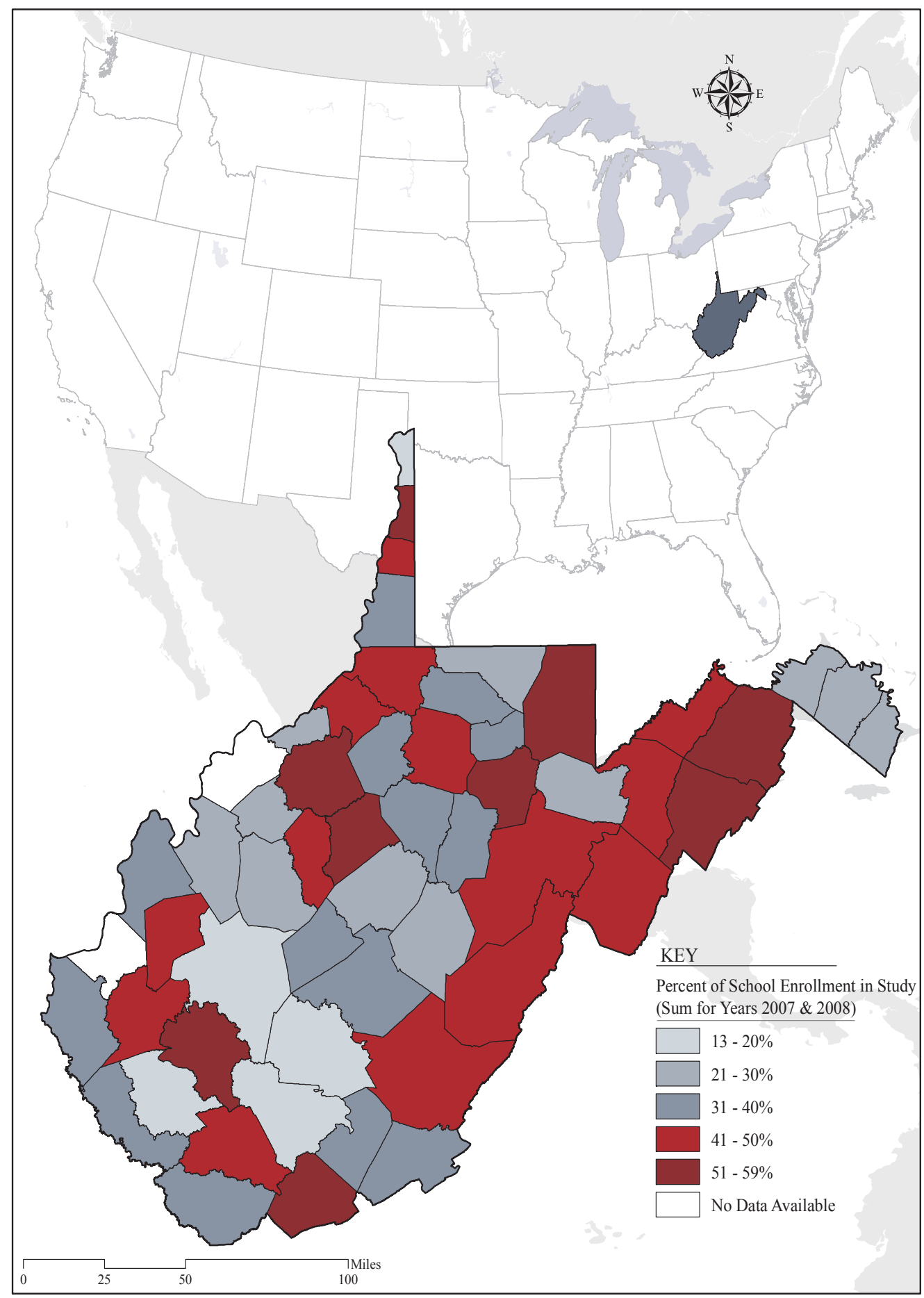

Figure A-1. Percentage of $5^{\text {th }}$ Grade School Enrollment by County Represented in the Study

Note: 1 Dot $=1$ Child Sample Participant. 


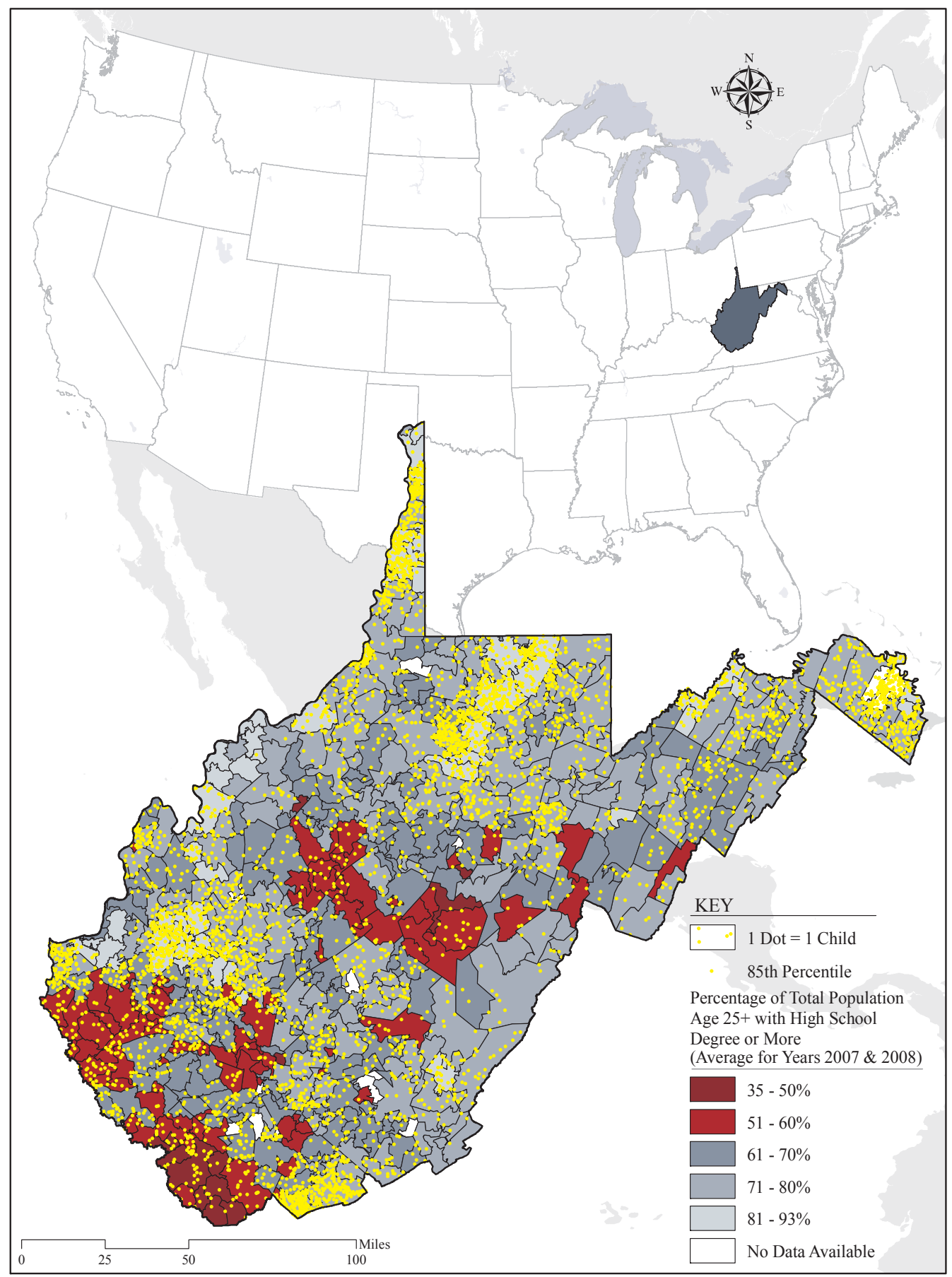

Figure A-2. Percent of Total Population Aged 25+ Years with a High School Diploma or Greater and Distribution of BMI Equal to or Greater than the $85^{\text {th }}$ Percentile by Zip Code

Note: 1 Dot $=1$ Child Sample Participant. 


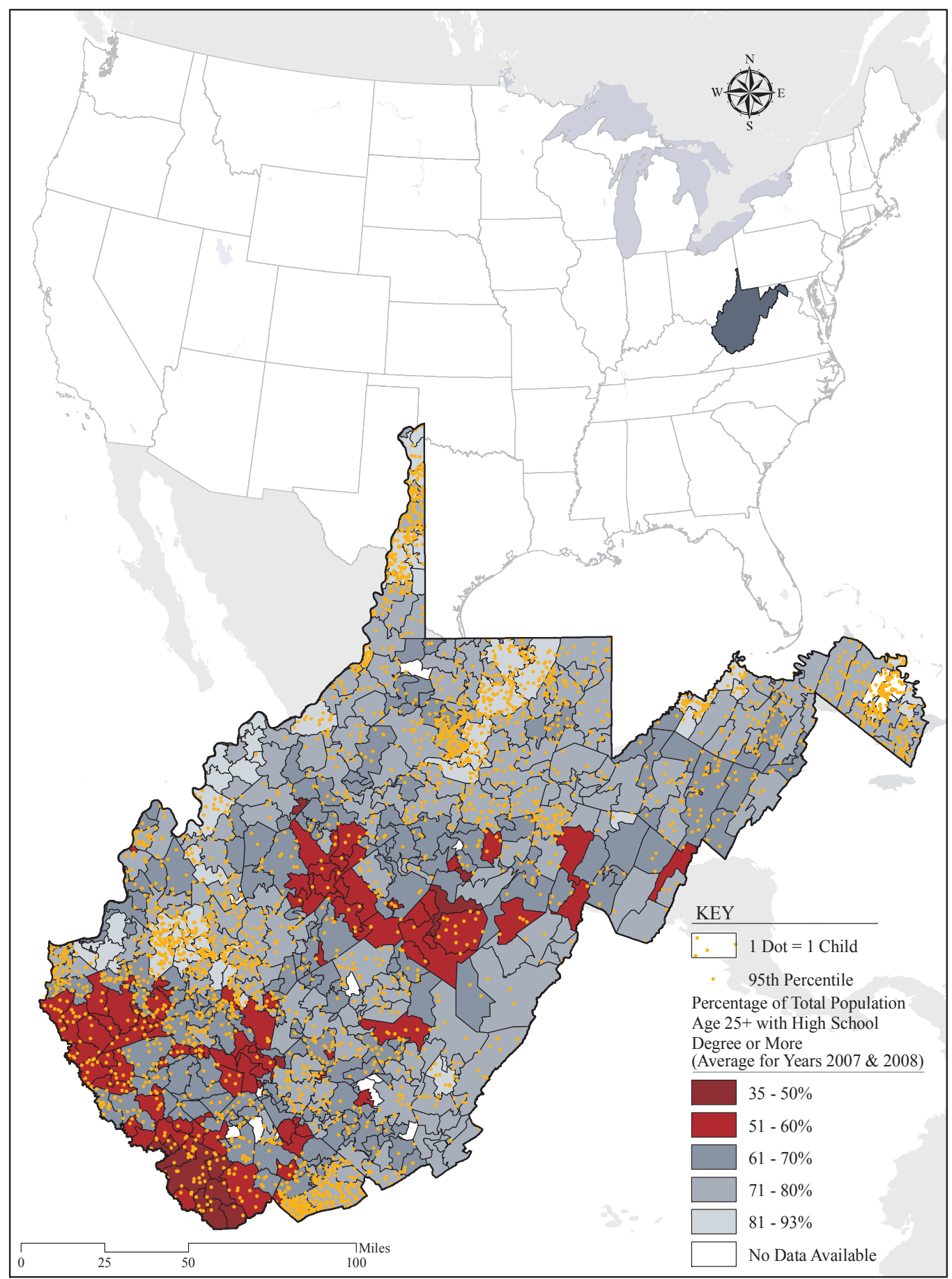

Figure A-3. Percent of Total Population Aged 25+ Years with a High School Diploma or Greater and Distribution of BMI Equal to or Greater than the $95^{\text {th }}$ Percentile by Zip Code

Note: 1 Dot $=1$ Child Sample Participant. 




Figure A-4. Percent of Total $5^{\text {th }}$ Grade Population Defined as Low Socioeconomic Status and Distribution of BMI Equal to or Greater than the $95^{\text {th }}$ Percentile by Zip Code

Note: 1 Dot $=1$ Child Sample Participant. 




Figure A-5. Median Household Income and Distribution of BMI Equal to or Greater than the $85^{\text {th }}$

Note: 1 Dot $=1$ Child Sample Participant. 


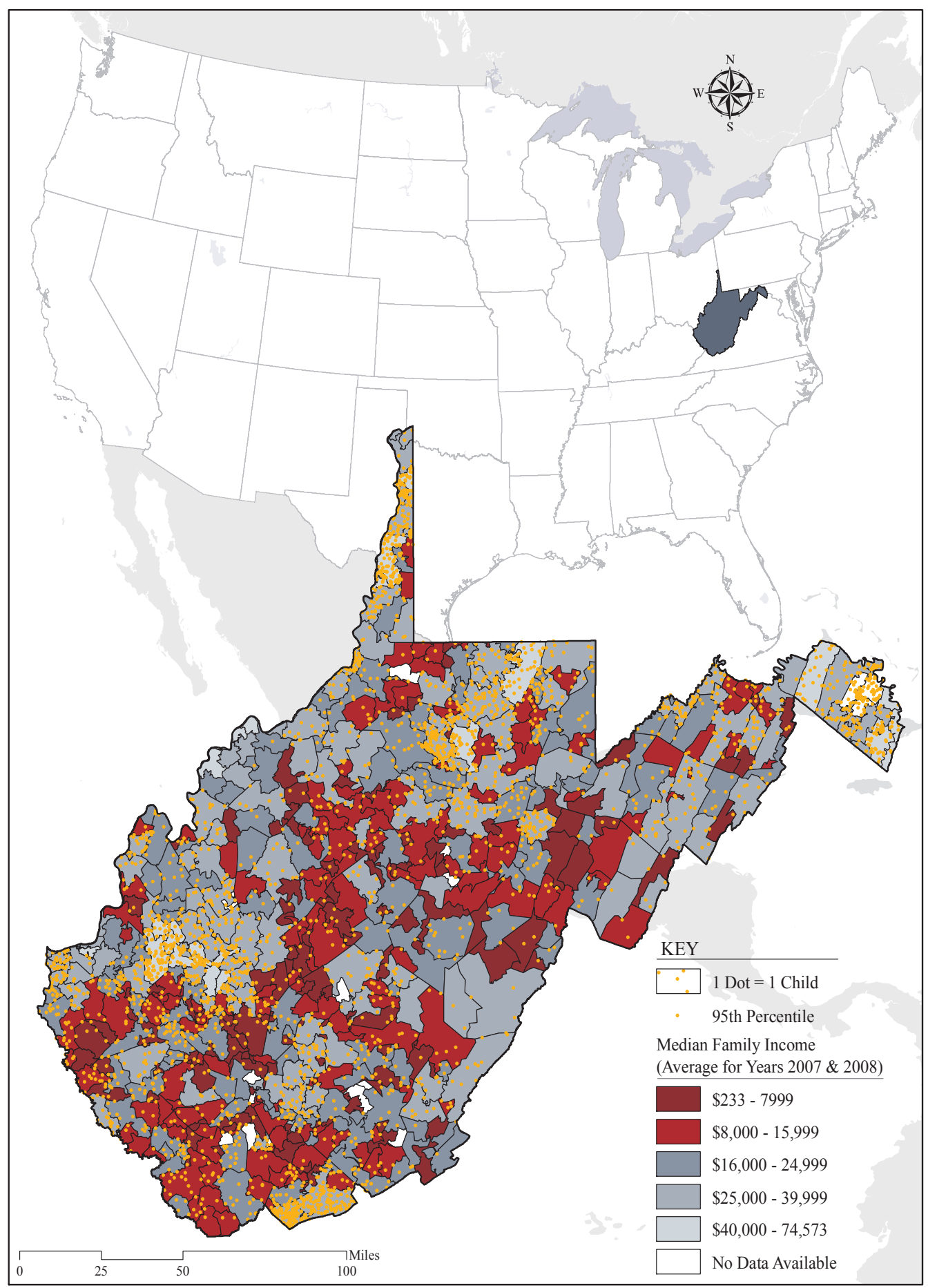

Figure A-6. Median Household Income and Distribution of BMI Equal to or Greater than the $95^{\text {th }}$ Percentile by Zip Code

Note: 1 Dot $=1$ Child Sample Participant. 




Figure A-7. Distribution of Super Markets and Grocery Stores by Zip Code and BMI Equal to or Greater than the $85^{\text {th }}$ Percentile by Zip Code

Note: 1 Dot $=1$ Child Sample Participant. 




Figure A-8. Distribution of Supermarkets and Other Grocery Stores by Zip Code and BMI Equal to or Greater than the $95^{\text {th }}$ Percentile by Zip Code

Note: 1 Dot $=1$ Child Sample Participant. 




Figure A-9. Distribution of Convenient Stores by Zip Code and BMI Equal to or Greater than the $85^{\text {th }}$ Percentile by Zip Code

Note: 1 Dot $=1$ Child Sample Participant. 


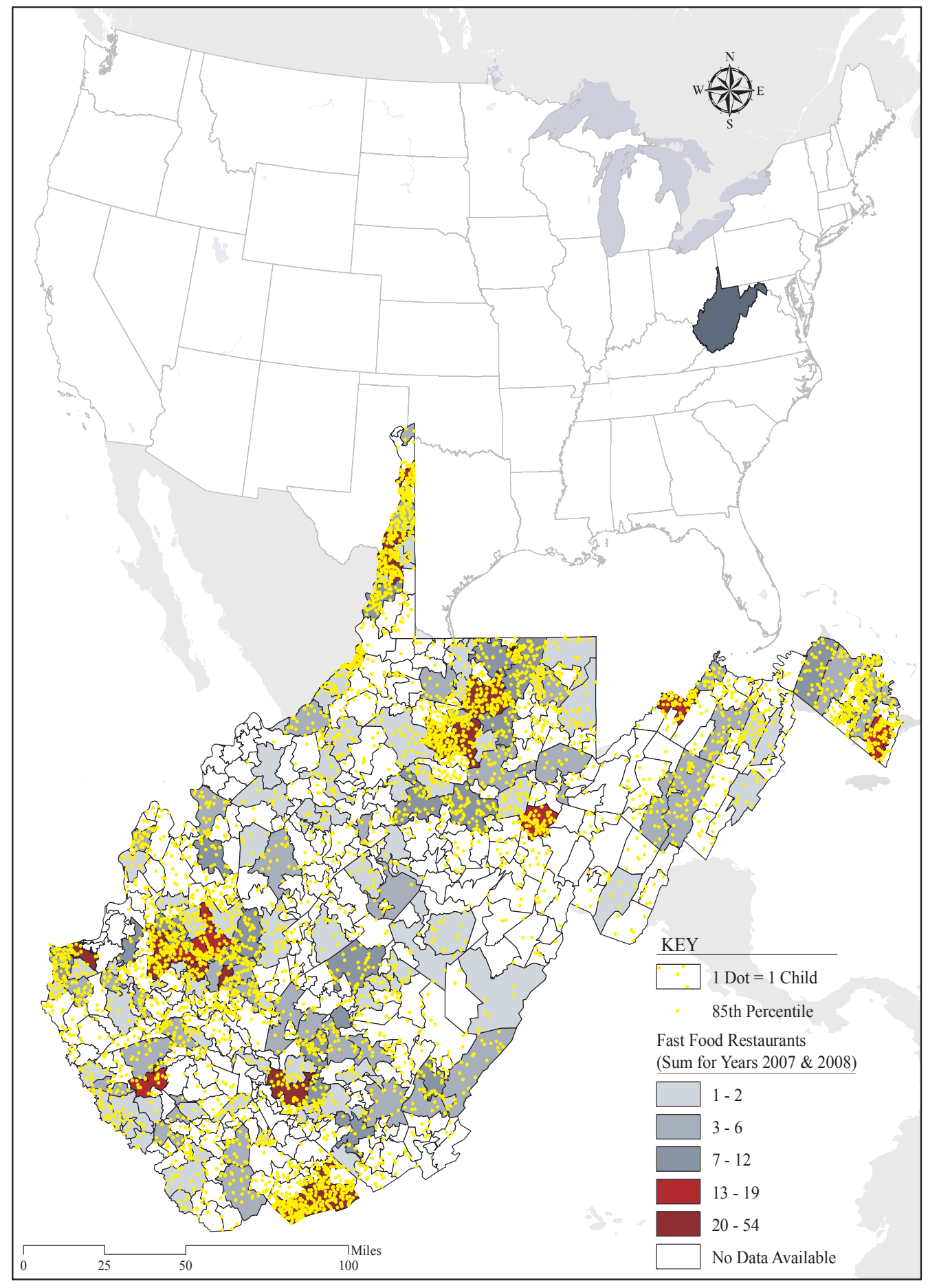

Figure A-10. Distribution of Fast Food by Zip Code and BMI Equal to or Greater than the $85^{\text {th }}$ Percentile by Zip Code

Note: 1 Dot $=1$ Child Sample Participant. 




Figure A-11. Distribution of Fruit and Vegetable Markets by Zip Code and BMI Equal to or Greater than the $85^{\text {th }}$ Percentile by Zip Code

Note: 1 Dot $=1$ Child Sample Participant. 




Figure A-12. Distribution of Fruit and Vegetable Markets by Zip Code and BMI Equal to or Greater than the $95^{\text {th }}$ Percentile

Note: 1 Dot $=1$ Child Sample Participant. 


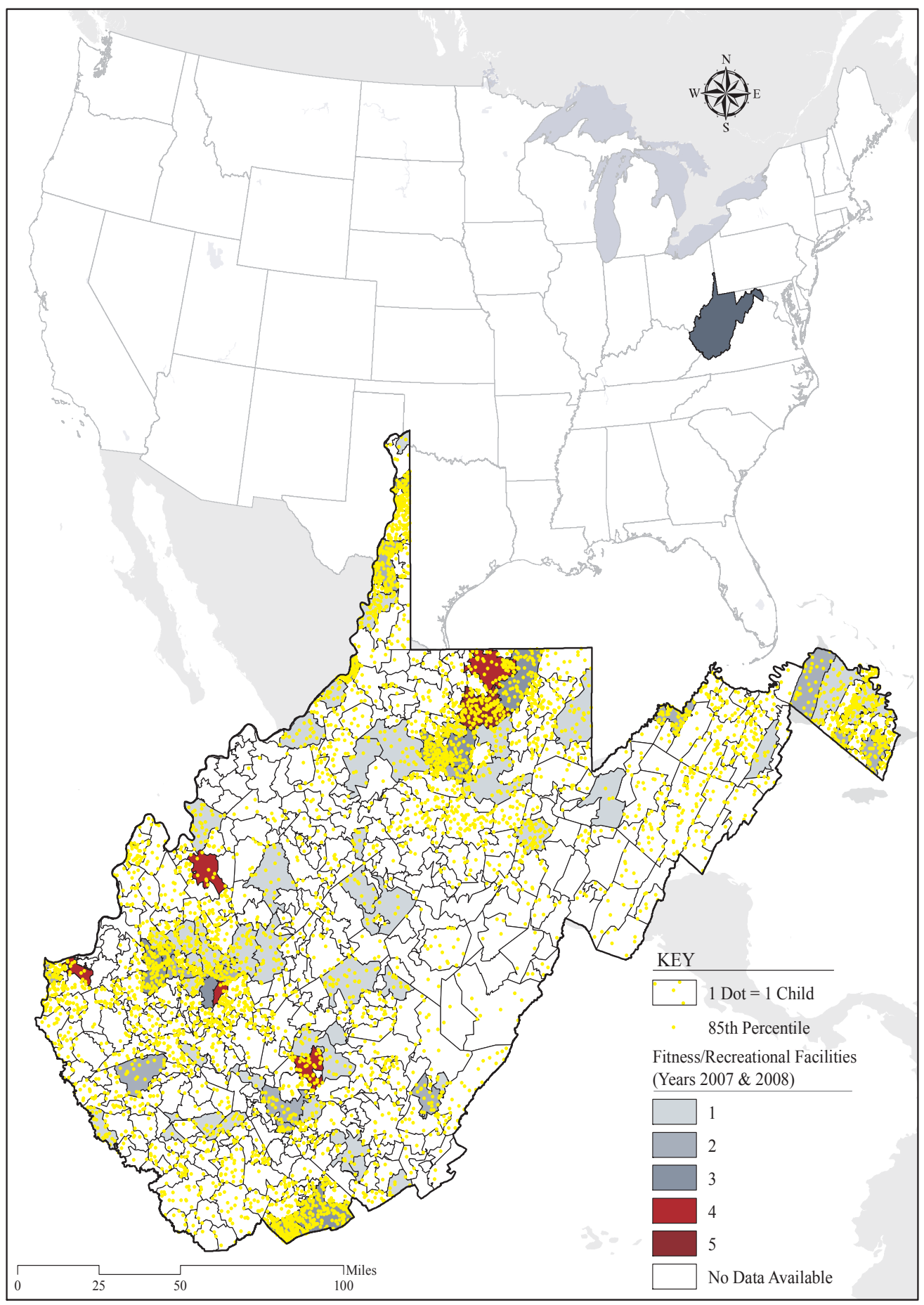

Figure A-13. Distribution of Fitness and Recreation Facilities by Zip Code and BMI Equal to or Greater than the $85^{\text {th }}$ Percentile

Note: 1 Dot $=1$ Child Sample Participant. 


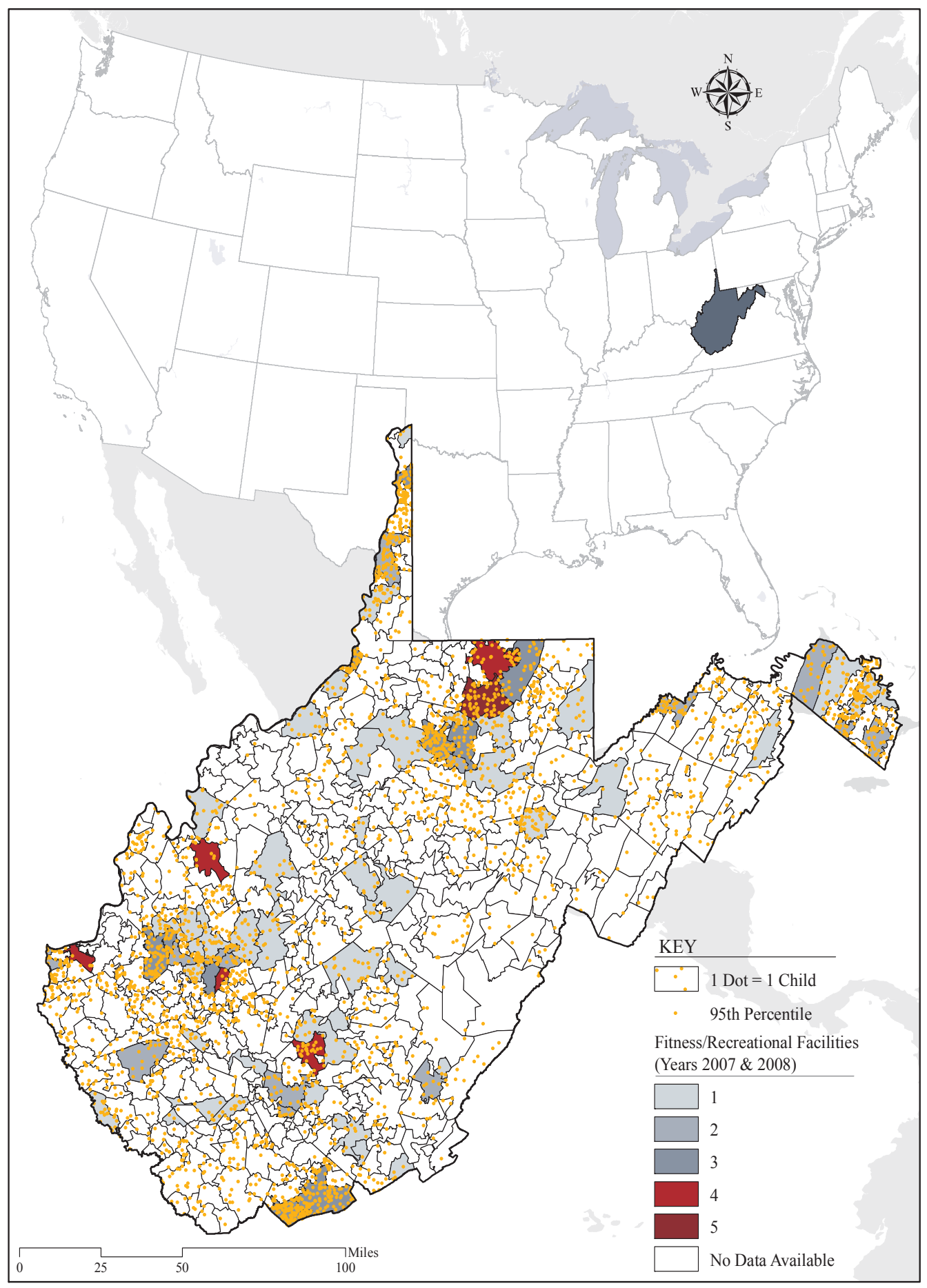

Figure A-14. Distribution of Fitness and Recreation Facilities by Zip Code and Distribution of BMI Equal to or Greater than the $95^{\text {th }}$ Percentile

Note: 1 Dot $=1$ Child Sample Participant. 




Figure A-15. Distribution of Subjects Reporting a Family History of Heart Disease by Zip Code and BMI Equal to or Greater than the $95^{\text {th }}$ Percentile by Zip Code

Note: 1 Dot $=1$ Child Sample Participant. 


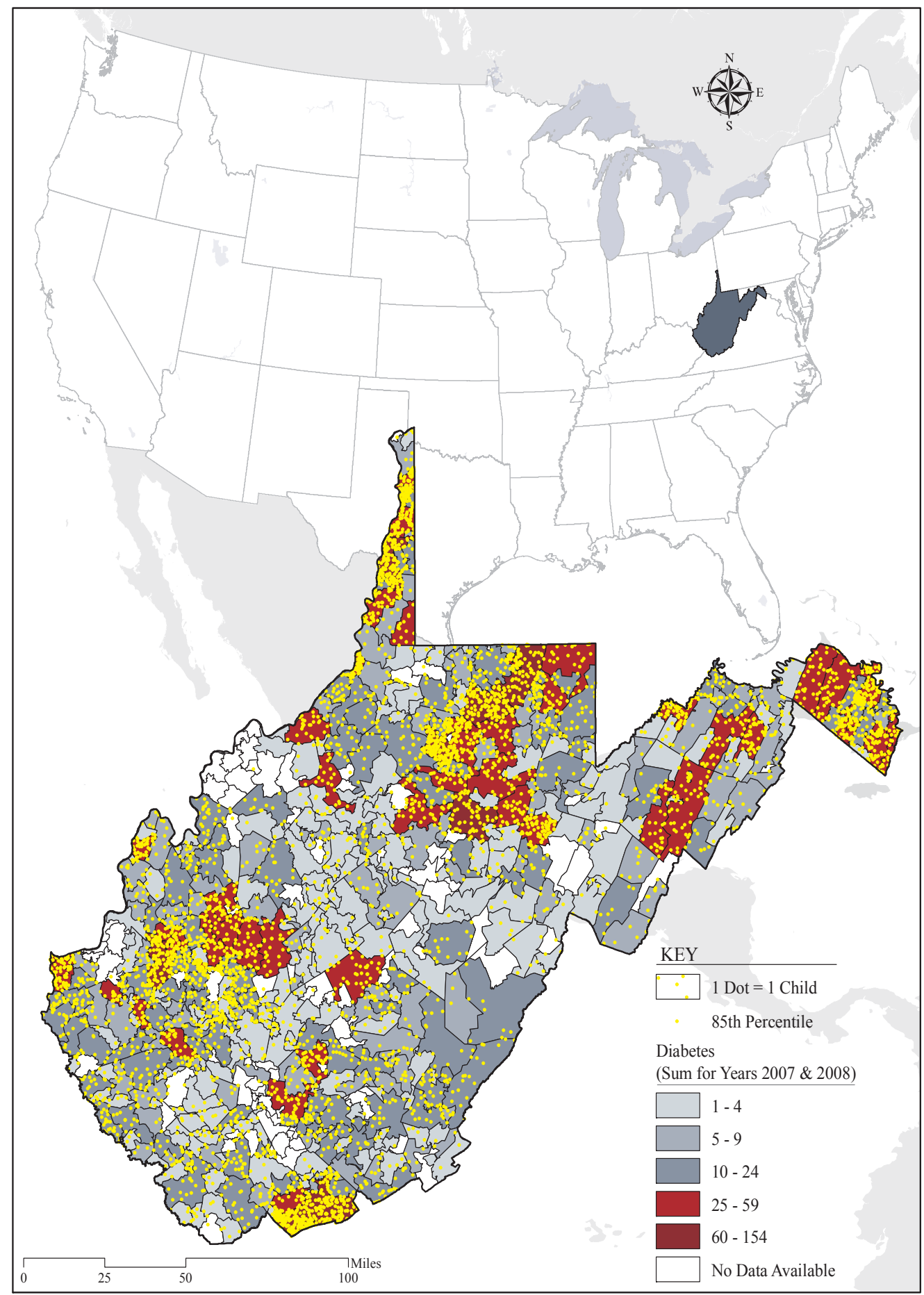

Figure A-16. Distribution of Subjects Reporting a Family History of Diabetes by Zip Code and BMI Equal to or Greater than the $85^{\text {th }}$ Percentile by Zip Code

Note: 1 Dot $=1$ Child Sample Participant. 




Figure A-17. Percentage of $5^{\text {th }}$ Graders by Class Defined as Aerobic Fit and BMI Equal to or Greater than the $85^{\text {th }}$ Percentile by Zip Code

Note: 1 Dot $=1$ Child Sample Participant. 


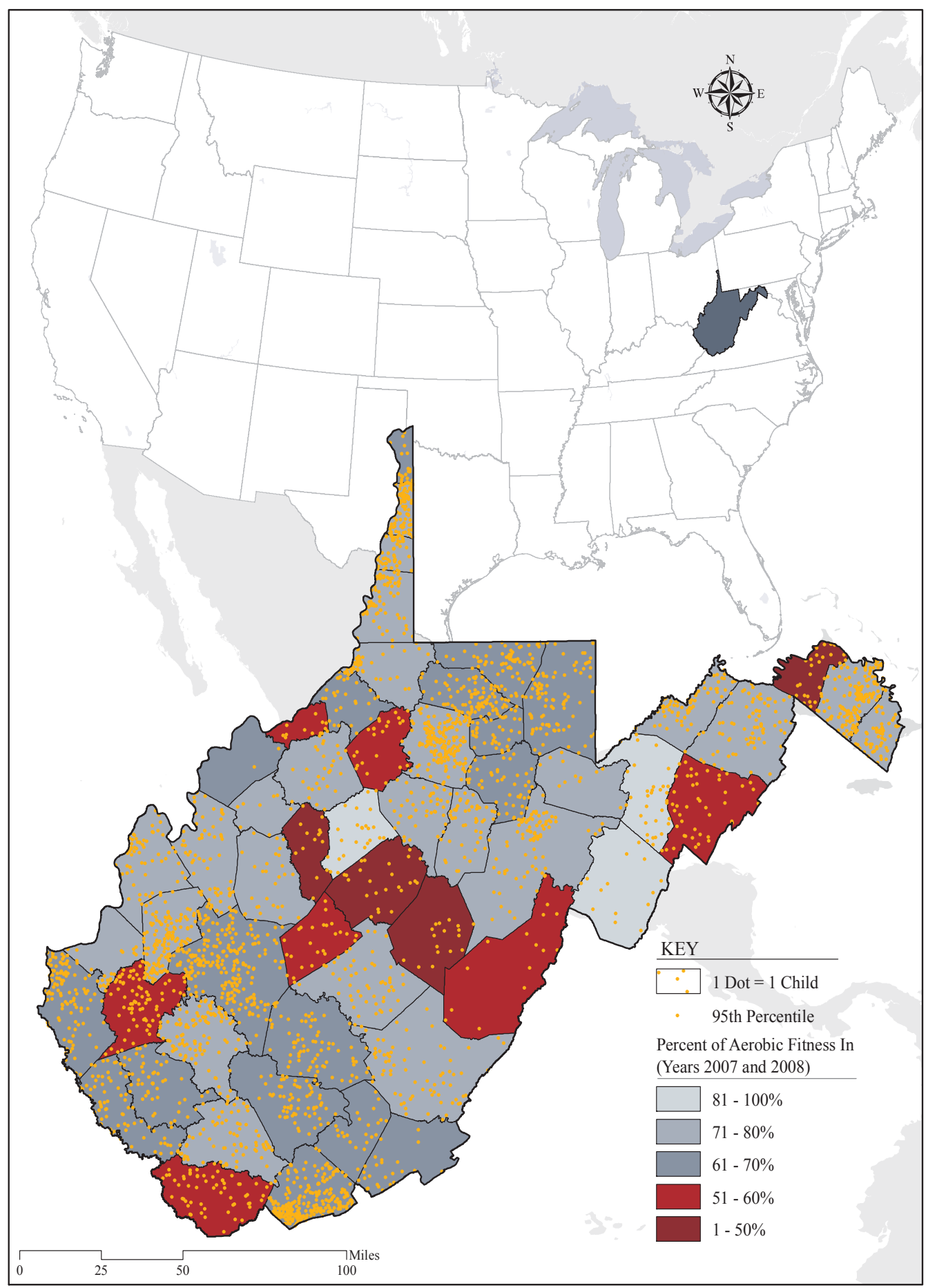

Figure A-18. Percentage of $5^{\text {th }}$ Graders by Class Defined as Aerobic Fit and BMI Equal to or Greater than the $95^{\text {th }}$ Percentile by Zip Code

Note: 1 Dot $=1$ Child Sample Participant. 
APPENDIX B. COUNTY CRIME DATA

\begin{tabular}{|c|c|c|c|c|}
\hline County & $\begin{array}{c}\text { Number Crime } \\
\text { Events } \\
2008\end{array}$ & $\begin{array}{c}\text { County } \\
\text { Population } \\
2008\end{array}$ & $\begin{array}{c}\text { Number Crime } \\
\text { Events } \\
2007\end{array}$ & $\begin{array}{c}\text { County } \\
\text { Population } \\
2007\end{array}$ \\
\hline Berkeley & 5,983 & 106,335 & 12,640 & 100,513 \\
\hline Boone & 868 & 24,927 & 2,137 & 25,389 \\
\hline Braxton & 465 & 14,495 & 899 & 14,752 \\
\hline Brooke & 499 & 23,140 & 912 & 20,173 \\
\hline Cabell & 9,650 & 92,113 & 18,662 & 96,934 \\
\hline Calhoun & 249 & 7,363 & 449 & 7,318 \\
\hline Clay & 191 & 9,966 & 432 & 10,195 \\
\hline Doddridge & 121 & 7,317 & 218 & 7,429 \\
\hline Fayette & 1,891 & 45,694 & 3,087 & 46,919 \\
\hline Gilmer & 178 & 6,835 & 408 & 6,904 \\
\hline Grant & 135 & 12,099 & 376 & 11,950 \\
\hline Greenbrier & 898 & 34,382 & 1,620 & 33,829 \\
\hline Hampshire & 705 & 22,970 & 1,710 & 22,697 \\
\hline Hancock & 1,112 & 29,865 & 1,990 & 34,196 \\
\hline Hardy & 456 & 13,471 & 1,091 & 13,462 \\
\hline Harrison & 4,060 & 68,497 & 8,372 & 68,434 \\
\hline Jackson & 642 & 28,072 & 1,099 & 28,370 \\
\hline Jefferson & 2356 & 52,925 & 4,885 & 51,455 \\
\hline Kanawha & 15,908 & 188,705 & 34,821 & 191,088 \\
\hline Lewis & 449 & 16,887 & 922 & 17,082 \\
\hline Lincoln & 769 & 21,891 & 1,628 & 22,281 \\
\hline Logan & 2,589 & 35,575 & 6,124 & 35,854 \\
\hline Marion & 1,994 & 22,828 & 4,133 & 56,459 \\
\hline Marshall & 1,692 & 56,092 & 3,452 & 33,189 \\
\hline Mason & 1,074 & 32,620 & 2,347 & 25,601 \\
\hline McDowell & 432 & 25,097 & 910 & 23,334 \\
\hline Mercer & 4,019 & 60,174 & 8,944 & 60,749 \\
\hline Mineral & 1,200 & 26,383 & 2,458 & 26,782 \\
\hline Mingo & 1,065 & 26,607 & 2,184 & 26,840 \\
\hline Monongalia & 4,025 & 84,218 & 8,915 & 84,762 \\
\hline Monroe & 444 & 13,572 & 818 & 14,402 \\
\hline Morgan & 479 & 16630 & 886 & 16,455 \\
\hline Nicholas & 1,573 & 26,190 & 3,084 & 26,302 \\
\hline Ohio & 2,894 & 43,427 & 5,950 & 44,412 \\
\hline Pendleton & 89 & 7,435 & 190 & 7,575 \\
\hline Pocahontas & 311 & 8,524 & 719 & 8,664 \\
\hline Preston & 531 & 30,458 & 814 & 30,394 \\
\hline Putman & 2,782 & 55,565 & 6,169 & 53,923 \\
\hline
\end{tabular}




\begin{tabular}{lcccc}
\hline County & $\begin{array}{c}\text { Number Crime } \\
\text { Events } \\
\mathbf{2 0 0 8}\end{array}$ & $\begin{array}{c}\text { County } \\
\text { Population } \\
\mathbf{2 0 0 8}\end{array}$ & $\begin{array}{c}\text { Number Crime } \\
\text { Events } \\
\mathbf{2 0 0 7}\end{array}$ & $\begin{array}{c}\text { County } \\
\text { Population }\end{array}$ \\
\hline Raleigh & 5,877 & 78,686 & 12,748 & 78,950 \\
Randolph & 1,215 & 28,033 & 2,396 & 28,362 \\
Richie & 380 & 10,575 & 794 & 10,619 \\
Roane & 534 & 15,527 & 1,016 & 15,525 \\
Summers & 424 & 12,310 & 721 & 13,357 \\
Taylor & 116 & 16,171 & 248 & 16,254 \\
Tucker & 160 & 6,548 & 335 & 6,762 \\
Tyler & 63 & 9,033 & 81 & 10,969 \\
Upshur & 740 & 23,274 & 1,532 & 23,611 \\
Wayne & 1,537 & 40,302 & 3,058 & 37,399 \\
Webster & 210 & 9,476 & 480 & 9,649 \\
Wetzel & 181 & 16,140 & 395 & 14,673 \\
Wirt & 244 & 6,039 & 466 & 5,965 \\
Wyoming & 647 & 23,620 & 1,340 & 23,918 \\
\hline
\end{tabular}

${ }^{\mathrm{a}}$ Population reported by the WV State Police. 


\section{VITA}

Sherry L. Martin Roper was born in 1966 in Richwood, West Virginia. She received an Associate of Liberal Arts from the Pennsylvania State University. She received a Bachelor of Science in Nursing and a Master of Science in Nursing with a focus in community and public health nursing from The Pennsylvania State University. Her thesis research explored childhood obesity among Cherokee Indian children. She was accepted in the PhD in Nursing in 2008. Her research in the PhD program focused on risk factors associated with childhood obesity children and spatial associations. She has been a nurse educator for over 12 years and is currently an Assistant Professor of Nursing at Sacred Heart University. 